\title{
ARCHITECTURE AS THIRD SKIN \\ SPATIAL DIMENSIONS OF STIMULI FOR DEMENTIA CARE
}

By

\author{
Sebastian Lubczynski \\ Bachelor of Architectural Science \\ Ryerson University \\ Toronto, Ontario, Canada, 2011 \\ A design thesis-project \\ presented to Ryerson University \\ in partial fulfillment of the \\ requirements of the degree of \\ Master of Architecture
}

Toronto, Ontario, Canada, 2014

(C) Sebastian Lubczynski, 2014 


\section{AUTHOR'S DECLARATION FOR ELECTRONIC SUBMISSION OF A THESIS}

I hereby declare that I am the sole author of this thesisproject. This is a true copy of the thesis, including any required final revisions, as accepted by my examiners.

I authorize Ryerson University to lend this thesis project to other institutions or individuals for the purpose of scholarly research. I further authorize Ryerson University to reproduce this thesis-project by photocopying or by other means, in total or in part, at the request of other institutions or individuals for the purpose of scholarly research.

I understand that my thesis-project may be made electronically available to the public.

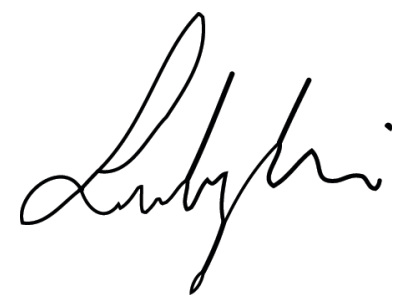

Sebastian Lubczynski 
ARCHITECTURE AS THIRD SKIN:

SPATIAL DIMENSIONS OF STIMULI FOR DEMENTIA CARE

\author{
Master of Architecture 2014 \\ Sebastian Lubczynski \\ Master of Architecture \\ Ryerson University
}

\title{
ABSTRACT
}

Our built environments have a direct correlation with our mental and physical health. This correlation is ever more evident with the process of ageing and the declining of neurological and physiological capacities of the human body. Architecture as Third Skin: Spatial Dimensions of Stimuli for Dementia Care thesis-project asserts that architecture, supported by evidence-based knowledge, can create an environment that triggers positive neurological changes in its users, negotiating the functional and social necessities of people with dementia in supporting their needs. The architectural model that informs this inquiry is explored through the design of a community-based Dementia Respite Care Centre, providing short and long term care as well as physical and mental therapy for those with early-to mid-stage dementia. Situated in Toronto, this thesis-project proposes a model that provides direct care for the specialized needs of dementia patients early in their illness condition to maintain independence and encourage living and ageing. 
iv | sebastian lubczynski master of architecture ryerson university 


\section{ACKNOWLEDGEMENTS}

Foremost, this journey from the beginning of thesis-project to its conclusion would not have been attainable without the guidance, leadership, and constant encouragement of George Thomas Kapelos, my thesis advisor. Our insightful conversations and his critical commentaries and design critiques assisted me in developing the necessary tools to tackle the challenging subject matter of this thesis.

Secondly, I would like to thank Jurij Leshchyshyn, my second reader for this thesis, who provided me with critical and timely feedback at important moments in the process, which guided me through this thesis-project.

Finally, I express my gratitude to my sister Violetta Laszkowski for her patience, insight and constant moral support throughout the development of this work. As a non-architect, she provided me with much appreciated commentary and thoughtful advice that helped ground and further enhance the logic, reasoning, and comprehension of the subject matter in this thesis-project.

Lastly, I would like to thank my colleagues and friends for being there throughout the good times and bad. Their feedback, encouragement and support proved invaluable in the development and realization of this thesis-project. 
AUTHOR'S DECLARATION

ABSTRACT

INTRODUCTION

01 CHAPTER 1 I DEMOGRAPHIC ANALYSIS

1.1 Introduction 6

$\begin{array}{lll}1.2 & \text { Macro Sacle: Global } & 7\end{array}$

1.3 Meso Scale: National $\quad 8$

1.4 Micro Scale: Local 9

1.5 Conclusion 10

02 CHAPTER 2 I EPIDEMIOLOGY OF DEMENTIA

2.1 Introduction 12

2.2 Dementia And The Brain 13

2.3 Dementia Subtypes 15

2.4 Effects On The Brain $\quad 19$

2.5 Memory 22

2.6 Conclusion 24

03 CHAPTER 3 I ARCHITECTURE'S RESPONSE TO DEMENTIA

3.1 Introduction 26

$\begin{array}{lll}3.2 & \text { Ideology } & 27\end{array}$

3.3 Development Of The Dementia Care Environment 28

3.4 Modes Of Delivery Today 30

3.5 Emerging Trends in Group Living Environments 31

3.6 Dementia Environment 37

$\begin{array}{lll}3.7 & \text { Conclusion } & 40\end{array}$

04 CHAPTER 4 I EMERGING MODELS CASE STUDY ANALYSIS

4.1 Introduction 42

4.2 Emerging Models 43

4.3 De Hogeweyk, Archiect: Molenaar\&Bol\&VanDillen 43

4.4 Hainburg Nursing Home, Architect: Christian Kronaus 
4.5 Santa Rita Geriatric Center, Architect: Manuel Ocaña 47

4.6 Alcácer do Sal Residences, Architect: Aires Mateus 48

4.7 Group Home in Noboribetsu, Architect: Sou Fujimoto 49

4.8 Urban Day Care Center, Architect: Cid + Santos 51

4.9 Conclusion 52

\section{CHAPTER 5 I DESIGN RESPONSE}

5.1 Introduction

5.2 Problem Analysis / Concern $\quad 55$

$\begin{array}{lll}5.3 & \text { Design Formulations } & 57\end{array}$

5.3.1 Design Goals

5.3.2 Design Strategies $\quad 60$

5.4 The Condition 63

5.4.1 The Urban Condition 63

5.4.2 Site Selection 64

$\begin{array}{ll}\text { 5.4.3 Urban Morphology } & 69\end{array}$

5.4.4 Site Conditions / Building Considerations 77

$5.5 \quad$ Spatial Program Development 83

$\begin{array}{lll}5.6 & \text { Design Process } & 87\end{array}$

5.7 Design Iteration One Process Development 90

5.8 Thesis-Project Design Proposal 99 


\section{LIST OF FIGURES}

Fig. 1.01

Source:

Fig 1.02

Source:

Fig 1.03

Source:

Fig 2.01

Source:

Fig 2.02

Source:

Fig 2.03

Source:

Fig 2.04

Source:

Fig 2.05

Source:

Fig 4.01

Source:

Fig 4.02

Source:

Fig 4.03

Source:

Fig 4.04

Source:

Fig 4.05

Source:

Fig 4.06

Source:

Fig 4.07

Source:

Fig 4.08

Source:
World Population Aged 60 Years Or Over, 1950-2050

Dementia: A Public Health Priority, World Health Organization, 2012

Prevalence Of Dementia By Sex 2008 To 2038

Alzheimer Society Of Canada, 2010

GTA Area Population 65 And Over And Dementia Cases

Pccc Mental Health Services, 2010

The three stages of progression in dementia patients

Alzheimer Society Of Canada, 2010

Brain Deterioration Of Alzheimer's Patients

http://www.alz.org/braintour/healthy_vs_alzheimers.asp

Consensus Estimates Of The Proportion Of All Dementia Cases

Accounted For By Different Dementia Subtypes, By Age And Gender.

Women

Dementia Uk Report

Consensus Estimates Of The Proportion Of All Dementia Cases Accounted For By Different Dementia Subtypes, By Age And Gender. Men

Dementia Uk Report

Dementia Subtype Syndrome Overlaps

Image by author

De Hogeweyk, Netherlands, 2012

http://www.detail-online.com/architecture/topics/dementia-village-dehogeweyk-in-weesp-019624.html

De Hogeweyk, Netherlands, 2012

http://www.detail-online.com/architecture/topics/dementia-village-dehogeweyk-in-weesp-019624.html

De Hogeweyk Floor Plan, Netherlands, 2012

http://www.detail-online.com/architecture/topics/dementia-village-dehogeweyk-in-weesp-019624.html

"household cluster"

http://www.detail-online.com/architecture/topics/dementia-village-dehogeweyk-in-weesp-019624.html

"household cluster"

http://www.detail-online.com/architecture/topics/dementia-village-dehogeweyk-in-weesp-019624.html

Hainburg Nursing Home Exterior Facade

http://www.archdaily.com/61115/hainburg-nursing-home-christian-

kronaus-erhard-an-he-kinzelbach/

Hainburg Nursing Home two-fold facade

http://www.archdaily.com/61115/hainburg-nursing-home-christian-

kronaus-erhard-an-he-kinzelbach/

Hainburg Nursing Home interior circulation corridor

http://www. archdaily.com/61115/hainburg-nursing-home-christian-

kronaus-erhard-an-he-kinzelbach/ 
Fig 4.09

Source:

Fig 4.10

Source:

Fig 4.11

Source:

Fig 4.12

Source:

Fig 4.13

Source:

Fig 4.14

Source:

Fig 4.15

Source:

Fig 4.16

Source:

Fig 4.17

Source:

Fig 5.01

Source:

Fig 5.02

Source:

Fig 5.03

Source:

Fig 5.04

Source:

Fig 5.05

Source:

Fig 5.06

Source:

Fig 5.07

Source:

Fig 5.08

Source:

Fig 5.09

Source:

Fig 5.10
Santa Rita Geriatric Center, Spain, 2009

http://www.archdaily.com/24725/santa-rita-geriatric-center-manuelocanal

Santa Rita Geriatric Center Floor Plan, Spain, 2009

http://www.archdaily.com/24725/santa-rita-geriatric-center-manuelocanal

Alcacer Do Sal Residences, Portugal, 2010

http://www.archdaily.com/328516/alcacer-do-sal-residences-airesmateus/

Alcacer Do Sal Residences Floor Plan, Portugal, 2010

http://www.archdaily.com/328516/alcacer-do-sal-residences-airesmateus/

Group Home, Noboribetsu, 2010

http://www.archdaily.com/23991/diagonal-walls-sou-fujimoto/

Group Home Floor Plan, Noboribetsu, 2010

http://www.archdaily.com/23991/diagonal-walls-sou-fujimoto/

Urban Day Care Center for Alzheimer Patients, 2012

http://www.archdaily.com/295469/urban-day-care-center-foralzheimer-patients-cid-santos/

Urban Day Care Center for Alzheimer Patients, 2012

http://www.archdaily.com/295469/urban-day-care-center-foralzheimer-patients-cid-santos/

Urban Day Care Center for Alzheimer Patients Floor Plan, 2012

http://www.archdaily.com/295469/urban-day-care-center-foralzheimer-patients-cid-santos/

Design Exploration 1

Image by author

Design Exploration 2

Image by author

Design Exploration 3

Image by author

City of Toronto population by age group, Statistics Canada 2001-2011 Statistics Canada Census 2011, City of Toronto

City of Toronto concentration of working age 25-64 years Statistics Canada Census 2011, City of Toronto

City of Toronto concentration of seniors age 65+ years, Statistics Canada Census 2011, City of Toronto

City of Toronto population concentration of age $45-54$ years map.toronto.ca/wellbeing/

City of Toronto population concentration of age 55-65 years map.toronto.ca/wellbeing/

City of Toronto population concentration of age $65-75$ years map.toronto.ca/wellbeing/

Proposed site location and neighbourhood context 
Fig 5.11

Source:

Fig 5.12

Source:

Fig 5.13

Source:

Fig 5.14

Source:

Fig 5.15

Source:

Fig 5.16

Source:

Fig 5.17

Source:

Fig 5.18

Source:

Fig 5.19

Source:

Fig 5.20

Source:

Fig 5.21

Source:

Fig 5.22

Source:

Fig 5.23

Source:

Fig 5.24

Source:

Fig 5.25

Source:

Fig 5.26

Source:

Fig 5.27

Source:
Proposed site location indicated in red

http://intranet.library.ryerson.ca/madar/indmaps/SVG_TOR_

ORTHO 2007/mapview/index.htm

Proposed site location indicated in red

http://www.bing.com/maps/default.aspx?q=230+sherbourne+street+ toronto\&mkt=en\&FORM=HDRSC4

Toronto Historical Maps - 1858

http://peoplemaps.esri.com/toronto/

Toronto Historical Maps - 1913

http://peoplemaps.esri.com/toronto/

Toronto Historical Maps - 1947

http://peoplemaps.esri.com/toronto/

Toronto Historical Maps - 2013

http://peoplemaps.esri.com/toronto/

Sherbourne Lanes project at Sherbourne and Dundas (right) Back portion of project along lane way (right)

Image taken by author

Sherbourne Lanes dotted in Yellow. Robertson House Crisis Care Centre dotted in red.

Image by author ( base map - http://intranet.library.ryerson.ca/madar/ indmaps/SVG_TOR_ORTHO_2007/mapview/index.html)

The Robertson House Crisis Care Centre interior courtyard http://www.hariripontarini.com/projects/retrofit/7-robertson-housecrisis-care-centre

Neighbourhood context along Sherbourne Street Image taken by author

Neighbourhood context along Sherbourne Street Image taken by author

Neighbourhood context along Sherbourne Street Image taken by author

Neighbourhood context along Sherbourne Street Image taken by author

Neighbourhood context along Sherbourne Street Image taken by author

Neighbourhood context along Sherbourne Street Image taken by author

Neighbourhood context along Queen Street Image taken by author

Neighbourhood context along Queen Street Image taken by author 
Fig 5.28

Source:

Fig 5.29

Source:

Fig 5.30

Source:

Fig 5.31

Source:

Fig 5.32

Source:

Fig 5.33

Source:

Fig 5.34

Source:

Fig 5.35

Source:

Fig 5.36

Source:

Fig 5.37

Source:

Fig 5.38

Source:

Fig 5.39

Source:

Fig 5.40

Source:

Fig 5.41

Source:

Fig 5.42

Source:

Fig 5.43

Source:

Fig 5.44

Source:

Fig 5.45

Source:

Fig 5.46

Source:

Fig 5.47

Source:
Site Massing Typology Study Image by author

1924 Property line division in plan Image by author

1924 Property line division in elevation Image by author

2012 Property line division in plan Image by author

2012 Property line division with existing home as reference for scale Image by author

Proposed site boundary and area

https://www.google.ca/maps/place/230+Sherbourne+St,+Toronto,+O $\mathrm{N}+\mathrm{M} 5 \mathrm{~A}+2 \mathrm{R} 7 / @ 43.6578665,-79.3709653,19 \mathrm{z} / \mathrm{data}=! 3 \mathrm{~m} 1 ! 4 \mathrm{~b} 1 ! 4 \mathrm{~m} 2$ !3 m1!1s0x89d4cb48269af14f:0x57300b7c615ba859

Site selected zoning designation http://map.toronto.ca/maps/map.jsp?app=ZBL_CONSULT

Zoning setback requirements in plan Image by author

Zoning setback requirements in elevation Image by author

Existing building heights around proposed site Image by author

Site selected looking north west Image by author

Site selected looking north west Image by author

Site selected looking south Image by author

Selected site perspective Image by author

Dementia Respite Care Program Breakdown Image by author

Spatial Program Relationship Analysis Image by author

Building Form Strategy 1 image by author

Building Form Strategy 2 Image by author

Building Form Strategy 3

Image by author

House Cluster Strategy 1 Image by author 
Fig 5.48

Source:

Fig 5.49

Source:

Fig 5.50

Source:

Fig 5.51

Source:

Fig 5.52

Source:

Fig 5.53

Source:

Fig 5.54

Source:

Fig 5.55

Source:

Fig 5.56

Source:

Fig 5.57

Source:

Fig 5.58

Source:

Fig 5.59

Source:

Fig 5.60

Source:

Fig 5.61

Source:

Fig 5.62

Source:

Fig 5.63

Source:

Fig 5.64

Source:

Fig 5.65

Source:
House Cluster Strategy 2

Image by author

House Cluster Strategy 3

Image by author

Existing Site Conditions

Image by author

Removal of back of existing house and trees

Image by author

delineate site as per previous existing property lines on site Image by author

Setbacks: 4.5 meters back and side yard for glazing. Face of wall allowed to be to property line if no glazing. 3 meters set back at front yard

Image by author

3 meter setbacks from each property line provides 4 volumetric forms on site

Image by author

Entry court yard as transition space between public and building Secondary space between volumes becomes internal circulation space

Image by author

Remove area within site to create 2 nd court-yard. Node at entry to provide orientation to external landmarks and city scape Image by author

Program placed on site and refined building boundaries. Activity court yard is provided at north end of site.

Image by author

Final design outcome of day centre ground floor

Image by author

Dementia Respite Day Centre Ground Floor Plan Iteration 1

Image by author

Dementia Respite Day Centre Second Floor Plan Iteration 1

Image by author

Dementia Respite Day Centre Third Floor Plan Iteration 1

Image by author

Iteration 1 Building Elevation

Image by author

Iteration 1 Building Elevation

Image by author

Residant Corridor Identification Wall Design

Image by author

Residant Corridor Identification Wall Design

Image by author 
Fig 5.66

Source:

Fig 5.67

Source:

Fig 5.68

Source:

Fig 5.69

Source:

Fig 5.70

Source:

Fig 5.71

Source:

Fig 5.72

Source:

Fig 5.73

Source:

Fig 5.74

Source:

Fig 5.75

Source:

Fig 5.76

Source:

Fig 5.77

Source:

Fig 5.78

Source:

Fig 5.79

Source:

Fig 5.80

Source:

Fig 5.81

Source:

Fig 5.82

Source:

Fig 5.83

Source:

Fig 5.84

Source:

Fig 5.85

Source:
Residant Corridor Identification Wall Design Image by author

Residant Corridor Identification Wall Design Image by author

Available footprint massing on site Image by author

Internal Coutyard to provide sensory garden and natural daylight into single loaded interior corridor

Image by author

Recess building planes to breakdown massing in response to existing victorian streetscape Image by author

Vertical circulation (yellow), Horizontal circulation (blue), Entry into facility (red)

Image by author

Dementia Respite Day Centre program on ground floor Image by author

Bedroom unit locations on second and third floor Image by author

Respite daily living program on second and third floor Image by author

Resultant building form in context Image by author

Ground Floor spatial program layout diagram Image by author

Day Centre Ground Floor Design Image by author

Entrance Foyer Security Design Image by author

View of interior corrdior at library Image by author

View of interior winter garden atrium space Image by author

View of outdoor courtyard Image by author

Second and Third floor spatial program layout diagram Image by author

Respite Program Second and Third floor plan Image by author

Residant corridor wall entry angle design Image by author

Residant corridor entry identification design Image by author 
Fig 5.86

Source:

Fig 5.87

Source:

Fig 5.88

Source:

Fig 5.89

Source:

Fig 5.90

Source:

Fig 5.91

Source:

Fig 5.92

Source:
View of residant corridor Image by author

View of sitting areas along corridor Image by author

View from third floor looking into winter garden atrium and outdoor courtyard

Image by author

Building section at bedroom units and outdoor courtyard Image by author

West Buildng Elevation

Image by author

West Buildng Elevation rendering indicating materiality Image by author

Perspective looking north west approach to building Image by author 




\section{INTRODUCTION}

As humans, we spend nearly $90 \%$ of our lives indoors. The "outdoor environment," i.e nature, has always been referenced as our natural environment. However, one of the realities of life is that buildings are part of this "natural environment" due to the extended time spent inside as they provide a platform for habitation (Martinussen, 2010). A building's physical compositional elements of walls, doors, windows, and roof relate at their most basic level to the human body. A building, as its basic construct, is a form of technology designed to order, organize, and modify the world to make it more habitable for human beings (Drake, 2014). The formal elements that construct a building determine the physical qualities of the interior spaces in use. The built environment alters the sensory interaction between the body and space. It is becoming increasingly apparent that this interaction, either direct or indirect, plays a crucial role in influencing the physical and mental states of human beings (Evans, 2003). The physical body is self-regulating, capable of adjusting to only a limited amount of environments, thus lowering the range of built environments that can be inhabited. A further extension of self-regulation is possible by adding an outer layer of clothing onto our first layer, our skin. These two layers are the initial "skin" layers that protect us from the elements. We encapsulate ourselves by constructing our third skin in the form of building. This third layer is the layer that effects our daily experiences (Drake, 2014). Our mental capacities are extremely powerful tools we use to process information and negotiate the space that provides us the experience. Our mind and body provide a dialogue with the external stimuli being provided by the third skin that can, for example, influence the awareness of our orientation in space (Eberhard \& Patoine, 2004). What happens when our mental capacities are hindered due to physical or mental deterioration as we age? How does our constructed third skin impact our mental capacities and in what way can this third skin impact changes in our mental state?

An increasing elderly population is evidence of improvements and advancements in medical science within the past century, contributing to people living longer and healthier lives. However, this aging population is still susceptible to diseases, for which there are currently no cures, in particular dementia. Dementia, as an umbrella term, is used to define a variety of brain disorders where the mind's capacities for negotiating with its body and the natural environment have been effected. John 
P. Eberhard, architect and founding president of the Academy of Neuroscience for Architecture, argues that the design of the built environment has the maximum effect when it reflects our understanding of how the brain reacts to different environments (Eberhard \& Patoine, 2004). Our understanding of the brain is even more necessary with dementia patients because of how their specific physical and mental conditions are altered by the disease.

As a large subset of two-thirds of dementia patients are affected by Alzheimer's disease, a growing global concern about the quality of care and quality of life in elderly care facilities has risen (World Health Organization, 2012). Changes to current institutional settings for elderly care need to be investigated and approached from different perspectives. The built environments that dementia patients inhabit could facilitate a therapeutic and ideal living condition that may be conducive to their varying needs and, at the same time, contribute to alleviating their symptoms. Conventionally designed environments that are for the cognitively able appear to put stress on the cognitive abilities of those with dementia.

Professor Fred H. Gage, from the Laboratory of Genetics from the Salk Institute, argues that the brain's physiology changes in response to enriched environments, where the brain continues to generate new functional neurons throughout its life span. People currently diagnosed with Alzheimer's are required to take medication to assist in remediating the symptoms of the disease. However, Dr. John Zeisel, sociologist and designer, asserts that in the treatment of patients with Alzheimer's disease, environmental modifications are often more effective than pharmacological and behavioural therapies. These environmental modifications can alleviate stress, which could reduce anxiety and aggressiveness in the patient. Furthermore, Gage asserts that modifications to the built environment would change the brain's physiology, resulting in a change in the behavioural response in patients (Eberhard \& Patoine, 2004). Therefore, this thesis-project asserts that architecture that acknowledges the physical, emotional, and psychological needs of dementia patients and responds to current evidence-based knowledge can create an environment that supports and sustains positive mental changes in its occupants.

Research on the impact of the built environment in long-term care settings 
has grown in the past decade. This research has slowly created a body of evidence-based information to describe and identify how the built environment and those affected by dementia are in dialogue with one another. This scientific-based knowledge provides a means of basing design decisions about the built environment on credible research to achieve the best possible outcome for design with the current body of information.

Chapter 1 of this thesis-project establishes a comprehensive understanding of this subject by examining current and projected demographic shifts. Anticipating the demographic shift of the baby boomer generation and associated growth of dementia cases, architects will increasingly have to account for this in facility designs.

Chapter 2 provides a breakdown of the understanding of dementia within society and analyses of the different subsets of dementia. This analysis provides an understanding of the characteristics of people with dementia and their abilities and inabilities in negotiating with the built environment. Establishing this platform helps in informing a sensitive spatial and programmatic response within the architectural realm as presented in this thesis-project.

Chapter 3 describes the history, present modes of delivery of care, and emerging trends that have affected the provision of services and the architectural environments that exist for those affected by dementia. This research is used as a tool for proposing an architectural typology and design methodology that is capable of responding to the challenges present today for those affected by this condition.

Chapter 4 presents a compilation of current trends and practices in the realms of assisted living, independent living and day centres for the elderly population, either affected or not affected by dementia. These trends illustrate shifting paradigms in healthcare facilities toward a humanistic approach in its design and architectural expression.

Chapter 5 presents a design proposal for a site in Toronto. The design is grounded in the research and requirements that have been outlined in previous chapters and the design strategies and contextual conditions that have been established for the final design proposal. 


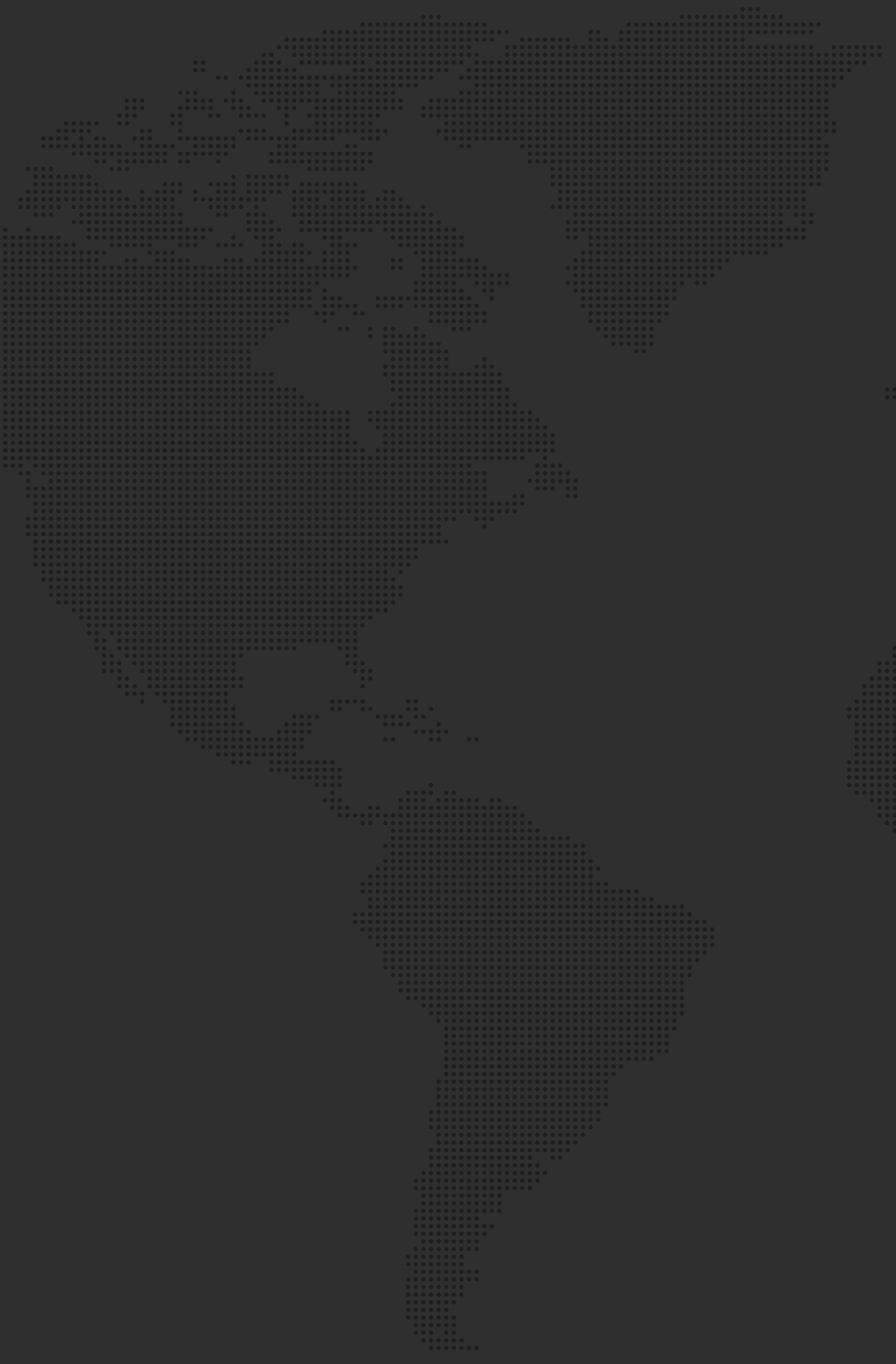




\section{CHAPTER 1 \\ DEMOGRAPHIC ANALYSIS}

\subsection{INTRODUCTION}

Chapter 1 examines the demographics on the macro, meso, and micro scales with a focus on analysing current statistics and projections in relation to the number of people affected by dementia. Evaluating the demographics at the different scales provides a platform for reflection on the future development of the built environment from a planning aspect. This allows for speculation on the future and long-term demands related to the growing elderly population. Recognizing this particular demographic as a major actor in society and the economy in the foreseeable future, helps project the nature of forthcoming demands and map out issues that are important in shaping the future environment in order to provide adequate support and response to the growing dementia demographic. 


\subsection{MACRO SCALE: GLOBAL}

The ageing of the world's population is evidence in improvements and advancements in medical science and health care in the past century, contributing to people living longer and healthier lives. According to the World Health Organization, the world's population over the age of 60 will double from approximately $11 \%$ to $22 \%$ between year 2000 and 2050 , for the first time exceeding the number of young people under the age of 15 . The $22 \%$ percent in year 2050 will indicate that 2 billion people over the age of 60 will be significant contributors to our society as family members, volunteers and as active participants in the workforce (fig. 1.01) (World Health Organization, 2007).

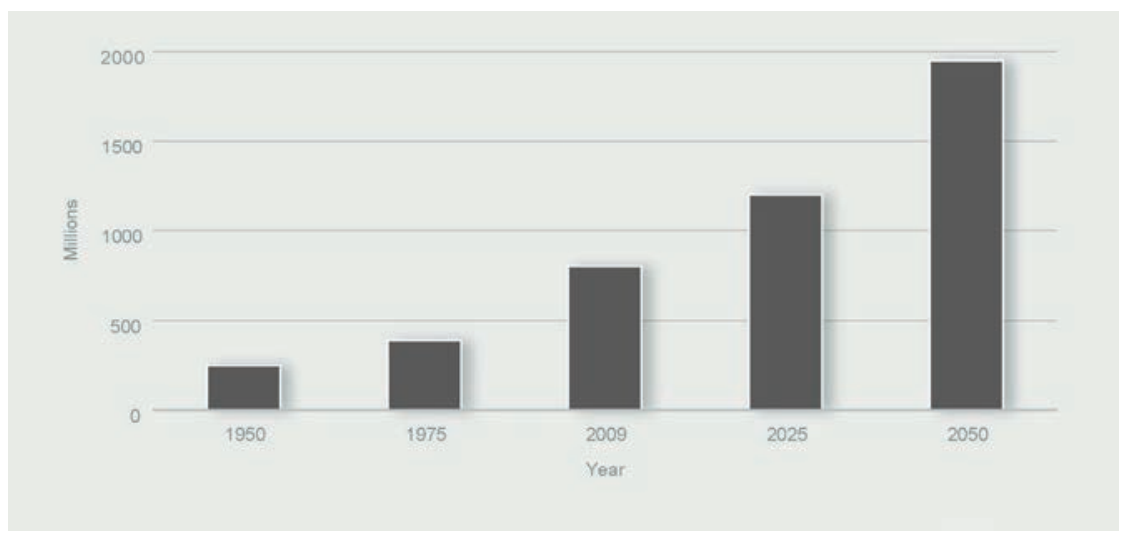

Fig. 1.01 - World population aged 60 years or over, 1950-2050

However, associated with this ageing population are health challenges in preventing and managing age-associated chronic diseases. One of the increasingly common age-associated disease is a rise of people with non-communicable disease, including dementia (World Health Organization, 2012). This disease mainly affects the older generations but is not considered to be a normal aspect of ageing. According to estimates reported by the World Health Organization, between 2\% and $10 \%$ of all cases of dementia occur before the age of 65 . Statistics indicate that as of 2001 there were 35.6 million people living with some form of dementia. That number is expected to double every 20 years, to 65.7 million in 2030 and 115.4 million by 2050 (World Health Organization, 2012).

As one of the major causes of disability in later life, dementia accounts for $12 \%$ of the years lived of people with their disability. As a leading cause for dependency upon care among the older generation, the 
cost of dementia worldwide is estimated to be $\$ 640$ billion US in 2010 (World Health Organization, 2012). As this financial impact continues to increase, the impact of dementia on the people who have the disease, their caregivers and families is severe from a medical, psychological, and emotional state. The quality of life of people with dementia and their caregivers is significantly impacted by the behavioural and psychological symptoms that are associated with dementia.

\subsection{MESO SCALE: NATIONAL}

Within the Canadian context, the Alzheimer's Society of Canada released Rising Tide: The Impact of Dementia on Canadian Society where statistics illustrate that approximately 500,000 (1.5\%) of Canadians aged 65+ are living with dementia today. The projected forecast (Fig. 1.02) estimates that 1.125 million (2.8\%) of the Canadian population will be living with a form of dementia by 2038 with a cumulative economic burden of $\$ 872$ billion (Alzheimer Society, 2010).

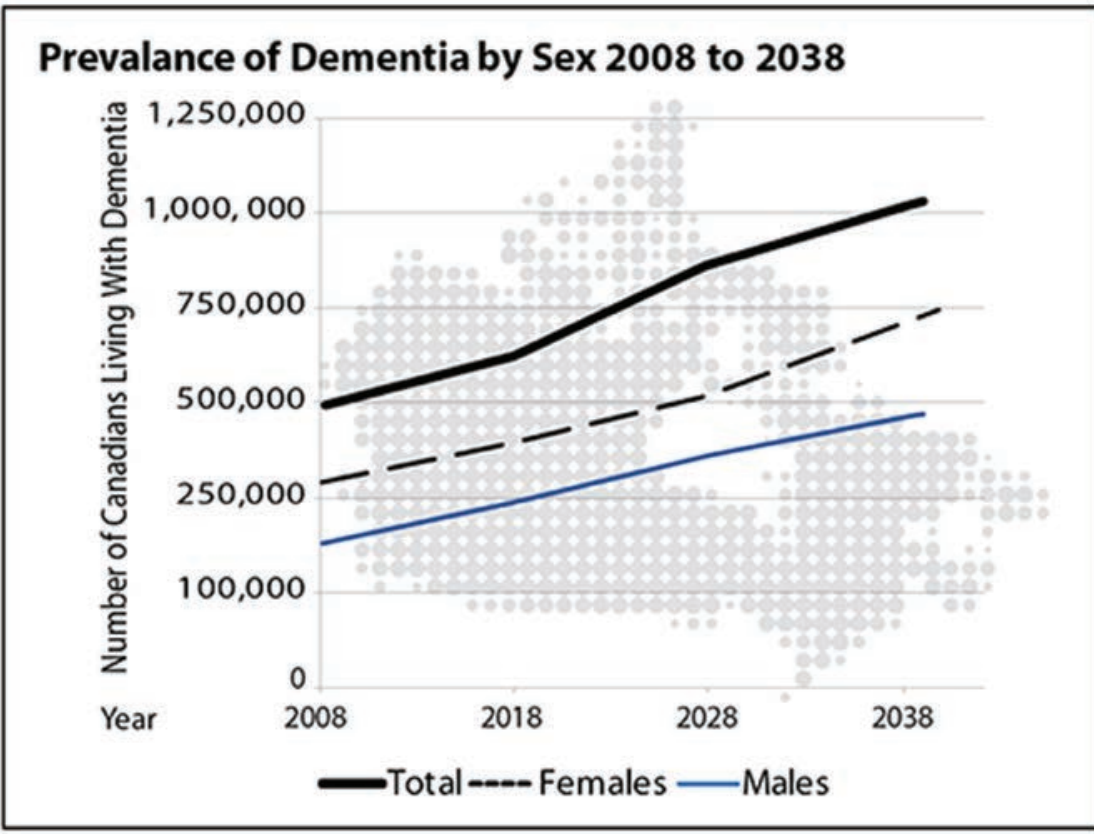

Fig. 1.02 - Prevalence of Dementia by sex 2008 to 2038 - Alzheimer's Society of Canada, 2010

Furthermore, the research suggests that approximately 70,000 Canadians under the age of 65, specifically those in their 40's and 50's, will also be affected by this disease. As a result, the prevalence of dementia will create an increase in the demand for long-term care beds and will cost the Canadian economy $\$ 153$ billion annually (Alzheimer Society, 2010). 
With the expected ten-fold increase demand for long-term care beds, as well as an increase from $55 \%$ to $62 \%$ of Canadians aged $65+$ living at home, a significant shift in the market for community-based care services will occur (Alzheimer Society, 2010). Community-based care services would allow people affected by dementia to live within their current home for a much longer time span before having to move to a long-term care facility. These facilities do not have a dedicated dementia-related community-based service to care for early onset dementia patients. This is an area of need because of the specific symptoms that people with dementia have. According to Rising Tide, by delaying and slowing down the causes of this disease through early interventions in prevention and support by at least two years, would yield a 30-year reduction in the total economic burden by $\$ 219$ billion. Increasing the level of activity by 50\% for Canadians $(65+)$ has the potential to create a reduction of $\$ 31$ billion in direct health care costs and $\$ 52$ billion of the total economic burden (Alzheimer Society, 2010).

\subsection{MICRO SCALE: LOCAL}

At the local scale for Toronto, the growth of the adult population is driven by two key factors. First, life expectancy has increased from 71.1 in the 1960's to 80.8 in 2009. Second, is the "baby boom" generation who are now between the ages of 55 and 64 years. Based on current censes figures, the number of seniors will grow from 1 in 7 Canadians in 2011 to 1 in 4 by 2036 (Toronto Community Foundation, 2013).

With the continued growth of the elderly population, an increase in the amount of dementia cases (fig. 1.03) will have a substantial impact on the health-care resources. People with dementia are considered to be hospitalized two times more often when compared to seniors without the disease. As well they are twice as likely to have alternate level of care days when they are hospitalized. The people who are receiving the "alternate level of care" are patients who no longer require acute care services and are waiting to be relocated to a better-suited environment for their specific needs (Alzheimer Society, 2012). However, instead of relocating and waiting for spaces, this thesis-project proposes that the urban fabric of the city needs to change to provide facility options that provide both respite and day care. This would allow for a continuum within the process of care without a significant disruption to an individual's life. 
Fig. 1.03 - GTA Area Population 65 and over and Dementia Cases, PCCC Mental Health Services, 2010

\subsection{CONCLUSION}

The baby boomers are the largest age group in Canada and are going to be impacting the health care environment immensely. As dementia becomes more prevalent, future markets and the future economy will be influenced by the demands that this disease will have in shaping the built environment and social support structures needed for dementia patients. The social, economic, and political agendas that are driving health care planning policies will be predicated on meeting the emerging market demands in a manner that would maximize the full benefits to people with dementia and to ensure dementia's minimizing impact on demands within the hospital system. Therefore, the ageing population with dementia can consider the option of aging in place with access to facilities which are specialized in providing both respite and day care, while responding to the physical, psychological, and emotional demands in the process. This level of integration within communities will be required to cater to baby boomers needs in order to maintain the notions of normality within their lives while at the same time providing places for a continuous care for dementia patients and their symptoms. 



\section{GHAPTER 2 EPIDEMIOLOGY OF DEMENTIA}

"We tend to think of memories as monuments we once forged and may find intact beneath the weedy growth of years. But, in a real sense, memories are tied to and describe the present. Formed in an idiosyncratic way when they happened, they're also true to the moment of recall, including how you feel, all you've experienced, and new values, passions, and vulnerability. One never steps into the same stream of consciousness twice. All the mischief and mayhem of a life influences how one restyles a memory" - Ackerman (2004)

\subsection{INTRODUCTION}

Chapter 2 focuses on establishing how dementia is defined and understanding the relationships of the different subsets of dementia. Establishing the inter-relationships of each type provides a platform for discussion and the generation of spatial and programmatic responses that will be utilized as part of the architectural response. Discussion and analysis of brain deterioration is discussed in relation to Alzheimer's disease and its capacities in negotiating with the built environment. 


\subsection{DEMENTIA AND THE BRAIN}

Within today's literature, when someone is speaking about dementia they are utilizing the word as an umbrella term in describing a variety of brain disorders (Alzheimer Society Canada, 2013). The World Health Organization defines dementia as a syndrome caused by a disease of the brain in which there is a disturbance of multiple high cortical functions, including memory, thinking, orientation, comprehension, calculation, learning capacity, language, and judgment and abstraction, visuospatial abilities, and skilled movement. The mind's consciousness is however not clouded. Impairments of cognitive functions are associated with, and occasionally preceded by, deterioration in emotional control, social behaviour, or motivation (World Health Organization, 2012). However, there are symptoms of dementia that are triggered by conditions that are treatable, such as depression, thyroid disease, infections or drug interactions. Symptoms that are considered un-treatable and progress with time are the result of damage to the nerve cells in the brain (Alzheimer Society Canada, 2013). Further research and tests are being conducted to better understand the disease and find a cure, but there are few breakthroughs in treatment and prevention of the associated symptoms. Alleviating environmentally-triggered symptoms that are a result of cognitive impairment can be effected through a well-designed environment specialized to those impairments.

Cognitive impairment affects each person in a different way, depending upon the impact of the disease and which type of dementia has been diagnosed for that person. Early diagnosis is encouraged as it provides access to treatment, allows planning of future care, helps explain behavioural changes and gives access to a wide range of rehabilitation approaches. According to the World Health Organization the problems linked to dementia can be understood in three stages: early stage (first year or two), middle stage (second to fourth or fifth years), and the late stage (fifth year and after) (World Health Organization, 2012). The matrix below illustrates the three stages and their associated symptoms (Fig. 2.01). These stages and associated time frames are only given as approximate guidelines as no two people are alike. Everyone's mind deteriorates at different rates and for some more quickly than for others. 


\begin{tabular}{|c|c|c|}
\hline Early Stage (1-2 Years) & Middle Stage (2-5 Years) & Late Stage $(5+)$ \\
\hline 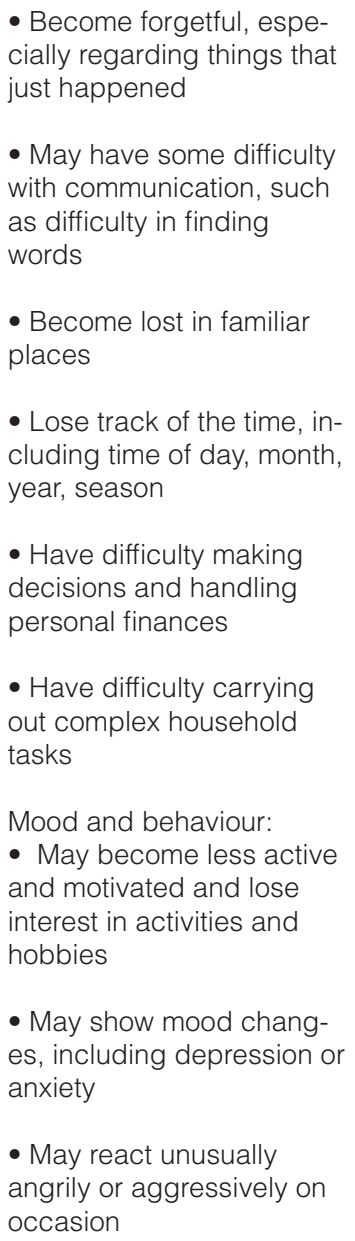 & $\begin{array}{l}\text { - Become very forgetful, } \\
\text { especially of recent events } \\
\text { and people's names } \\
\text { - Difficulty comprehend- } \\
\text { ing time, date, place and } \\
\text { events } \\
\text { - Have increasing difficulty } \\
\text { with communication } \\
\text { - Need help with personal } \\
\text { care (i.e. toileting, washing, } \\
\text { dressing) } \\
\text { - Unable to successfully } \\
\text { prepare food, cook, clean } \\
\text { or shop } \\
\text { - Unable to live alone } \\
\text { safely without considerable } \\
\text { support } \\
\text { - Behaviour changes } \\
\text { may include wandering, } \\
\text { repeated questioning, call- } \\
\text { ing out, clinging, disturbed } \\
\text { sleeping, hallucinations } \\
\text { - May display inappropri- } \\
\text { ate behaviour in the home } \\
\text { or in the community (e.g. } \\
\text { dis-inhibition, aggression) }\end{array}$ & $\begin{array}{l}\text { - Usually unaware of time } \\
\text { and place } \\
\text { - Have difficulty under- } \\
\text { standing what is happen- } \\
\text { ing around them } \\
\text { - Unable to recognize rela- } \\
\text { tives, friends and familiar } \\
\text { objects } \\
\text { - Unable to eat without } \\
\text { assistance, may have dif- } \\
\text { ficulty in swallowing } \\
\text { - Increasing need for as- } \\
\text { sisted self-care (bathing } \\
\text { and toileting) } \\
\text { - May have bladder and } \\
\text { bowel incontinence } \\
\text { - Change in mobility, may } \\
\text { be unable to walk or be } \\
\text { confined to a wheelchair } \\
\text { or bed } \\
\text { - Behaviour changes, } \\
\text { may escalate and include } \\
\text { aggression towards carer, } \\
\text { nonverbal agitation (kick- } \\
\text { ing, hitting, screaming or } \\
\text { moaning) } \\
\text { - Unable to find his or her } \\
\text { way around in the home }\end{array}$ \\
\hline
\end{tabular}

Fig. 2.01 - The three stages of progression in dementia patients

The most common form of dementia is Alzheimer's, which was discovered by psychiatrist Alois Alzheimer in Germany in 1906. Alzheimer's disease contributes to $60 \%-70 \%$ of all diagnosed cases. The other major form includes vascular dementia, dementia with Lewy bodies, and a group of diseases that contribute to frontotemporal dementia. These different types of forms of dementia have overlapping boundaries in terms of symptoms and causes and often mixed forms of dementia co-exist (World Health Organization, 2012). 


\subsection{DEMENTIA SUBTYPES}

Dementia is an umbrella term used in describing a variety of brain disorders, each subtype of dementia has a different cause and effect on people relative to the affected areas of the brain. In most cases when initially diagnosing someone with dementia, the exact type is hard to detect because all types have some symptoms in common. Listed below, from most to least common, are four types of progressive dementias that are most often diagnosed in the older population. It is possible of having more than one type of dementia occurring at the same time (Alzheimer Society Canada, 2013).
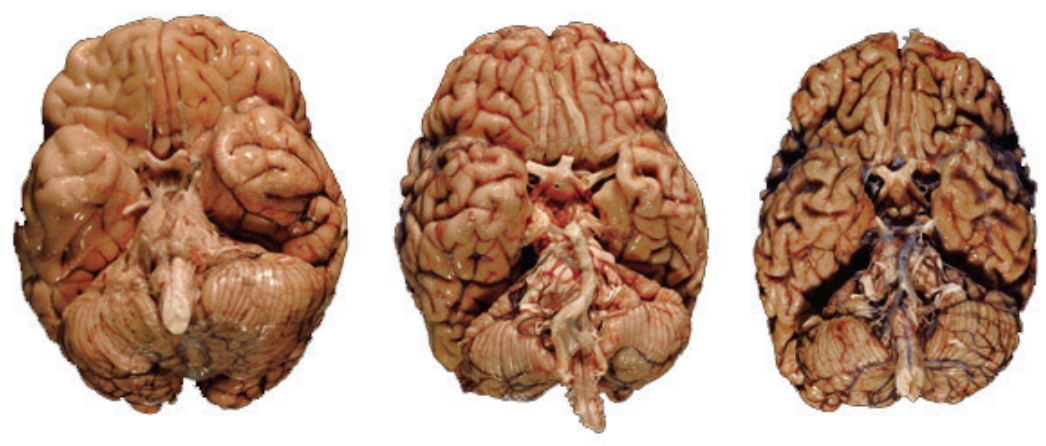

Fig. 2.02 - Brain Deterioration of Alzheimer's Patients

\section{ALZHEIMER'S DISEASE}

Alzheimer's disease is the most common type of dementia that people encounter as they age because it affects most areas of the brain. It is recognized as a fatal, progressive and degenerative disease that destroys brain cells. The symptoms illustrated previously within the 3 Stage dementia matrix are commonly associated with this disease (National Collaborating Centre for Mental Health, 2007).

\section{VASCULAR or MULTI-INFARCT DEMENTIA}

Vascular dementia occurs for patients who have cells in the brain being deprived of oxygen. This occurs when there is a blockage in the vascular system, or if there is a disease present so that the blood running through the vascular system is prevented from reaching the brain. This results in brain deterioration and causing symptoms of dementia to be present 
(National Collaborating Centre for Mental Health, 2007).

\section{DEMENTIA WITH LEWY BODIES}

Lewy body dementia occurs when there are abnormal deposits of a protein called alpha-synuclein inside the brian's nerve cells where these deposits interfere with the brain's messages that involve thinking and mobility. The symptoms that are exhibited by someone with Lewy bodies is much like Alzheimer's disease where there is a progressive loss of memory, language, reasoning and other higher mental functions. Depression, anxiety, alertness, insomnia, and apathy are also other factors that can be present in patients who are diagnosed with Lewy bodies (Alzheimer Society Canada, 2013).

\section{FRONTOTEMPORAL DEMENTIA}

It is estimated that two to five percent of all dementia cases are frontotemporal dementia. This type of dementia occurs at a much younger age than Alzheimer's disease and it also involves a progressive degeneration of brain cells that is seen as irreversible. Within this form of dementia common symptoms to Alzheimer's are present such as onset of memory loss, behaviour changes, difficultly with speech and physical movement (Alzheimer Society Canada, 2013). Frontotemporal dementia differs from Alzheimer's disease because it primarily affects the frontal and temporal lobes of the brain which are the areas that are generally associated with personality and behaviour. These changes in the brain affect the person's ability to function normally on a daily basis (National Collaborating Centre for Mental Health, 2007).

Current research is in analysing different dementia subtypes to further understand the breakdown comparisons according to age and sex. According to an analysis conducted by the United Kingdom as reported in Dementia UK figures 2.03 \& 2.04, frontotemporal dementia was a common subtype present in early-onset dementia. Men aged 45-75 years of age were commonly diagnosed with vascular dementia, while the proportion of dementia cases related to Alzheimer's disease was constant among women varying between 40\%-60\% from the range of 30 years and over. For men however, the proportion increases from around $20 \%$ at age 30 to around $70 \%$ at ages 95 and over (World Health Organization, 2012). 
The UK research illustrates that dementia can occur well before the age of 65 and the associated symptoms that are present for the most common cases are also seen as overlapping (figure 2.4). The built environment and proposed building typologies for dementia care should take these elements into account because of the specific needs of individuals and triggers it may induce.

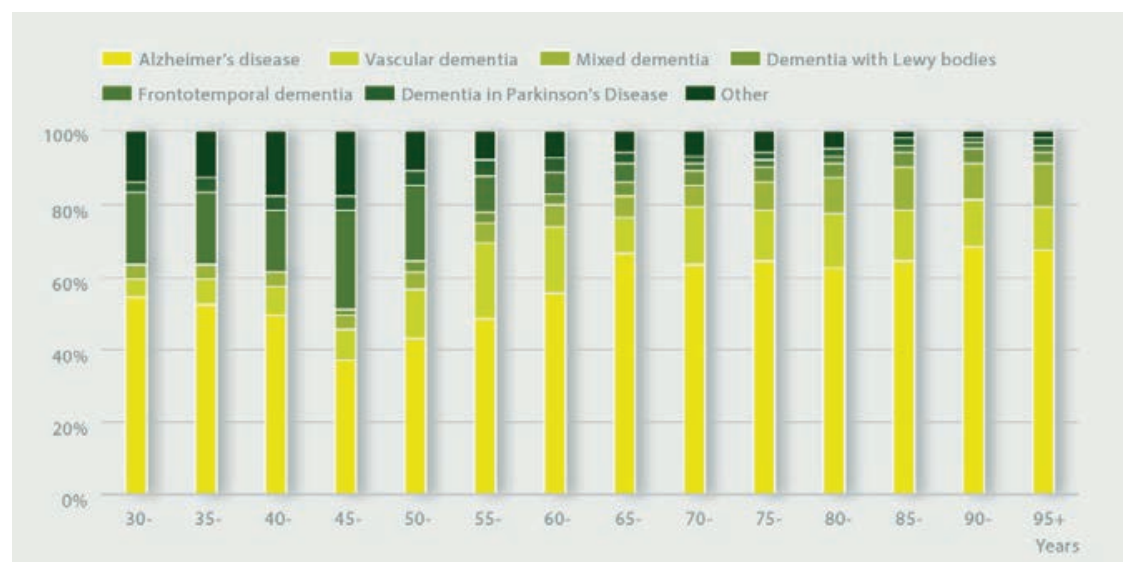

Fig. 2.03 - Dementia UK report: consensus estimates of the proportion of all dementia cases accounted for by different dementia subtypes, by age and gender. Women

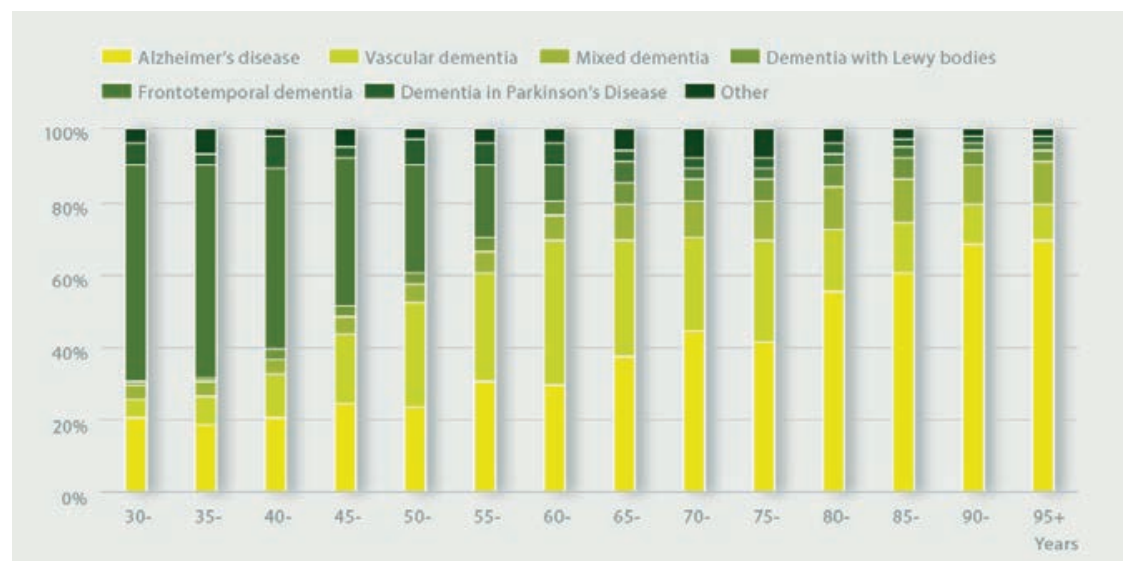

Fig. 2.04 - Dementia UK report: consensus estimates of the proportion of all dementia cases accounted for by different dementia subtypes, by age and gender. Men 


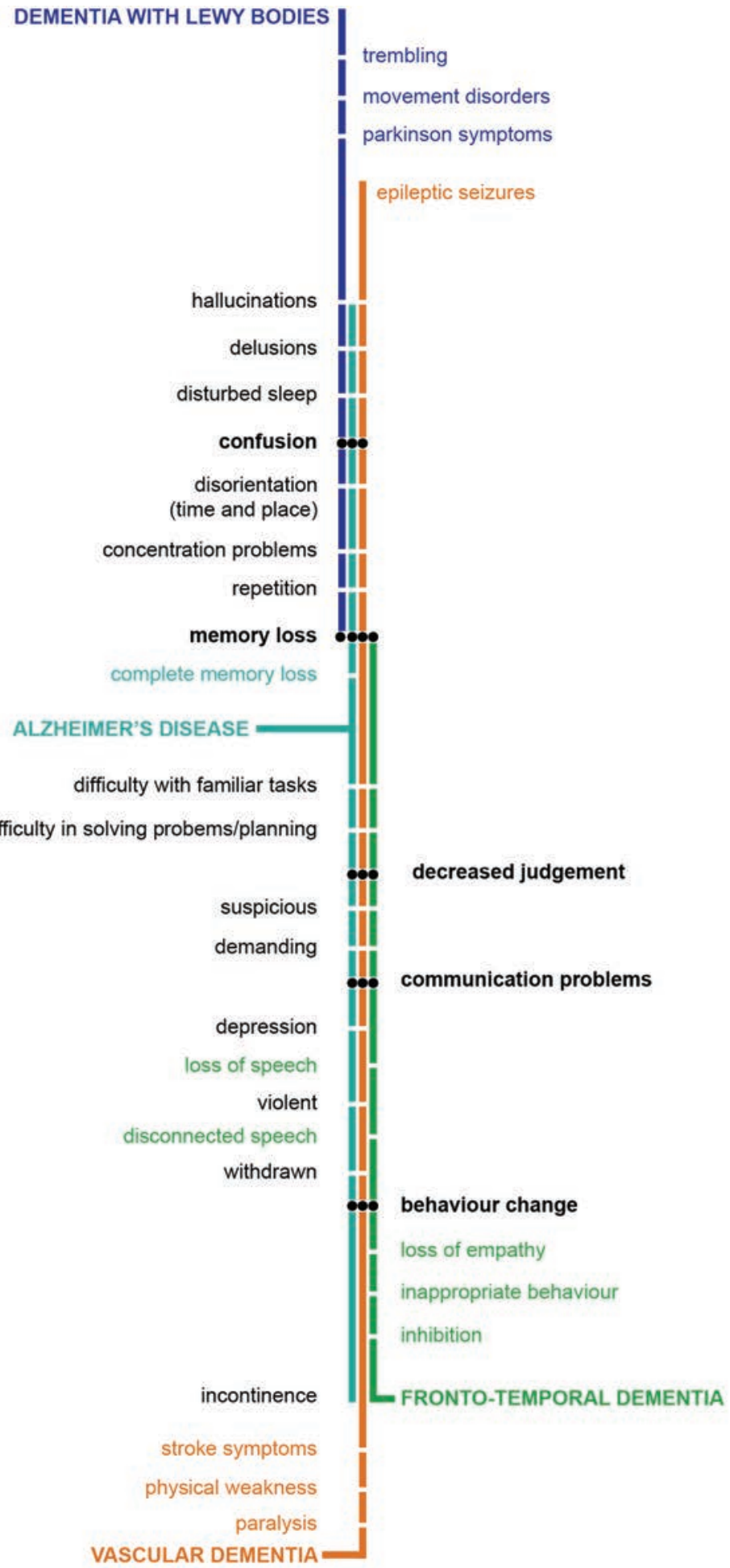

Fig. 2.05 - Dementia subtype syndrome overlaps 


\subsection{EFFECTS ON THE BRAIN FUNCTIONS}

The human brain is very complex and powerful; the essential component of the brain is the neuron. We have about 100 billion neurons in the brain with virtually endless number of connections between them. Each neuron is constantly changing, communicating and networking with other neurons to enable thoughts and actions. Neurons connect to one another via electrical impulses or chemical release at the synapse. However, when someone is diagnosed with a specific type of dementia that number of brain neurons starts to decrease, so that when someone dies at the end of the course of Alzheimer's disease his or her brain is likely to have lost up to $40 \%$ of its original weight. The positive side is that people living with Alzheimer's still have approximately 70-90 billion active brain cells. Studies have indicated that these cells are still active in retaining memories, abilities to learn, ability to be creative and to enjoy life's gifts that have been present in a persons life (Zeisel, 2010). Studies have further indicated that the aging brain is much more adaptable than once previously thought. As one ages, our minds improve in some cognitive areas, such as vocabulary and other forms of verbal knowledge. One of the significant findings from neuroscience is that the brain continues to develop new neurons (nerve cells) in certain regions of the brain even late in life (National Institute on Aging, 2009). As mentioned previously, Alzheimer's disease affects all parts of the brain. It affects individuals differently, which is why symptoms vary as different parts of the brain are affected by the disease. Different parts of the brain control and impact different responses and actions in a person.

When a person forms a memory, it is the result of experiences produced in changes in the synapses, a physical alteration in the brain. In this way, the mind makes memory physical. Alzheimer's disease however disrupts these connections between the neurons because of a buildup of betaamyloid in the brain causing "sticky" deposits that effectively "choke" neurons. Since neurons now can no longer communicate with one another, new thoughts cannot be formed. There is a common sequence to Alzheimer's disease where neurons are grouped in "families" that coordinate to bring out certain functions. Alzheimer's attacks each of the four major lobes within the neocortex: the frontal, parietal, occipital, and temporal (Zeisel, 2010). Each of these areas is responsible for different functions that are necessary for acting out certain human capacities. 
The frontal lobe controls functions controlling movement, encoding new information, recalling knowledge, planing, judging, evaluating, reasoning, socializing, and personality. For example, the damage to the executive functions in the frontal lobe makes it difficult for people living with Alzheimer's to organize sequences of events into a single process that would be a part of the process of recalling previously encoded information.

The parietal lobe, however, concerns itself with receiving sensory information from the surface of the skin and processing sensory information from hearing and seeing that are being sent from other areas of the brain. One's eyes and touch are important when dealing with negotiations in understanding the spatial relationships and perceptions of stimuli that the built environment is providing.

The occipital lobe is an equally important function within the brain. It processes visual input that is sent to the brain from the retinas. Which includes visualization and deciphering of colour, depth perception and motion detection. The fact that the visual system gets an entire lobe for processing clearly indicates the importance of high visual perception and processing among our senses. A number of factors can affect the visual perception in the aging people. The natural effects of aging eyes can cause problems with vision including: taking more time to adapt to changes in light levels, needing excessive lighting in order to see clearly, reduced peripheral vision, increased glare sensitivity, and decreased contrast sensitivity and limited depth perception. Lighting therefore becomes an architectural tool that can be used in designing spaces that are conducive to the needs of not only dementia patients but the elderly as well.

The last lobe that is affected as well is the temporal lobe. This part of the brain functions to regulate memory functions, emotions, hearing as well as verbal responses. A specific area that gets damaged by Alzheimer's is the hippocampal complex deep in the inner parts of the temporal lobes (Zeisel, 2010). Its functions get impaired early in the course of the disease and its importance is relevant to the fact that it is the site of the short-term memory which is also known as "map room of the brain" (Zeisel, 2003). This map room of the brain is crucial to indexing experiences, inserting them into long-term memory, and retrieving all memories. As a result of this, the brain does not function correctly for 
people when they are locating themselves spatially and remembering spatial relationships within the built environment. This is because there is a broken connection between the transmissions of experiences in the short-term memory to storing them in the long-term memory. When a person with Alzheimer's disease is in the built environment, they have difficulty with orientation and they tend to get lost more easily than most people, wandering in search of something they can clearly visualize or easily find, often triggering agitation and aggression within the person. The built environment can reduce such dysfunctional symptoms and behaviours if the information to negotiate it is embedded in the built environment itself, either through clearly demarcated circulation space, place makers and clearly identifiable destinations. This approach to designing the built environment and objects within it is considered to be seen as "naturally mapped" (Zeisel, 2010).

However, it is often difficult to identify which particular stage of the disease someone is experiencing at any given moment. As noted previously, the early stages of Alzheimer's may be characterized simply by increased forgetfulness. Individuals may have difficulty planning activities, completing tasks, or recalling information about recent events. The middle stages of the disease reveal greater difficulty in a person recalling personal history and the names of friends and family, changes in personality, perceptual-motor problems, and loss of impulse control. In the final stages of Alzheimer's, the person requires constant supervision, lacks control of bodily functions, and has no self-recognition. There is no prescribed time-line for the progression of the disease, but depending on the age at which the disease first manifests itself, it may last from five to twenty-five years (Brawley, 1997). 


\subsection{MEMORY}

"You have to begin to lose your memory, if only in bits and pieces, to realize that memory is what makes our lives. Life without memory is no life at all, just as an intelligence without the possibility of expression is not really an intelligence. Our memory is our coherence, our reason, our feeling, even our action. Without it, we are nothing" - Luis Buñuel

Amongst the fear and frustration of being diagnosed with any type of dementia, often the conversation circulates and focuses on the inabilities of the person instead of their abilities. John Zeisel presents a different approach to caring and understanding for someone who is diagnosed with Alzheimer's in his book "I'm Still Here". He states "The way the world sees Alzheimer's today is that a person is almost totally lost once he or she receives an Alzheimer's diagnosis, lost both to themselves and to those that love them. An Alzheimer's diagnosis is seen as an Alzheimer's 'sentence'. But this just isn't so" (Zeisel, 2010). An appreciation for the numerous capabilities of an individual with Alzheimer's can contribute to the enriching of the built environment with such people in mind.

A person's memory is a vital aspect of their self-knowledge. There are however two forms of memory storage that occurs within our minds: memory for facts and memory for skills, known as declarative and nondeclarative memory (Eberhard J. , 2009). Zeisel outlines the kinds of memories that persist through even the later stages of the disease. He states that "memories are not like objects we store in a kitchen cabinet. They do not exist fully formed in a part of the brain into which we have placed them for later retrieval. Rather, attributes of experience are placed in different parts of the brain-faces in one part, colours in another, emotions related to an experience in another" (Zeisel, 2010).

Declarative memory is associated with the memory for facts, ideas and past events that have occurred in a person's life. Our mind is capable of bringing this kind of information to conscious recollection as a verbal proposition or visual image, which is typically understood as memory. For people with Alzheimer's, these memories, sensory, music, engaging the body, remain retrievable throughout the course of the stages as well as memories that are strongly associated with emotions; marriage, a birth, or a death (Zeisel, 2010). 
However, nondeclarative memory results from physical experience and is expressed as changes in a person's behaviour instead of a memory recollection. An example of this type of memory occurs when, for example, if you learned to play the piano or a sport, skills learned will be allocated within the nondeclarative memory. These memories when activated and used at later times, do not come to consciousness, they are essentially unconscious actions (Eberhard J. , 2009). These types of memories, which can be understood as motor memory, are often preserved for Alzheimer's patients because of previous constant repetitive actions that are associated with muscle memory rather than informational memory (Zeisel, 2010).

Zeisel equates that the memories in Alzheimer's patients do not completely disappear, it is the process of retrieval that is damaged as noted previously. Within the early symptoms of the disease, patients are characterized by a decreased ability to recall new - or short term information. However, Zeisel indicates that new memories are possible to be encoded into the brain by creating repetitive techniques and cues through the sequence of complex tasks and locating memory boxes outside a person's room. Furthermore, environmental memories of colours and places and moods or emotions that are associated with specific spaces remain as a part of their memory. This becomes important in designing spaces that are therefore clear in their intent in facilitating the proper behavioural expectations for that particular space and user (Zeisel, 2010).

This notion of creating repetitive elements corresponds as well with movement and circulation within the built environment. A comprehension of the built environment evolves from internalized actions rather than from mental images. We know things not only by using our brain, but also by incorporating the movements of other parts of the body (Piaget \& Inhelder, 1971) (Designing Inclusive Systems, 2012). These repetitive actions seem to recruit additional neurons in the motor cortex and are therefore reflected in increased dexterity and speed of execution of the actions (Eberhard J., 2009). Epidemiological studies that have been completed identified certain behaviours of people that helped preserve memory functions. The result of their research indicated that people with higher levels of physical activity associated with daily living, walking long distances, climbing stairs, lifting objects, maintained their memory and other cognitive functions longer. The study illustrated that the 
neurochemical mechanisms by which nerve cells in the hippocampus communicate had been enhanced by exercise. Physical activity has always been an important aspects of healthy living. It not only improves the cardiovascular system but also affects specific positive changes in parts of the brain involved in memory. Other positive stimulations for the brain's cognition are gained from social engagement. This is attributed to feelings of self-worth which becomes important because they are seen as a measure for feeling how connected people may be to others in their family and community and how much they think they can influence their independence, which is very important to people with Alzheimer's (Eberhard J. , 2009).

\subsection{CONCLUSION}

John P. Eberhard asserts that the design of the built environment for those with dementia has the maximum impact when it reflects our understanding of the brains reactions to different built environments. By outlining the various conditions of the mind and how the mind processes external information from decoding new spaces, to creating a mental mapping of the spatial layout, Eberhard provides an understanding of the various conditions that a person who is diagnosed with dementia may be living with. These conditions need to be addressed when designing for the aging population that will be impacted by this disease. 



\section{CHAPTER 3 \\ ARCHITEGTURE'S RESPONSE TO DEMENTIA}

\subsection{INTRODUCTION}

Chapter 3 focuses particularly on the historical, present day approaches to provide present and emerging dementia-care architecture. This chapter presents current modes of delivery of care and the emergence of evidence-based design, illustrating the conditions and elements that are influencing the design processes and building typologies for new facilities that house people affected by dementia. 


\subsection{IDEOLOGY}

Since the mid-nineteenth century, architecture and health has been slowly evolving as a specialized area of design, rising to become a place of recognized professional stature and relevancy (Verderber, 2010). Hospitalization due to any type of illness is a nuance and often a stressful experience for the patient and family. For most people b eing hospitalized is a critical moment in one's life often signalling a crisis, and a signifier of a loss of control over one's life. The architectural environment must not be an added source of stress or lead to feelings of loss of control. Architecture has the opportunity to provide therapeutic and curative support at those critical times in a person's life (Verderber, 2010). With certain types of illnesses in age-related populations, institutional settings are not at times conducive environments for healing or care.

In the 1960's, Charles Jencks asked the question "can architecture be good for your health?" and "can it affect longevity or make a difference" in a patient's outcome within a hospital setting prior to his taking on the task of designing the Maggie Centers for cancer patient's (Jencks, 2012). He argued that architectural space does have an effect on your health beyond the expected functionalities and that its effects on patients are indirect but significant. This position stems from the idea that the ambiance of architecture, landscape, art and interior design can have a physical and psychological effect on both patients and caregivers within their specified settings (Jencks, 2012). Architectural determinism asserts that a building's environment directly affects person's behaviour and attitude. The concept that design matters, that it can make a real difference to people's lives, is in essence fundamental in the process of design (Marmot, 2002). Charles Jencks argues that architectural determinism has its potential to work for the built environment under some conditions. It would be dependent on the culture of the inhabitants and their conditions of well-being to have an influence on individuals (Jencks, 2012).

Alzheimer's and dementia are fast becoming significant epidemiological features of the early twenty-first century and the composition of the physical environment holds great potential to improve the well-being of people with dementia (Kitwood, 1997) (Calkins, 2009). Architecture mediates almost all experiences and moderates a great deal of human behaviour within their settings (Golembiewski, 2012). Furthermore, the 
influence of space on people with dementia is starting to be recognized more in literature as a significant factor that is likely to have an impact on the quality of life, particularly since many people with dementia have been limited in the range of environments they get to experience (Calkins, 2011). Despite the limited extent of research, evidence is pointing to the fact that the design of the built environment, by itself and in combination with organisational policies and procedures, has a direct and measurable impact on the physical and psycho-social functioning of residents with dementia, which may translate into higher quality of life (Calkins, 2009). Therefore, design for people with dementia should not only be seen as a therapeutic resource to promote wellbeing and functionality but also could act as a 'prosthetic' by compensating for their cognitive deficiencies.

\subsection{DEVELOPMENT OF THE DEMENTIA CARE ENVIRONMENT}

Prior to the nineteenth century, the primary focus of institutional care for people with dementia was within an almshouse where they lived for the remainder of their lives. Within this setting, other individuals were also housed including the clinically insane, inebriated, and homeless. Within this environment, the elderly who were housed, regardless of their varying needs and mental states, were labelled as the community's "needy" and often considered to be social outcasts (Watson, 2009). However beginning in the first half of the 20th century, people with dementia were place in either mental hospitals or asylums. As the knowledge base for mental health system developed after the 1950's, mental institutions were seeing significant declines in their patient populations. As a result of this decline, nursing homes started to take care of the demographic of elderly citizens with cognitive diagnoses (Calkins, 2011).

In the mid-1970's, the first specialized nursing home was developed for people with dementia by gerontologist Dr. Powell Lawton, at the Philadelphia Geriatric Center. Dr.Lawton's investigations into the psychological and social aspects of ageing recognized the importance of designing living environments for the elderly and, in particular, people with dementia. Traditional nursing homes were being designed for only 40 residents, and bedrooms were spatially arranged around a large open pavilion, representing a radical shift in the approach and design of these types of facilities (Calkins, 2011). 
Through Lawton's research and investigations, this design approach provided an increase in visual access to desired destinations, as a means to improve wayfinding, and provide a critical mass of people to support spontaneous social engagement. Density of people was an initial concern in the development of such spaces because if the population were too small in number, these would have provided insufficient opportunities for unintentional social engagement (Calkins, 2011).

Lawton further enhanced his research of the built environment through undertaking post-occupancy evaluations of the facility to determine if changes in the physical space, social engagement and treatment regiments had any impact on the users of the building. Lawton's research findings illustrated an increased engagement in planned/ staff-led activities, decreased pathological behaviours, increased visual gazes (i.e looking around), an increase in the number of physical areas of the complex accessed and an increase in the number of visitors there. However, the study also indicated that there was no increase in social behaviour or change in sleep patterns. Lawton, Fulcomer, and Kleban concluded at the end of their investigation that while basic competencies declined the most pliable behavioural variables did not but showed improvements in five instances (Calkins, 2011).

There were few efforts in developing the promising investigation that allowed to test and implement necessary changes needed in creating settings specifically for individuals with dementia. The Alois Alzheimer Center opened its doors to the public in 1987 in a reconfigured elementary school. In 1988, the Alzheimer's Care Center of Gardner Maine and in 1989 the Corinne Dolan Alzheimer Center in Chardon Ohio were opened. These projects received significant attention from the larger community since the Corinne Dolan Center attempted systematically to evaluate the impact of the physical environment on residents with dementia and their caregivers. With this progression of knowledge provided by Lawton, other researchers and designers began to investigate the impact of therapeutic environments for this specific demographic (Calkins, 2011).

As part of the recognition of these early models of care for people with dementia, "specialized" care facilities were increasingly moved to segregate residents from non-cognitively impaired residents. However, the impact and benefits of segregation were not immediately clear, but more often it was a means to isolate dementia patients from residents and 
their families who did not want to be in their proximity (Calkins, 2011). This notion of segregation versus integration is still a topic of discussion today in relation to the level of care being provided.

\subsection{MODES OF DELIVERY TODAY}

Within today's system of continuing care in Canada, there are four established components. These include home care, community support services, supportive/assisted-living homes, and long-term care facilities. Each of these components is either directly or indirectly connected as part of the Canadian network of care.

In most cases, each of these types of services and care facilities is directed towards an age group that is 65 years or older. The design and development of these facilities is lacking in specified design consideration for those with cognitive impairments.

Home Care

The Alzheimer's Society of Canada cites that one-in-five Canadians age 45 and over are currently providing some form of care to seniors who have long-term health problems while balancing this role with their own jobs and family responsibilities. As these family members are not medically trained, acting as caregivers can lead to heavy tolls both physically and mentally. However, home care services today encompass an array of health services that are delivered to individuals in their homes directly. Some of these services encompass personal hygiene activities, routine personal activities of living, training a person to carry out or assist them in doing specialized activities for their health (Canadian Healthcare Association, 2009).

\section{Community Support Services}

Community support services are identified as an array of health services and programs across the country. These health services are provided in various settings outside the home, long-term care facility, or a hospital. These services include respite programs, adult day programs and personal care services. Programs tend to be located within long-term care homes and assisted living homes that are geared towards the age 65 years and older. The intent of these programs, however, is to 
provide services to better meet the client's individual health needs and to delay or avoid admittance into long-term care (Canadian Healthcare Association, 2009).

\section{Supportive/Assisted-Living Homes}

Assisted-living is identified as collective housing that seeks to provide services such as meals and basic housekeeping, personal care services and health services. This type of service is designed to bridge the gap between the home and skilled professional nursing home. Within these supportive environments, residents still exercise some level of independence but are able to receive assistance with various tasks depending on the severity of their condition. This would entail care services that are available 24 hours a day (Canadian Healthcare Association, 2009).

\section{Long-Term Care Facilities}

Long-term care is identified as both a home for residents and a workplace for health providers. Nearly half of the patients living in longterm care homes suffer from some form of dementia. This means that a large portion of dementia patients are living within the confines of this environment that was designed with little attention to their cognitive and physical abilities. People living in these homes require more daily assistance because of their complex health needs and are no longer able to remain at home or in a supportive living environment (Canadian Healthcare Association, 2009).

\subsection{EMERGING TRENDS IN RESIDENTIAL GROUP LIVING ENVIRONMENTS}

The challenge facing architects, urban planners and heath care provisions today is keeping up to date with the current body of research that pertains to designing for individuals with any type of neurological impairment, be it degenerative or the result of a traumatic event or injury. With cross-disciplinary research and collaboration, this body of research allows for proper integration and execution in design, resulting in better and engaging living environments. 
As a result of people with neuro-disabilities requiring support in social, psychological, and cognitive areas of their lives, the most evident trend within the past 10 years is the replacement of standard institutional environment settings with residential style environments. Because of this shift to residential style environments, the emerging trends within group living models are focusing on increasing privacy, control, choice, independence, autonomy and freedom for dementia patients.

Many people seek to maintain a sense of normality in their lives, and it becomes imperative to maintain a sense of continuity with the past, being able to connect with the familiar, and able to adapt to current situations that are present in our ever changing circumstances. These ideals of independence and autonomy become vital when developing a connection with the particular spaces we inhabit, from the physical environment to the inclusion of friends, neighbours, and community institutions in our daily lives.

As part of the research and analysis, ten design qualities and characteristics have emerged as evidence in creating better environments for people with neuro disabilities. Some of these trends and practices go beyond environmental influences and include management and service components.

\section{TEN DESIGN PRINCIPLES}

\section{Small scale cluster connected to a larger scale service provision}

New models are focusing on creating small-scale clusters of groupings of people based on the evidence gathered from studies from large scale long term care settings illustrating that the noise, confusion and over stimulation was leading to agitation and aggression in its residents. A small group cluster is still not completely defined, but the range of people living together is from 6 to 10 units, within 5 to 7 group cluster (50- 70 residents). In some cases, within a nursing home, the trend is to reduce the size from a 60 bed residence to less than 20 to 24 units. Depending on the use and necessities of the associated program for the facilities, this impacts the overall building size, orientation and placement within the cities context (Calkins, 2009) (Regnier, Denton,2009). 
Since the trend is to decrease the number of units within a facility, in northern Europe the approach is to have the housing facilities physically connected to a community centre that is open to other older people who live in the neighbourhood. Residents therefore receive help, are engaged socially, and receive therapeutic assistance since the community and housing become connected as a single entity where activities become centralized (Calkins, 2009) (Regnier, Denton,2009).

In keeping people independent within their communities, the current practice within northern Europe and North America is to provide access to a day care setting where the program is dedicated to servicing those in need who can not stay at home safely during the day. As part of the day program in the northern European system provision is made for residents to stay temporarily for short periods. Having this dual role within the community has illustrated that consolidated efforts and increase in efficiency results in family members staying longer within their homes, in turn satisfying the need for independence and economic savings in the long run (Calkins, 2009) (Regnier, Denton,2009).

\section{Non-institutionalized appearance of interior and exterior design}

One of the first trends in changing the perception and feeling towards long term care settings was to change the institutional atmosphere into a setting that looked more "home-like." As part of this transition, the architectural language references home design that includes iconic identifiers such as the sloping roofs and fireplaces. However, each home and interior is different, and not everyone has identical elements within their home. These were steps taken to start the transition, but it should be stated that a pitched roof and fireplace do not necessarily define a home (Calkins, 2009) (Regnier, Denton,2009).

Furthermore, regarding today's approach to the use of colour for interiors, the trend has been towards lighter colour reflecting a contemporary feeling. Areas such as common rooms, entry foyers, dining rooms, and lounges, are spaces that establish a building's interior character. The design of these areas is often inspired by hotels, spas and destination resort interiors. A key element is to provide an environment that is stimulating to the point that it is helpful for residents who experience a decrease in visual acuity (Calkins, 2009) (Regnier, Denton,2009). 
Colour therefore becomes a vital aspect in giving a room character and balance and with the right colour balance is capable of making space inviting and comfortable. Colours such as red/yellow/orange/brown/ green are typically used because they are understood as soothing, warm and comfortable (Calkins, 2009) (Regnier, Denton,2009).

\section{Focus on visual and physical access to outdoor spaces}

A critical aspect in designing group living arrangements is the ease of access to outdoor spaces. These areas become vital for residents who spend many hours of the day indoors and do not get a chance to be outside often. Studies completed by Roger Ulrich illustrated that having visual and physical connections with the outdoors has the capability of making a difference in the health and recovery of patients. In the case of residents with cognitive disabilities, secured outdoor garden spaces are seen as therapeutically beneficial because they provide natural stimuli that improves attention and induces "involuntary attention" with the outer space composed of water, plants, trees, etc. (Calkins, 2009) (Regnier, Denton,2009).

The second aspect that is vital in creating access to these outdoor spaces is the rooms that overlook or connect to them. These interstitial spaces are edge conditions that can facilitate visual and physical connections. These strategically positioned spaces are located between indoor and outdoor areas, i.e a three season porch, bay window or winter garden (Calkins, 2009) (Regnier, Denton,2009).

\section{Watching activities and exercise / transparency and previewing}

Providing outdoor spaces and visual access to other areas of the building provides residents the ability to be aware of what activities are taking place and determining whether they want to participate. These outdoor spaces, when visible from common interior spaces, can be the setting for special events that are staged in the summer when weather permits (Calkins, 2009) (Regnier, Denton,2009).

Having the capability of seeing beyond the single room a patient may be engaged with, provides the users the desire to maximize control of their interactions. Room to room transparencies highly benefit residents with neuro-disabilities because they are often unable to imagine what is on 
the other side of a solid wall. Providing users with visual connectivity to adjacent rooms allows for a level of understanding of what is occurring in those spaces and is particularly helpful in motivating users to participate in activities (Calkins, 2009) (Regnier, Denton,2009).

\section{Use pattern of spaces}

The design and consideration of how spaces will be utilized can often impact how well they are occupied and how effective the space is at generating casual encounters and friendships. Some of these considerations should take into account creating variability in size to prevent overcrowding and should differ in character to create separate "moods" for each room. In the end this allows the users to distinguish each room's function and establish their appropriate behaviour in choosing their desired environment (Calkins, 2009) (Regnier, Denton,2009).

\section{Encourage movement}

Physical movement has always been considered an important activity for residents to maintain health. The easiest and most straightforward way to maintain fitness is indicated to be walking. Residents with dementia tend to "wander" around the building, therefore corridors with convenient seating can help with providing destinations along the pathway to provide breaks when needed. Another trend is the provision of exercise rooms and activity spaces with aerobic and strength training equipment to aid residents to strengthen their muscles that assist in maintaining balance (Calkins, 2009) (Regnier, Denton,2009).

\section{Looped pathways for orientation}

As mentioned above, wandering or "social wandering" is recognized as an opportunity in designing purposeful wandering, preventing undesired behaviours in every resident. "Social wandering" provides residents with a source of exercise and a way of exploring opportunities for stimulation without having a sense of being lost. As part of this method of using "social wandering," locating oneself in a naturally mapped physical environment is one in which the environment provides constant wayfinding cues as to the direction one should travel. (Calkins, 2009) (Regnier, Denton,2009). 


\section{Natural Light}

Natural daylight within any space has been recognized as a beneficial element when dealing with users who have difficultly seeing and/or are starting to exhibit characteristics of the ageing eye. There are four conditions where natural light becomes a major asset to the needs of people with dementia: 1. Exposure to a diurnal cycle of darkness and bright light, 2. Provision of natural external view. 3. Support for activity and social interaction and 4. Enhanced recognition of 'place' (Calkins, 2009) (Regnier, Denton,2009).

From the research evidence provided, high exposures to natural light have been shown to lessen sleep disturbances of the residences and lowered the amount of late night wandering within the corridors. Furthermore, the evidence illustrated that the absence of a clear day-night lighting cycle has a deleterious effect on health. Therefore, providing as much natural light throughout the building is essential in not only regulating the circadian rhythms but also providing internal and external visual cues for orientation within the building (Calkins, 2009) (Regnier, Denton,2009).

\section{Building Configuration}

Typical building configurations layouts for traditional nursing home design are of the letter plans $\mathrm{T}, \mathrm{H}$, and L. Within this framework shared and/or private bedrooms are along a straight double-loaded corridor. These letter plans would, therefore, not have the social spaces visible to the resident from their bedrooms. Another approach that emerged in spatial layout was the open plan design. The open plan design allowed the bedrooms to open up onto the social spaces. Studies that indicated that the open plan configuration was beneficial for resident orientation. Other studies illustrated that there was higher orientation in the $\mathrm{H}$ and $\mathrm{L}$ plans than the open plan regardless of the location of the social spaces. Everyone is different and perceives space differently; therefore, our reactions to building layouts will be different from person to person so these studies should be read with caution. Van Haitsma proposed a particular typology for different unit configuration. This proposal looks at the different configurations being hallway-based, open plan, and mixed. A ratio of $2 / 3$ rd of bedrooms opening up onto a single loaded corridor is a hallway-based configuration. A ratio of $2 / 3 \mathrm{rd}$ of bedrooms opening up onto social spaces is an open plan configuration. In the 
mixed version, more than $1 / 3$ rd of the bedrooms would be located within a single loaded corridor, and the rest would open onto the social space. The mixed version configuration resulted in positive outcomes where the residents had greater activity levels, displaying less anxiety and greater interest in their surroundings. It should be noted that the outcomes could differ based on the person's stage of dementia (Calkins, 2009) (Regnier, Denton,2009).

\section{Private Rooms}

A growing trend in the design of nursing homes and assisted living settings is to provide private rooms instead of shared rooms. Current research illustrates that when a resident with dementia is moved from a shared room to a private room, sleep had improved, there were fewer confrontations with other people, and the use of psychotropic medications was reduced. Research conducted by Margaret Calkin, provided evidence that there was a strong positive psychosocial outcome by this change. The evidence illustrated that there were increased preferences and satisfactions from doing activities and daily life among the users, as wells as staff. Units or households composed predominately of private rooms illustrated less time spent by the caretakers dealing with patient conflicts and reduction in staff turnover rate. Lower turnover rate was a result of the staff feeling less stressed with not dealing with roommate conflicts and other behaviour outcomes of sharing living spaces (Calkins, 2009) (Regnier, Denton,2009).

\subsection{DEMENTIA ENVIRONMENT}

In light of the discussion of the emerging trends in residential group living, it is important further to recognize the tools and principles designated for addressing the specific criteria that are relevant to people with dementia and the design decisions needed when designing for people with dementia.

\section{Evidence-based Design:}

The term 'Evidence-based Design' (EVD) is used to describe studies, which began with Professor Archie Cochrane in 1972, which examine effects of physical and environmental elements on human behaviour. This approach has geared itself towards aiding design decisions 
with scientific evidence in order to promote health and wellbeing. EVD has greatly influenced the healthcare environments in a way that has influenced health related outcomes such as length of stay, pain, medication intake, stress, arousal, mood, or environmental appraisals. These types of analyses are important in the case of people with dementia because they provides relevant outcome measures on the effects of the physical healthcare environment.

\section{Person-Centred Care}

The second aspect that is as important as evidence-based design is 'person-centered care'. This type of care strives to meet both the therapeutic space (physiological) and psycho-soical needs of someone who is diagnosed with dementia. This becomes a vital aspect when designing care facilities because it is essential to recognize that the social needs of residents is as important as their physical needs.

\section{Combining Evidence-based Design and Person-Centred Care}

When both of these tools are part of the design process in creating a well-designed facility, then traditional care institutions, such as nursing homes, will be able to properly provide adequate therapeutic needs of early and mid-stage dementia patients. This integration of tools is strongly significant because care for dementia patients requires a "..focus on the psychosocial needs.." encompassing therapeutic care with particular detail to cognitive and physical abilities (Brawley, 1997). Any new dementia care facilities will need to provide a physical space that has the capability to enhance the behavioural patterns of the users.

In what capacity can a dementia care facility enhance the behavioural patterns? Studies conducted by Zeisel to enhance a patient's environment take into account spatial needs such as space for wandering, lighting design, and also the ability for personalization. Spaces should help facilitate and encourage compassion, understanding and provide stimulation of physical, mental, and social skills (Zeisel, 2003a).

As noted previously in section 3.5 'Ten trends for residential group living', dementia patients' lives can be improved when provided with the appropriate environment for their physical and social needs. When habitable environments are designed accordingly, these spaces are 
capable of reducing aggression, increasing interaction, supporting autonomy, assisting with orientation, and recalling memories (Zeisel, 2003a).

However, poor sensory environments from over-stimulations and disorientating layouts are capable of impeding the improvements of medical therapies. When dementia patients are over stimulated, they tend to have feelings of anger and frustrations. These feeling of anger and frustrations are a consequence of rooms that are too large or overcrowded, leading to an increase of noise and activity. Environments designed with smaller scale social settings have been shown to decrease aggression within patients. Large common rooms, i.e dining rooms, which also serve as main activity spaces are indicative as impersonal to those with dementia who occupy these spaces causing confusion, and changes in behaviour. Furthermore, when examining transitional spaces such as corridors, researchers found that the longer the corridor is, the more un-welcoming they appear to the user (Zeisel, 2003a).

Long corridors are uninviting. When a person has dementia, one of the common behavioural traits is "wandering". The act of movement should not be seen as a negative symptom as it is found to be therapeutic. A design that promotes safety and direction to activities should be taken into account in the spatial layout of the building. What this achieves is a form of movement that is well-defined and secure within the building. As it is noted, "..wandering is a coping mechanism to relieve stress and tension". The spatial layout is required to be very clear to the users because the damage in the hippocampus does not allow for dementia patients to have the capability to create and use cognitive mapping for their environment leading to their disorientation. A way to guide the users of the building is to provide objects that aid in orientation at strategic locations along pathways, known as landmarks, but also provides a sense of transparency to the building so that someone can always anticipate what will be coming ahead of them. The method and ability to orient oneself, recalling where one wants to go and have a clear understanding of how to get there is vitally important to a person's personal comfort and mental well-being (Zeisel, 2003a).

The affective experience of the users is another aspect to acknowledge. This refers to the extent in which the environment might cause or raise agitation and depression levels of an individual with dementia. Spaces 
that are dark, dull, or uninteresting are counter-intuitive to prescribing medication for depression. The aesthetics of spaces effects individuals in an indirect manner, where it impacts them on a psychological and emotional state. Creating spaces that present a warmer appeal can promote socialization, physical movement, and increase self-esteem.

These kinds of design features enable residents to have a greater sense of control over their lives and empowers them, and as a result reduces their tendency to withdraw and be depressed. Enabling and giving control to the user of his or her space is another means to provide a sense of autonomy. Allowing residents to bring their personal furniture to their rooms provides a link to their personal history.

\subsection{CONCLUSION}

Overall the intent of any designed space should be to enable users and not disable them. In the case of people with dementia, design decisions should address cognitive impairments, memory loss confusion, wandering, over/under stimulation, and lack of judgment. What this leads to is a design that is clear in its spatial layout and intent for navigation, interaction and engagement. Such attributes provide cues and prompts, reduce over-stimulation, eliminate decision points and provide reassurance and familiarity. 



\section{GHAPTER 4 \\ cASE STUDY}

\subsection{INTRODUCTION}

The following chapter presents a compilation of current trends and practices in architecture for the elderly and dementia-care. These trends illustrate shifting paradigms in the architectural expression of how healthcare facilities are being designed with a humanistic approach. 


\subsection{EMERGING MODELS}

The task of designing places for the elderly and those affected by dementia has seen great strides in raising awareness of how design can impact and improve lives by creating calming, dignified, and expressive spaces while at the same time minimising dependence and maximising quality of life.

As elderly and dementia-care architecture keeps evolving with new concepts and ideas, the following precedent studies represent a compilation of current trends and practices for living environments for the elderly and those impacted by dementia. The importance of this research illustrates and defines emerging programmatic and social agendas as we deal with the growing needs of ageing population as described in previous chapters.

\subsection{DE HOGEWEYK (DEMENTIA VILLAGE)}

Name: De Hogeweyk (Dementia Village)

Location: Weesp, Netherlands

Date of Completion: 2012

Architect: Molenaar\&Bol\&VanDillen architekten, Vught

The first case study focuses on a new model that was designed by Dutch architects Molenaar\&Bol\&VanDillen. The De Hogeweyk, which means Dementiavillage, is a dementia-focused living community that provides a new meaning for the relationship between patients and the kind of care they receive. The intent of the village design was to create a type of home where residents would participate in daily life, in a way similar before their entry into long term dementia care (fig. 4.01 and 4.02)

The building's form on the site has a resemblance that of a fortress. The site is bound by the residences along the perimeter enclosing the internal courtyards, closing itself off from the outside world. From

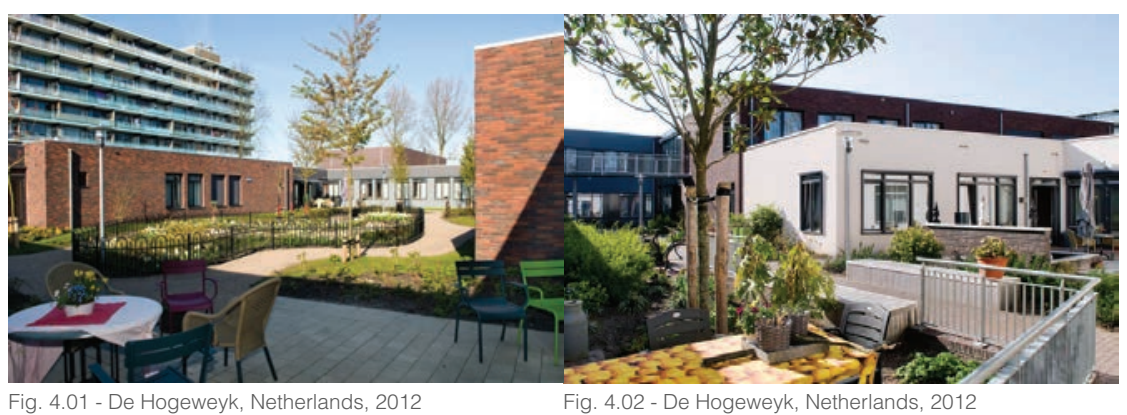




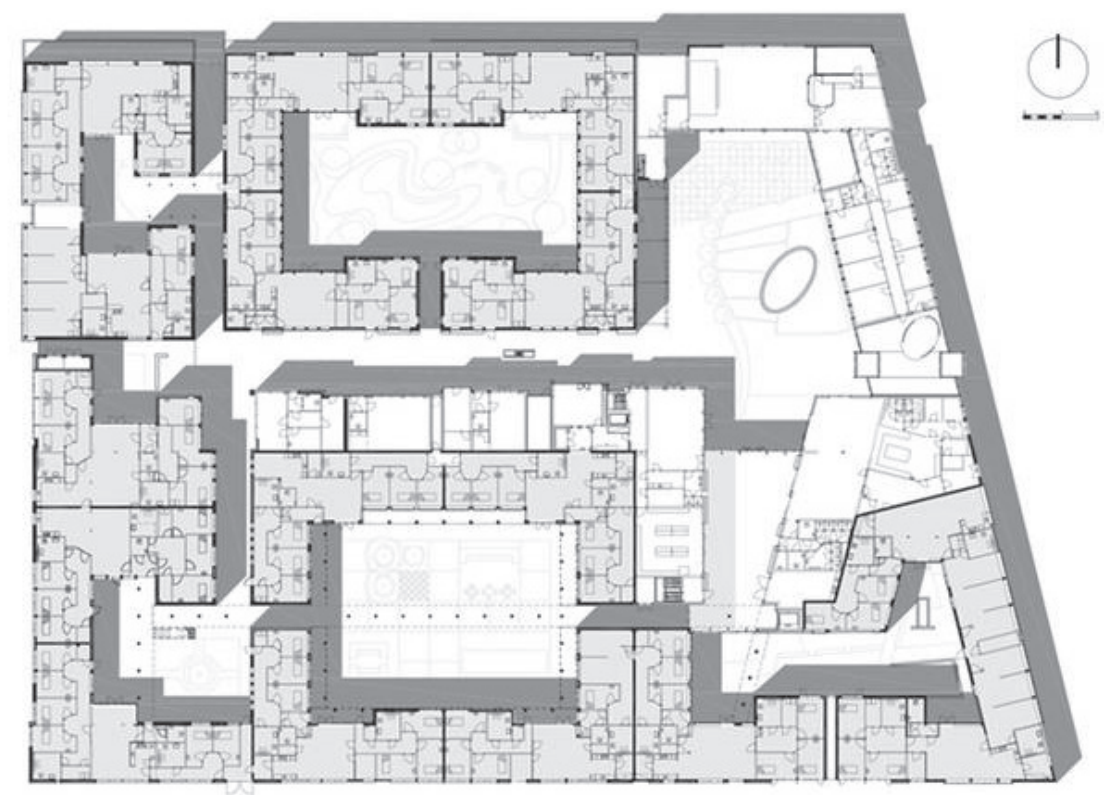

Fig. 4.03 - De Hogeweyk Floor Plan, Netherlands, 2012

a security standpoint, the village uses gates and security fences as a means of control, with only two points of access within the village located at the north and west side of the site.

The interior of the village is a self-contained area containing restaurants, cafes, a supermarket, gardens, etc. allowing patients to move about freely without risk. The unit structure of the village is carefully designed. Each housing cluster is self contained housing 6 to 8 people, including a caretaker's suite and is separated from other clusters. Each household has its own entrance and the use of different facade colour palette distinguishes each cluster (fig.4.01 and 4.02). There is a high level of transparency, visual and physical access to outdoor spaces within the bound facility as articulated in trends 3 and 4 in chapter 3 . Corridors are kept to a minimum as well, as the main circulation to other parts of the village is outdoors. This approach is highly effective in creating a

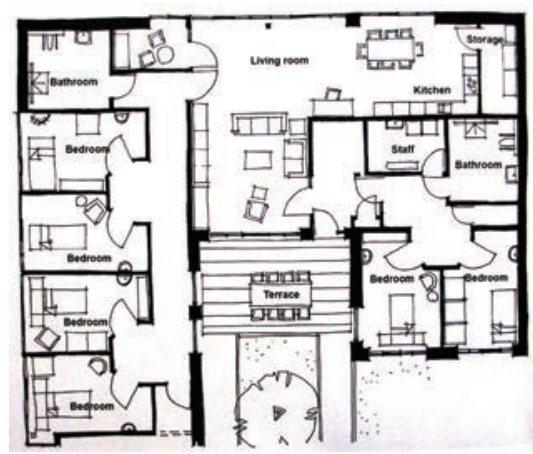

Fig. 4.04 - "household cluster" 
sense of place that isn't confined to one entity but a series of places and destinations. The design approach of maintaining familiarity and creating a de-institutionalized character of place avoids the dehumanizing effect that long-term medical care can cause.

\subsection{HAINBURG NURSING HOME}

Name: Hainburg Nursing Home

Location: Hainburg, Austria

Date of Completion: 2009

Architect: Knowspace

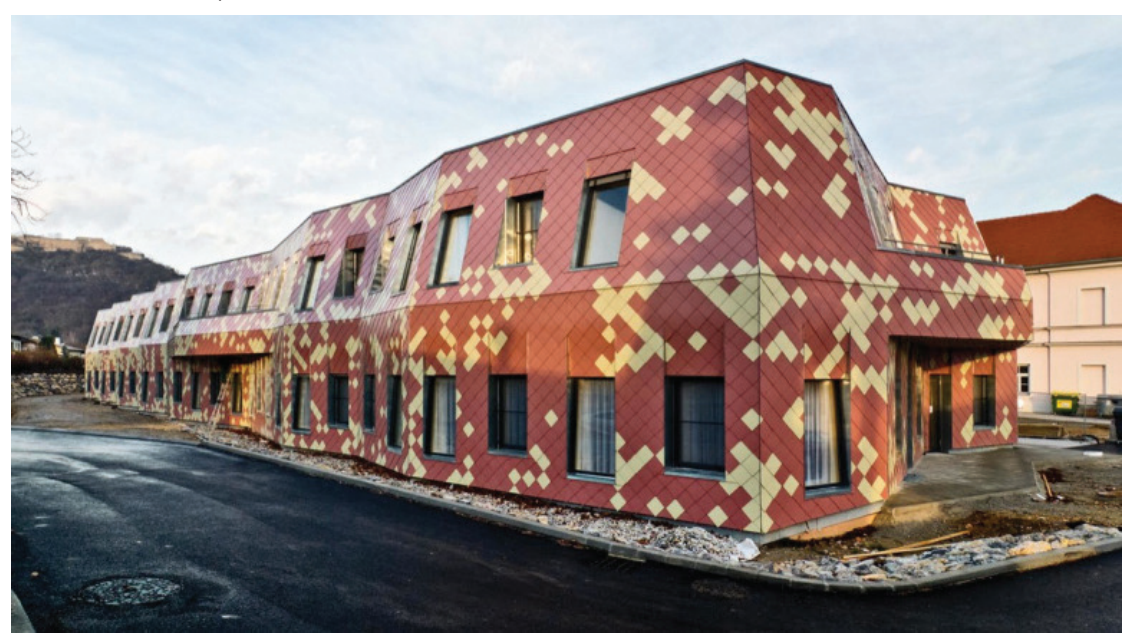

Fig. 4.06 - "household cluster"

The second trend described in section 3.5 is the concept of moving away from a institutionalized appearance, a breaking of the rigidity of design which is typically driven by standards and regulations.

Architect Erhard An-He Kinzelbach, from the architecture firm Knowspace, states that retirement communities and nursing homes conceived as hospitals are highly regulated, standardized, and repetitive, are highly program driven and have little space for privacy, small amount of space for interaction amongst people. A method that Knowspace utilizes to break the mould for intervention is based on four specific elements: 1. Common external space, 2. External facade, 3. Internal common space, and 4. Internal facade (Kronaus \& Kinzelbach, 2010).

In the design of the Nursing Home in Hainburg, Austria, Knowspace addressed this issue of institutional appearance of repetitive program by designing the external and internal "facades" of the building using a design strategy of a two-way fold (fig 4.06). This design strategy was driven by a desire for individual differentiation. By utilizing this approach, 


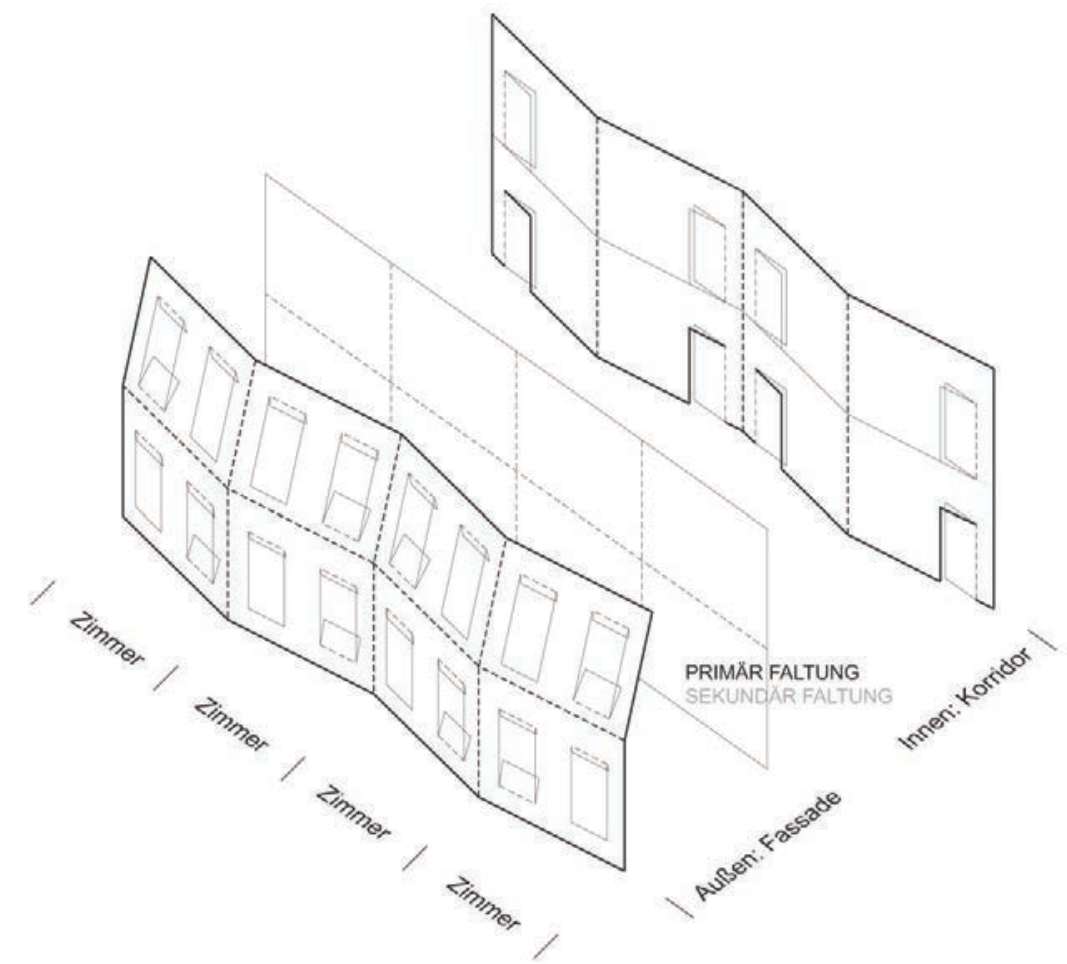

Fig. 4.07 - Hainburg Nursing Home two-fold facade

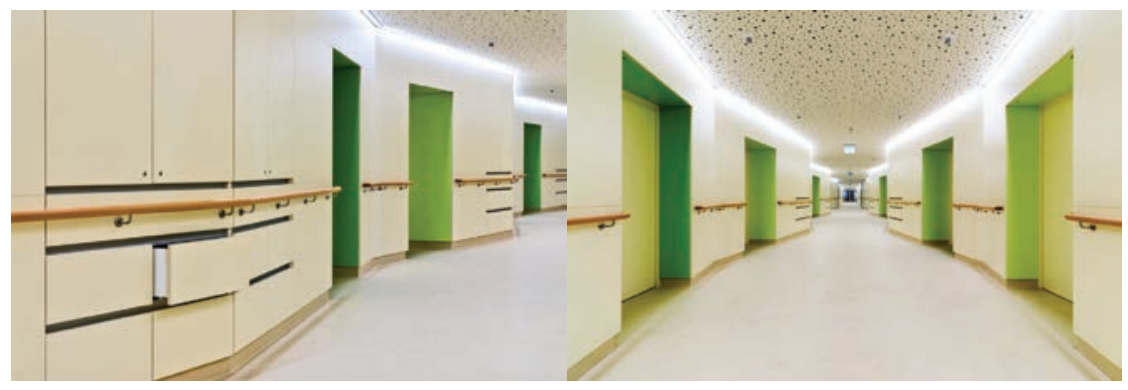

Fig. 4.08 - Hainburg Nursing Home interior circulation corridor

the folding of the facade breaks the length of the bar volume and enhances the readability of each internal room. Internally, the folding generates niches (fig 4.9) in front of the entrance to each individual room, resulting in spaces for congregation and creating a corridor that is more than just a circulatory space.

However, even with the attempt to move away from an institutional appearance, the interior corridor of the nursing home still has a sterile institutional atmosphere. This is due in part of the choice in colour and material composition. 


\subsection{SANTA RITA GERIATRIC CENTER}

Name: Santa Rita Geriatric Center

Location: Ciutadella, Illes Baleares, Spain

Date of Completion: 2009

Architect: Manuel Ocana

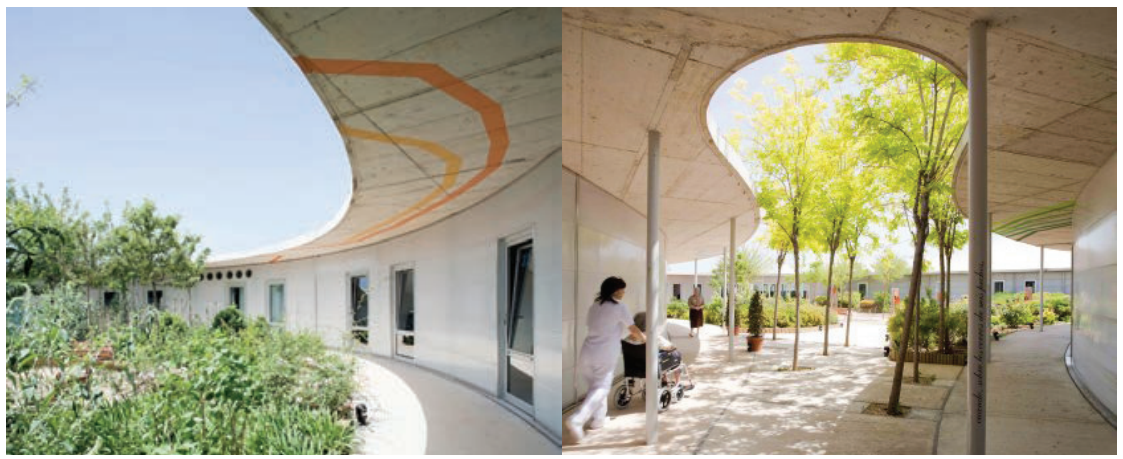

Fig. 4.09 - Santa Rita Geriatric Center, Spain, 2009

The Santa Rita Geriatric Center designed by Manuel Ocana is also looking at shifting the design construct of the institutional typology with a design strategy that he calls "sensitive pragmatism and artistic functionality". All residents' rooms are directed towards the internal garden, by eliminating all corridors and architectural barriers in an open plan. The internal garden is intended to serve as a sort of "lobby" space acting as an access point to other areas within the centre.

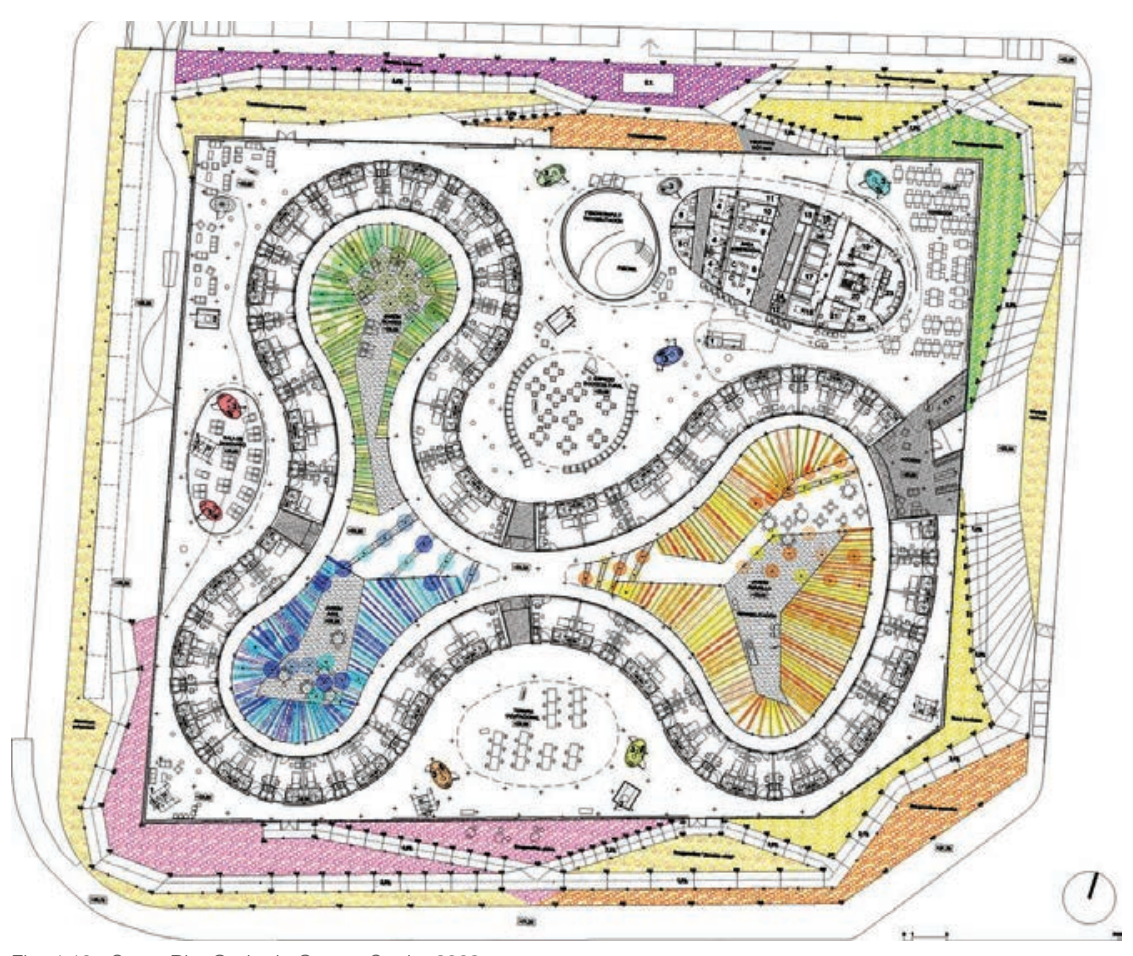

Fig. 4.10 - Santa Rita Geriatric Center, Spain, 2009 
The spatial layout of the centre provides accessibility to its residents by open spaces beside the bedrooms. Circulation of the centre is not prescribed to one single path, where Ocana identifies this concept as a "polyatmospheric circulation space: a series of events that can stimulate the senses and ease the disorientation and spatial tedium that one can 'experience' in a geriatric centre."

\subsection{ALCÁCER DO SAL RESIDENCES}

Name: Alcácer Do Sal Residences

Location: Alcacer do Sal, Portugal

Date of Completion: 2010

Architect: Aires Mateus

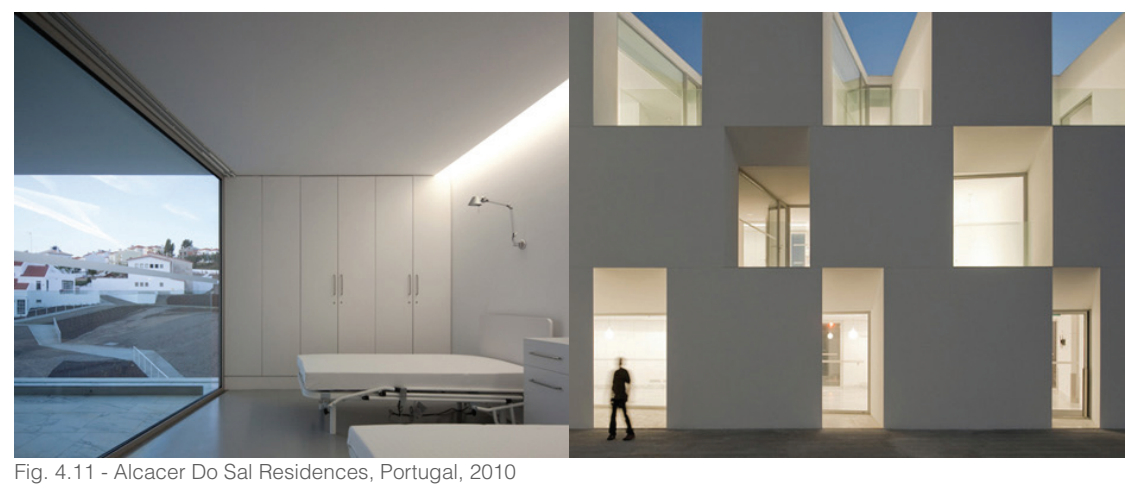

The Alcacer Do Sal residence, designed by architect Aires Mateus, is a building that addresses one of the concepts of sensorial qualities. The architects were capable of attaining this by engaging with the existing sloping landscape, embedding the structure, and allowing for the form of the architecture to emerge from the ground. All individual rooms are situated outwards toward the sloping landscape and are provided with full glazed walls for maximum exposure to daylight (fig 4.11).

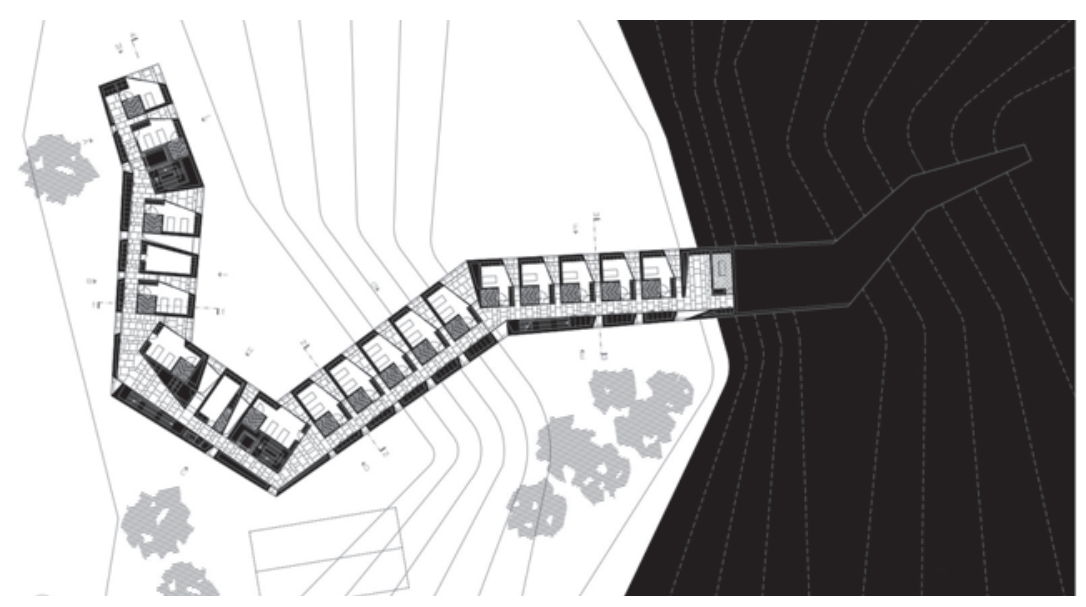

Fig. 4.12 - Alcacer Do Sal Residences, Portugal, 2010 
The building's programmatic approach, as noted by Mateus, is defined as something between a hotel and hospital. The challenge was to reinterpret the combination of social/private spaces for social life and solitude (Warmann, 2011). As seen in plan (fig 4.12), the internal circulation is linear, along a single loaded corridor. All units exit out along a singular path with external windows providing visual connectivity and orientation within the site.

\subsection{GROUP HOME IN NOBORIBETSU}

Name: Group Home in Noboribetsu

Location: Hokkaido, Japan

Date of Completion: 2006

Architect: Sou Fujimoto Architects

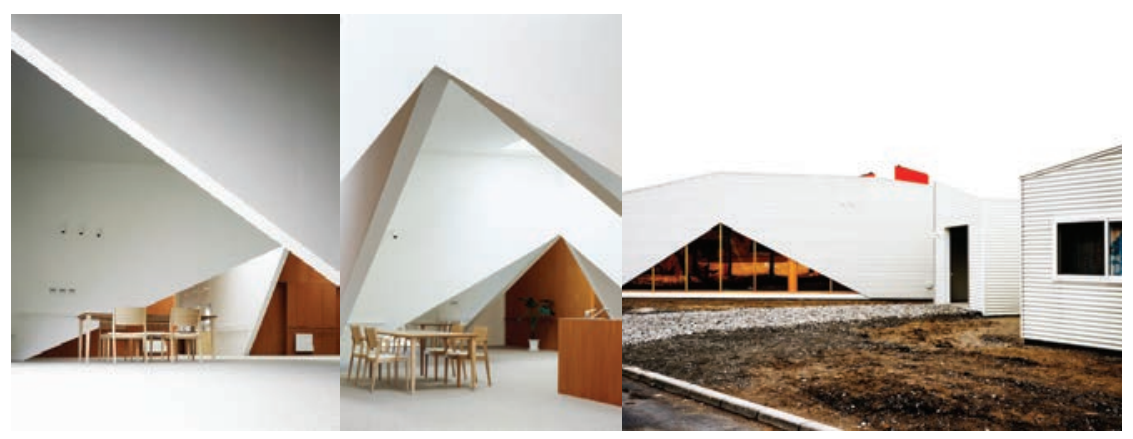

Fig. 4.13 - Group Home, Noboribetsu, 2010

Japanese architect Sou Fujimoto designed a group home in a residential section in Noboribetsu City, Hokkaido, Japan in 2006 for people who suffer from dementia. The design of the spatial layout for this facility is on a $3 \times 3$ parallel grid, which is quite different than the projects illustrated so far. The building is divided into two housing units, each comprised of nine bedrooms, flanking the main entrance (fig 4.14).

Referring back to trend 9. Building Configuration, we see here a clear intent of creating a centralized place for the living and dining spaces for the residents as they exit out of their bedrooms. This design allows for disorientation to be completely eliminated from interior living/dining spaces. The angulation away from the main entrance allows for a continuous perspective from both ends of the living spaces, providing natural daylight to illuminate the spaces.

As seen in figure 4.13 the design of the interior retreats away from an institutional feel with the use of angled walls. As this is a residence for dementia patients, the limited use of colour and other materials provide 
a sterile space, a space that is attempting to be warm and inviting but lacks the level of detail to distinguish the use of spaces from one another.

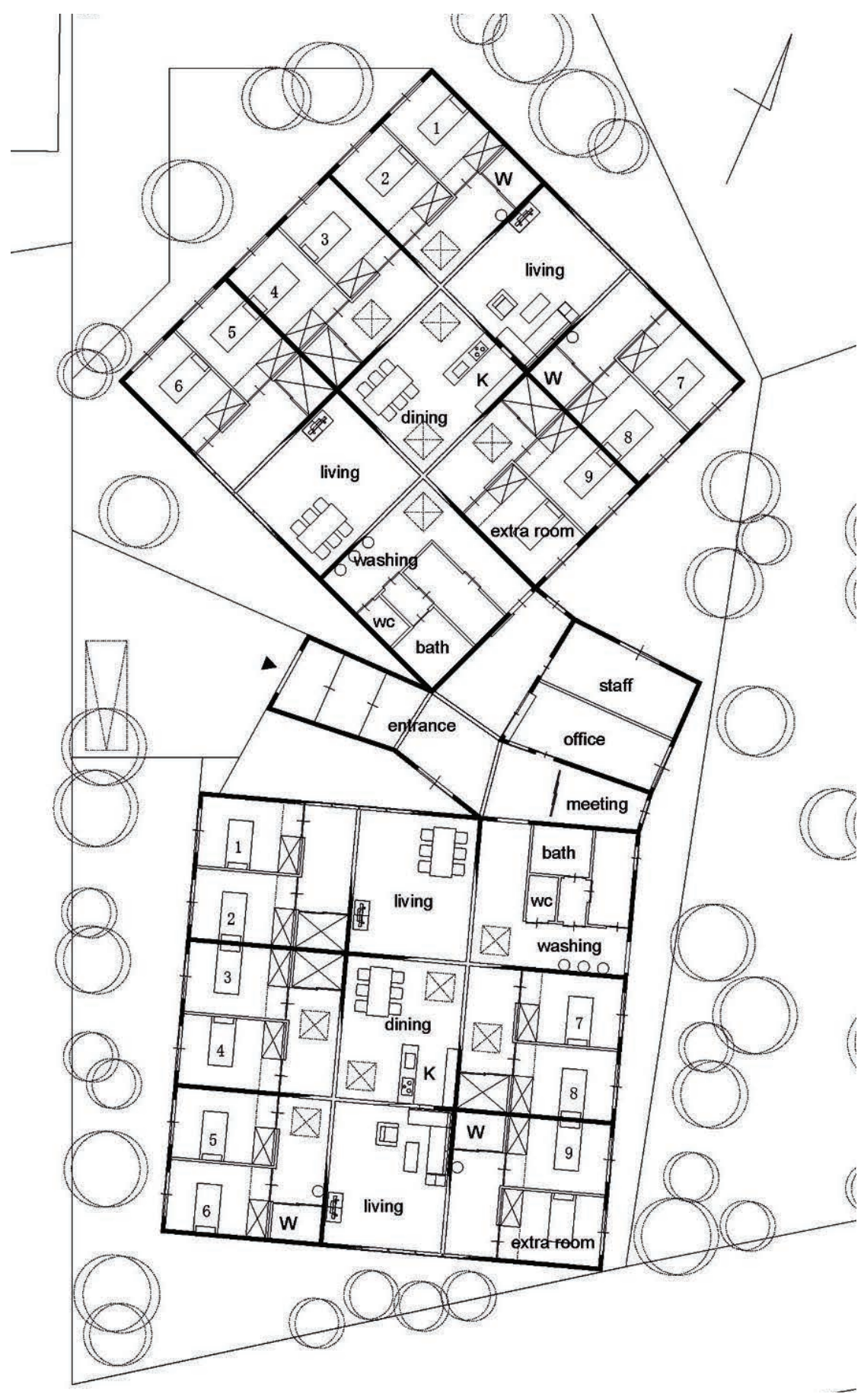

Fig. 4.14 - Group Home, Noboribetsu, 2010 


\subsection{URBAN DAYCARE CENTRE FOR AZHIEMER PATIENTS}

Name: Urban Day Care Center for Alzheimer Patients

Location: Pontevedra, Spain

Date of Completion: 2011

Architect: Santos + Mera Arquitectos

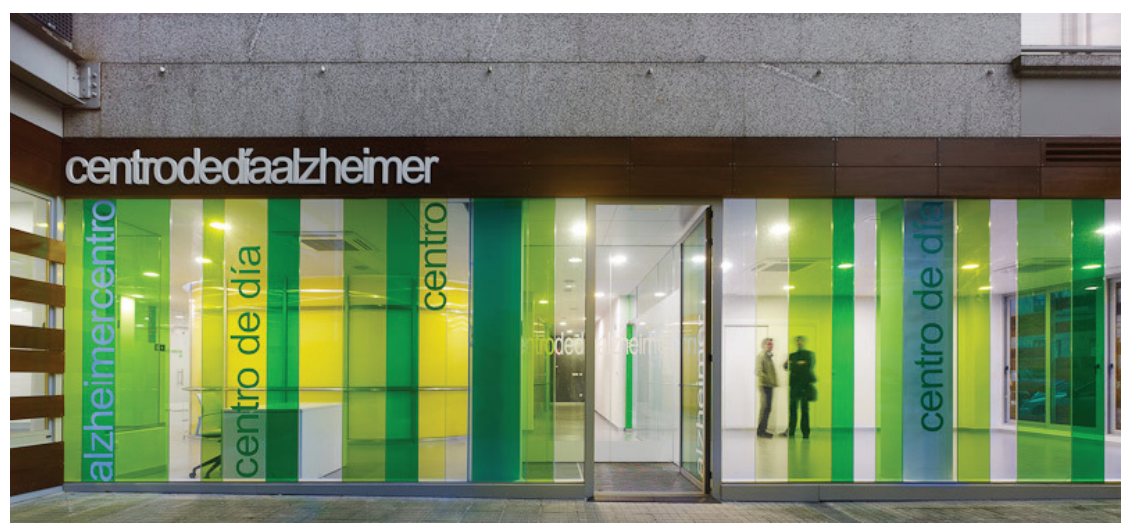

Fig. 4.15 - Urban Day Care Center for Alzheimer Patients, 2012

The Urban Day Care Center for Alzheimer Patients, designed by the architecture firm Santos + Mera Arquitectos, is intended to provide a warm, pleasant and calming atmosphere. The subtle use of colour on the exterior facade and interior wall partitions provides visual references that are easily distinguishable to the user identifying rooms and open areas within the centre.

The exterior facade is not closed off from the public realm. The facade is clad in wood and affords degrees of permeability, screening exterior light illuminating the interior public areas. The gradient coloured glass filters the sunlight into a green, combining translucent and transparent bands.
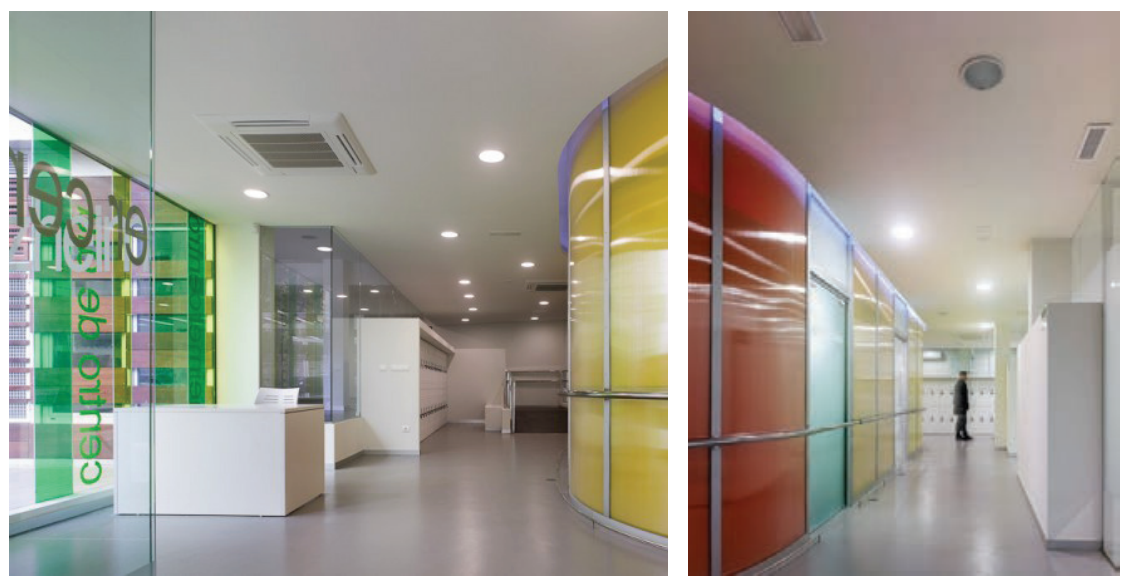

Fig. 4.16 - Urban Day Care Center for Alzheimer Patients, 2012 


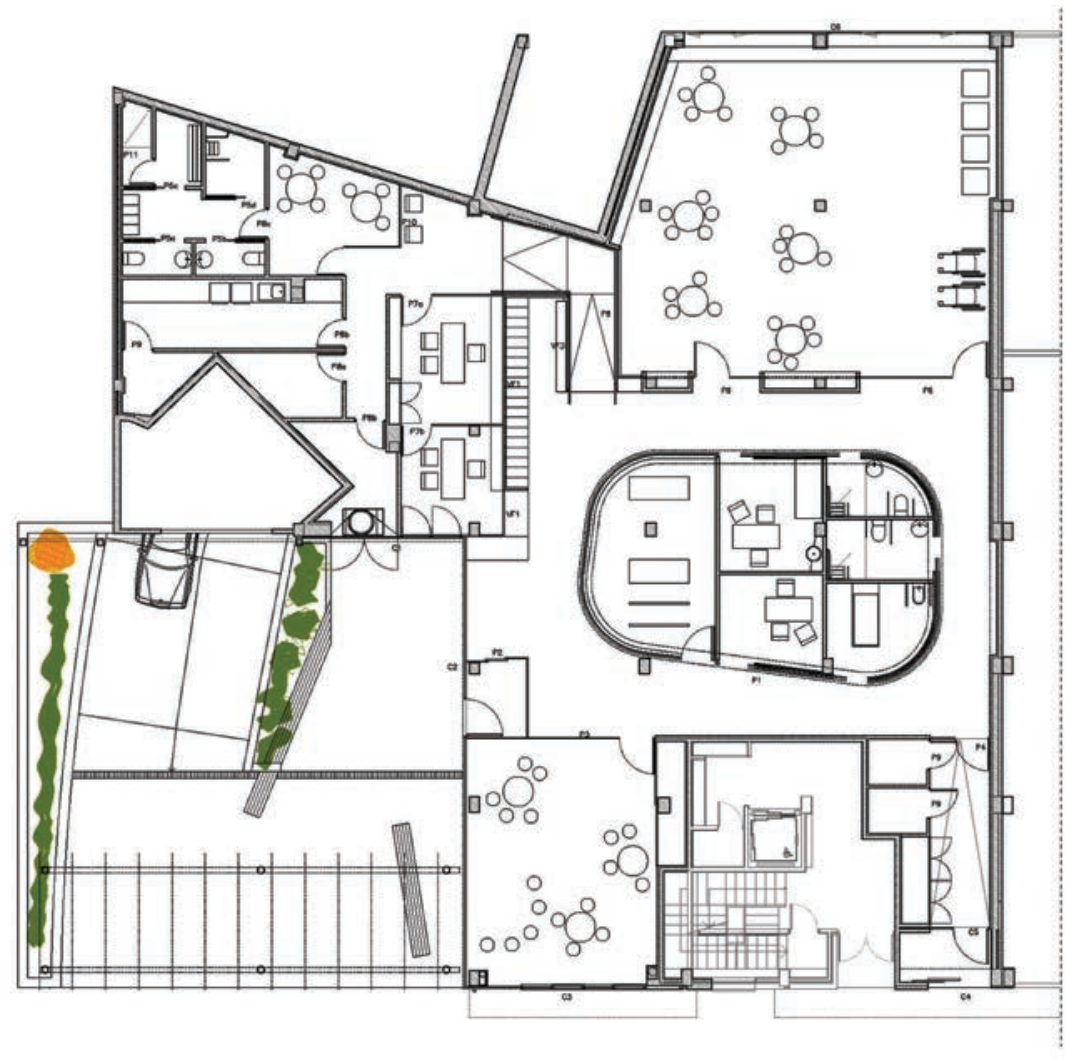

Fig. 4.17 - Urban Day Care Center for Alzheimer Patients, 2012

As this is a small day centre within the urban core of the city, the internal circulation is easily identifiable (fig 4.17). The centre core houses administrative offices and public washrooms as the perimeter houses activity spaces. The user therefore always exits out into the circulator corridor as they move into other areas of the centre.

\subsection{CONCLUSION}

By reviewing the selected range of projects, we see a clear shift in thought and design approach that has sought to raise awareness in how design can impact and improve people's lives by creating calming, dignified, and expressive spaces. 



\section{GHAPter 5 \\ DESIGN RESPONSE}

\subsection{INTRODUCTION}

The ultimate meaning of any building is beyond the architecture, it directs our consciousness back to the world and towards our sense of self and being. Meaningful architecture makes us experience ourselves as complete embodied and spiritual beings. - J. Pallasma, The Eyes of the Skin

Chapter 5 illustrates a design response that recognizes and articulates an architectural model that represents a rising demographic. The conceptualized design response is generated from the analyses and synthesization of knowledge related to dementia. 


\subsection{PROBLEM ANALYSIS / THE CONCERN}

Alzheimer's and dementia are fast becoming significant epidemiological features of the late twentieth century and the compositions of the physical environment holds great potential to improve the well-being of people with dementia (Kitwood, 1997) (Calkins, 2009). As it is defined to be a progressive cognitive dysfunction, affecting one's ability to recall familiar objects, places and task, those who suffer from this cognitive impairment are highly sensitive to their built environment. However, looking at traditional architectural typologies of nursing homes, longterm care homes, etc., there has been limited attention to the resident and more focus instead on staff needs, function and sterility. Healthcare architecture should focus on promoting personhood and community alongside the medical aspects and not at the cost of losing a sense of individuality, community, and sensual stimulation. To achieve this the formal architectural elements that construct the building are required to be taken into consideration for this demographic. This is where the third skin element comes in as a factor. The building form that encapsulates us provides a layer of information, from materiality to tectonics, for us to read and comprehend it in order to understand allowable behaviours that are appropriate within that space. Is the space familiar to us? Is the building form designed in a way that allows for a clear understanding for navigation? These are just some types of questions that the designer should consider when designing these facilities. The perception and image that the built environment provides us with, one in which we engage with both physically and mentally, affects us and our daily experiences. Our mental capacities are powerful tools we use to process information and negotiate the space that provides us with these experiences.

Over the past several years, research has illustrated that the space surrounding us represents an invisible force that influences how we feel and can dictate our instinctive behaviours, leading to improvements in the design of healthcare facilities. When there are changes in the architectural representation in healthcare facilities, what are the hidden messages that the architectural environment conveys to patients, families, and employees? This hidden element, our third skin, has a direct and indirect impact on our understandings of others and the human relationships that are at play in these places. Those who are affected by dementia will respond more intensely to this "third skin" than those without cognitive disabilities because of how their minds process what 
architectural information is presented to them. Therefore, it is required to provide distinctive environments for those who are affected, rethinking architectural space using orientation, volume, and lighting to produce distinctive atmospheres.

Chapter 1 of this thesis-project illustrated a shift in the types of integrated care models that will occur in the future. The ageing population is changing and with it so must the approach to architectural design for this demographic. Meeting the emerging market demands will be predicated on the social, economic, and political agendas that drive the planning policies. However, it will be required to maximize benefits for people with dementia but also ensure in the minimizing impact on the growing demand within the healthcare system. There is no "onesize fits all" solution for dealing with these medical conditions. The postwar generation has a stronger sense of self, awareness of rights, and individuality, allowing for alternative options to be consider that keeps them integrated within their communities. Specialized community-based facilities that factor in physical, psychological, and emotional needs are necessary to be present in the continuum of care as a viable option for ageing within one's home and neighbourhood. The shift away from a medical solution to a human solution allows for architecture to respond to the varying needs of people with cognitive disabilities.

To comprehend the requirements needed to design for this demographic, chapters 2 and 3 established the neurological effects of dementia and the roles that design participates in the quality of life and overall wellbeing. With current scientific research of evidence-based information illustrating how environments affect people with dementia, I strongly believe that the future environments for these individuals can be created, allowing for a comprehensive design approach that responds greatly to their physical, psychological and emotional needs. 


\subsection{DESIGN FORMULATIONS}

\subsubsection{DESIGN GOALS}

Reviewing contemporary thinking on dementia has provided research conclusions that identified particular design goals that aid in the creation of a dementia-friendly and supportive environments. In addressing the design of the Dementia Respite Care Centre, the use of colour, light, movement, space, materials, smells, orientation and specific standards will be utilized in the development of the building. Formulating a supportive and enhancing environment, the overall hierarchy of information, based on the scale of issues and design goals, need to be taken in as a factor. Three design goals have been established for this thesis-project that address design issues and their impacts on the articulation and formulation of the built form.

\section{Design Goals:}

1. The design of the built environment has a high level of legibility

2. The design of the built environment has a high level of transparency

3. The design of the built environment has a high level of orientation

These design goals engage the various design issues that arise from planning and creating for this demographic. At the forefront in designing for this demographic is that dementia affects memory and cognition, affecting our capacity to place ourselves in the built environment. For the most part, we know where we are because we recall the journey of getting there. A built environment that is specially designed for people with dementia must be able to renew this sense of presence that provides them with the autonomy to locate themselves within any situation. The three design goals stated above are expanded below to provide further context to the issues.

\section{The design of the built environment has a level of legibility}

The legibility of the architecture form, space, and functions is important for numerous reasons. The way interior space is created and presented to an individual will indicate the expected appropriate behaviour. The scale, proportion, materials, and furnishings of the environment aid in the reading and deciphering of the space. Distinctive spaces become memorable and easily locatable from such design decisions. In turn, this 
allows for users of the spaces to spatially orientate themselves as part of their way-finding.

The building's spatial layout is the critical to the architectural legibility. The spatial layout requires a degree of control and clarity for access to the site, internal circulation, and a clear spatial hierarchy in the form of a public/private gradient. The design intent is to provide an environment that is safe and providing users a sense of autonomy to walk within the building, venturing to different spaces without a loss of orientation.

\section{The design of the built environment has a high level of transparency}

A high level of transparency of the internal and external spaces that one is to engage with is required to allow for visual access and overview. Being able to have foresight is important because of the degeneration of the brain and its incapability in using the mental-mapping in the temporal lobe. Chapter 2 Section 2.4 Effects on the Brain Functions discussed this portion of the brain indicating it's crucial task in indexing experiences for later retrieval. However, since this area of the brain gets damaged during the stages of dementia, people are incapable of locating themselves spatially where they cannot see a space directly. Spaces that are relevant to the user should be exposed to access their immediate environment visually, overseeing situations people may be inclined in participating.

The availability of natural light permeating into occupied spaces is the other underlying layer of transparency. The source of natural light within these types of building's and visual access to outdoor conditions is critical to the well-being of people with dementia. Taking into account the location of thesis-project, the city of Toronto, the length of winters, the density of the urban core, angle of the sun, the amount of natural daylight entering the building becomes a crucial design aspect. With the ageing eye and the damage in the occipital lobe, as discussed in previous chapters, and the amount of sun entering the building also affects the regulation of seasonal affective disorder. Depression is a symptom of many illnesses associated with ageing, but in particular it is more common with the early stages of dementia. Symptoms such as oversleeping, mood changes, lack of energy, over-eating, etc. occur during these times. How this effects someone is clearly evident in his or her level of exposure to natural light and is noticed more often in the winter than in the summer. The design intent therefore is to provide ample 
natural light as part of the therapeutic element as an anti-depressant. Winters are typically longer within this region, and with more natural light entering the building, it is beneficial to the users more than artificial light due to the high intensity of light stimulating the body effectively uplifting people's moods who are effected by the winter depression. The second significant reason to providing high levels of exposures to natural light is to combat the common symptom of dislocation of diurnal rhythms. Those who are affected by this symptom tend to be awake and active at night, running into the risk of not obtaining adequate exposure to daylight. As a result, this leads to disruption of the daily sequence of physiological changes, rising depression and sleep disorder within patients. Research studies illustrate that an increase of daylight exposure lessened sleep disturbances resulting in less agitated people and awakening over the course of the night.

Having visual access from windows to the outdoors can have a therapeutic effect and reduce discomfort for the users. Farley and Veitch reported in their studies that windows with contextual views onto nature provided a level of life satisfaction, for its restorative quality, as well as enhancing control over the environment. The other element of providing openings and views is that people tend to congregate around areas that have interesting views, resulting in lower stress within people. Since a facility of this nature is required to have a moderate level of security and confinement, views of everyday activity of people outside provides a sense of connection and not exclusion.

\section{The design of the built environment has a high level of orientation}

A main difficulty for people living with dementia is losing their sense of orientation in the world. Part of the first two design goals, legibility and transparency, being able to situate oneself within the confines of the space one engages is required to allow a person to recall the journey that got them there. A building should not require an individual to gain new skill sets in navigating and utilizing the spaces. The navigation of the floor plan should be led intuitively and not demand the user to choose from several options in planning a path of travel. Depending on the building configuration on site, when there are changes in the direction of the path of travel, meaningful reference points should be present as a form of landmarking indicative of destination points. This allows for a reduction in decision making needed and lower frustration levels in the 
occupant. These landmark locations become anchor points for residents as they circulate and situate themselves throughout the day.

\subsubsection{DESIGN STRATEGIES}

The development and understanding of the design goals involved and the scale of issues that entail, each of the design goals engage with several design strategies are part of the design process for this thesisproject exploration.

\section{Design Goal 1:}

The design of the built environment has a high level of legibility

\section{Design Strategies:}

1. Architectural articulation is to be distinct to the use and intent of the facility.

2. Scale of private and public spaces are to reflect the spatial hierarchy of use, aiding in understanding of behavioural expectations.

3. Use of materiality and of colour to distinguish spaces from one another

\section{Design Goal 2:}

The design of the built environment has a high level of transparency

\section{Design Strategies:}

1. Direct visual access to relevant spatial programs

2. High level of natural light exposure for all common spaces

3. Continuity of public/semi-private/private spaces

\section{Design Goal 3:}

The design of the built environment has a high level of orientation

\section{Design Strategies:}

1. Simple decision/reference points, serving as spatial anchors

2. Clear spatial circulatory system

3. Allow for orientation through time and space 


\section{Design Explorations}

Initial design ideas that permuted from these design goals and strategies were developed as a means of exploring these concepts without a site in mind. These concepts are intended to be applied to any site in any location.

\section{Design Exploration 1}

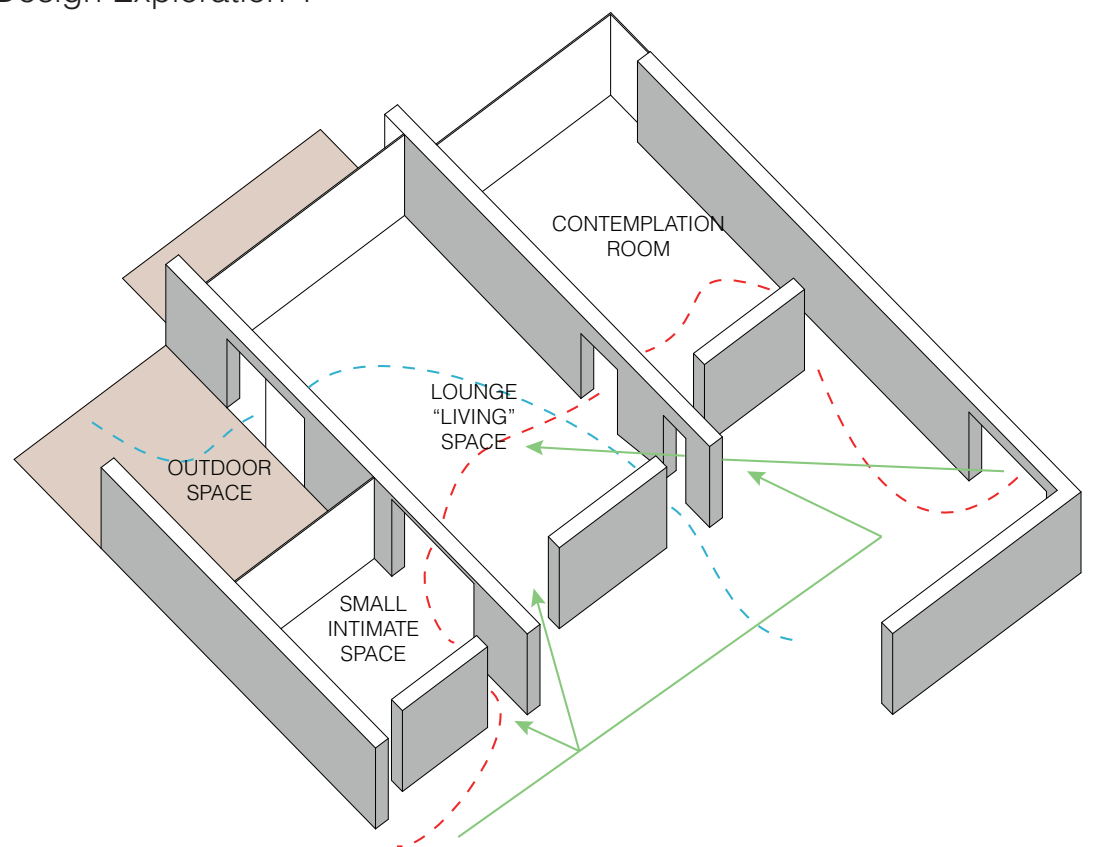

Fig. 5.01 - Design exploration 1

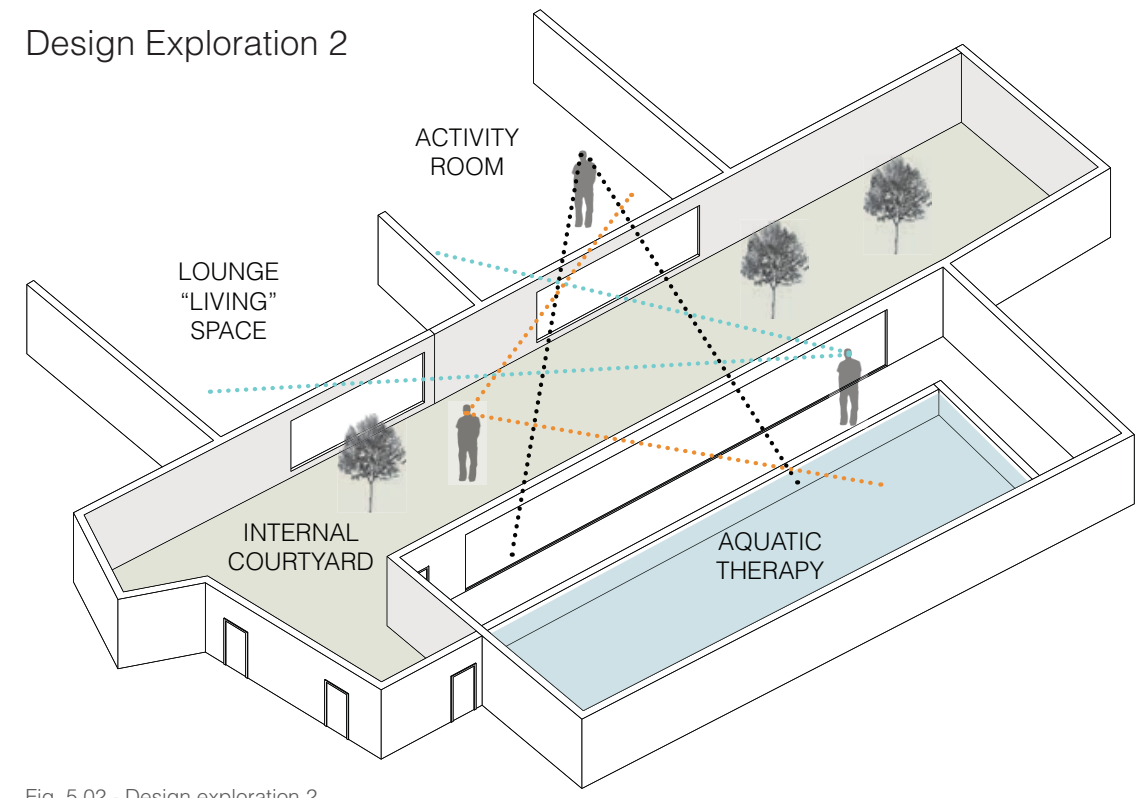

Fig. 5.02 - Design exploration 2 


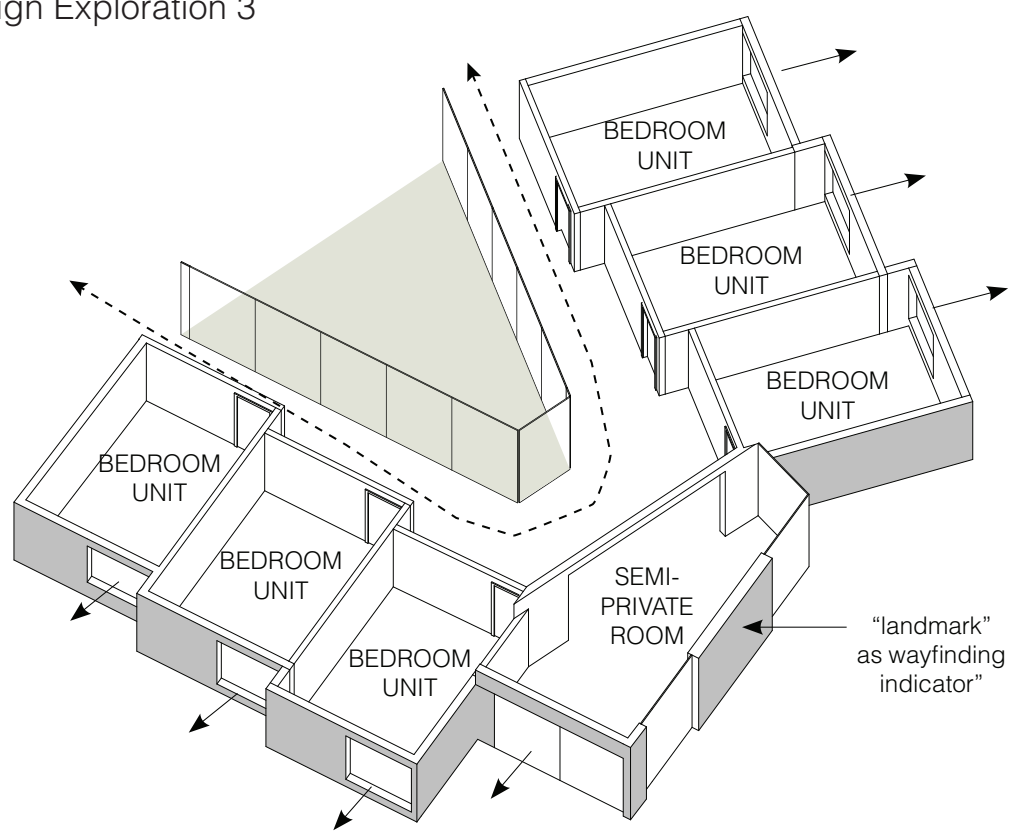

Fig. 5.03 - Design exploration 3

The intent of the first design exploration was to explore the ideas of movement through programmed spaces as a means of social wandering. All three design goals are being utilized in this exploration. The ample amount of glazing on the exterior allows for maximum daylight exposure and views to the exterior gardens. Programmed spaces are not closed off from one another allowing for a level of transparency to occur in aiding decision making in engaging with the space.

Within the second design exploration, the intent is to explore the ideas of transparency from the standpoint of observation. Observing and overseeing activities without engaging in them promotes social and sensory stimuli.

The third design explores anchoring certain spatial program at directional changes in circulation and the design of single loaded corridors allowing visual access to outdoor spaces. In this exploration, a sense of orientation through time and space is provided by allowing users of the space visually to foresee their destinations and orient themselves within the building. 


\subsection{THE CONDITION}

\subsubsection{THE URBAN CONDITION}

Dementia is a disease that affects individuals indiscriminately across the landscape, from rural, suburban to urban conditions. There are no boundaries for a disease of this kind. Chapter 1 indicated economic conditions and changes in mode of delivery of care that lead to the exploration of a respite and day care centre within the urban fabric of cities, allowing for people to remain in their established communities. With the City of Toronto being a metropolis, the urban core has not provided a location for individuals a place of comfort in dealing with dementia. What is lacking within the urban fabric of the city is a platform of integration in cores of existing established residential neighbourhoods. Why is integration need? The question lies within the construct of 'what becomes of the urban dweller who built a life within the urban core of the city with no desire of leaving and only aspiring to continue the life they have established, being able to live within their current home and receive care within their neighbourhood?'. This type of care centre is not particularly site specific for one location, it is however a care centre that can be integrated and connected with the existing dementia network within the city. This thesis-project explores the design of a Dementia Respite Care Centre within the urban context, with the intent on providing a viable option for people living with dementia seeking to remain close to home, receive care, and provide their loved ones a chance to recharge.

The urban city provides an interesting and valuable platform in the development of this type of care centre. An urban city provides many amenities that one is capable of walking to, or by taking public transit, when driving is no longer a viable option for transportation.

John Zeisel equates that people underestimate the abilities of those with Alzheimer's and suggests that trips to local theatres, museums, or other civic events can keep the individuals involved with the outside world (Zeisel, 2010). The urban environment provides these types of amenities at a larger scale with greater public transportation access then those within a suburban context. Therefore, the development of this type of care centre for city residents provides them the opportunity to stay within their established communities, continue to use these resources, and continue being engaged with their daily activities, reinforcing the idea of 
continuity within their lives. As the transition in the age of the population grows, respite care centres as an option will become even more valuable to not only to the families but also on the economic aspects.

\subsubsection{SITE SELECTION}

There are numerous opportunities for urban interventions involving respite care centres in cities across the country. Locating various sites across any city would need to be evaluated based on a list of criteria with a degree of varying importance. As noted per chapter 1 , the city of choice has been established as the City of Toronto for this thesisproject exploration. The choice in locating a viable site within this city resulted from a process of demographic statistical analysis of Toronto and the Greater Toronto Area. The analysis indicated that the population of Toronto stood at 2,615,060 in 2011 and the population aged 45-65 years accounted for $26.9 \%$ and for seniors aged $65+$ was $15 \%$ (fig 5.04). In comparison, the GTA regions population aged $45-65$ years of age accounted for $28.1 \%$ and $11.5 \%$ for seniors aged $65+$. These are important factors to consider for the future growth patterns of the city and the potential dementia cases that may occur in the future as noted in Chapter 1.4 Micro Scale indicating the dementia cases projections for the senior's population aged $65+$. Statistical numbers for dementia cases below the age of 65 are not well documented within the Canadian context and therefore cannot be accounted for in this analysis.

\section{Population by Age Group, Toronto, 2011}

\begin{tabular}{lrrrrrr} 
& \multicolumn{2}{c}{2001} & \multicolumn{2}{c}{2006} & \multicolumn{2}{c}{2011} \\
\cline { 2 - 7 } & Number & Percent & Number & Percent & Number & Percent \\
\hline $0-4$ & 143,510 & 5.8 & 134,980 & 5.4 & 140,510 & 5.4 \\
$5-14$ & 290,310 & 11.7 & 274,640 & 11.0 & 260,350 & 10.0 \\
$15-24$ & 308,415 & 12.4 & 318,655 & 12.7 & 333,515 & 12.8 \\
$25-34$ & 413,020 & 16.6 & 385,925 & 15.4 & 413,015 & 15.8 \\
$35-44$ & 429,860 & 17.3 & 415,615 & 16.6 & 387,805 & 14.8 \\
$45-54$ & 337,470 & 13.6 & 362,425 & 14.5 & 398,915 & 15.3 \\
$55-64$ & 221,080 & 8.9 & 257,585 & 10.3 & 303,495 & 11.6 \\
$65-74$ & 185,180 & 7.5 & 178,995 & 7.2 & 188,630 & 7.2 \\
$75-84$ & 116,400 & 4.7 & 131,350 & 5.2 & 133,845 & 5.1 \\
$85+$ & 36,265 & 1.5 & 43,100 & 1.7 & 54,965 & 2.1 \\
\hline Total & $2,481,510$ & 100.0 & $2,503,270$ & 100.0 & $2,615,045$ & 100.0 \\
\hline
\end{tabular}

Fig. 5.04 - City of Toronto population by age group, Statistics Canada 2001-2011 
The following statistical maps reflect the total population distribution in the City of Toronto by age group, figure 5.05 for ages 25 to 65 and figure 5.06 for ages $65+$. From this analysis and observation, the proposed Dementia Respite Care Centre location will be situated within the downtown core of the city that has the highest concentration of

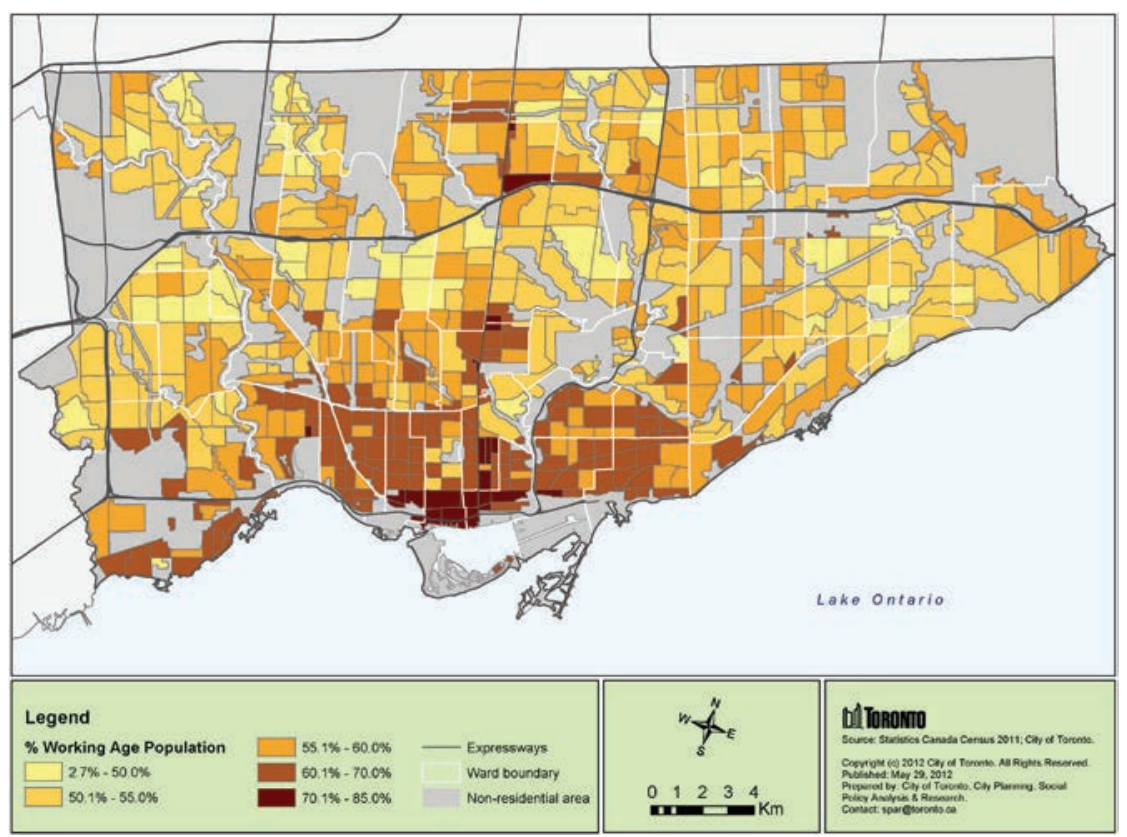

Fig. 5.05 - City of Toronto concentration of working age 25-64 years, Statistics Canada 2001-2011

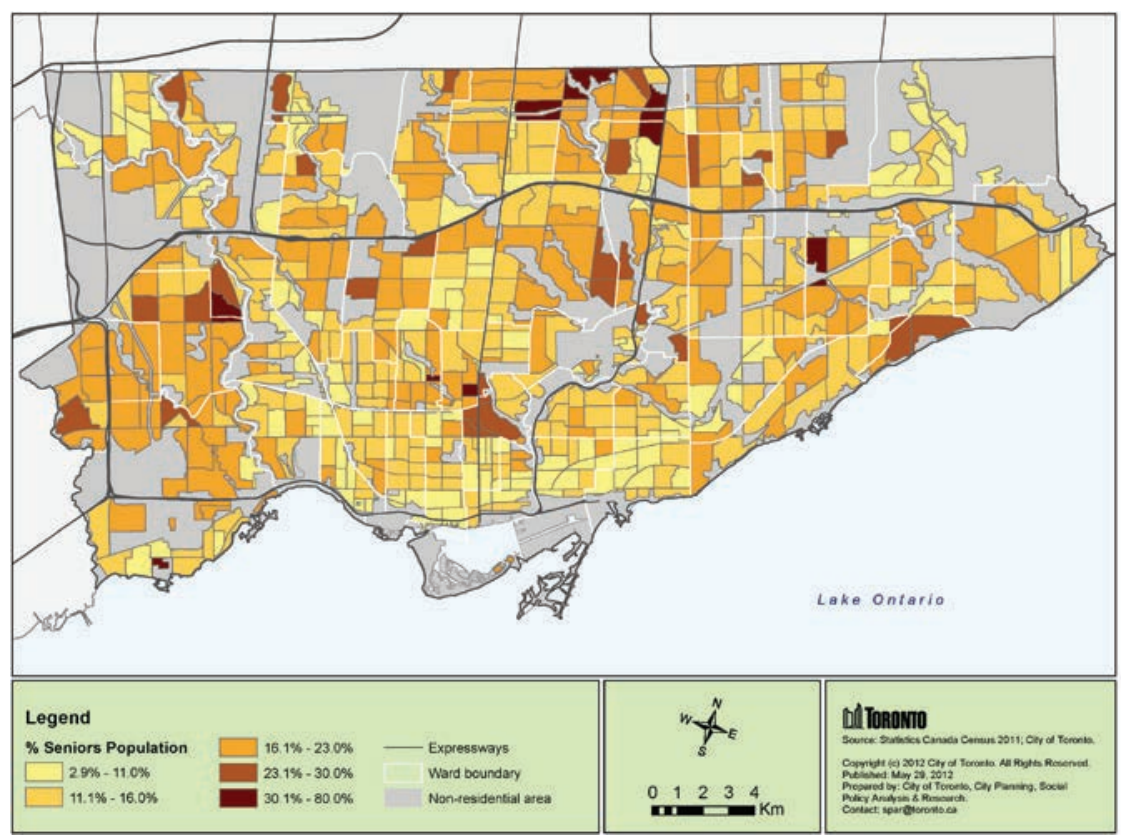

Fig. 5.06 - City of Toronto concentration of seniors age 65+ years, Statistics Canada 2001-2011 
population aged 25 to 65 .

A further analysis of the downtown core was conducted to review the demographic population distribution between the ages 45 to 54,55 to 65, and 65 to 75 (fig. 5.07 to 7.09). This analysis identified the location and concentrations of the target demographic that informs site selection that is of concern to this thesis-project.

Next condition to consider is the location to the proximity of civic and cultural amenities that can be accessed throughout the day while at the respite care centre. Access to parks, access to public transportation,

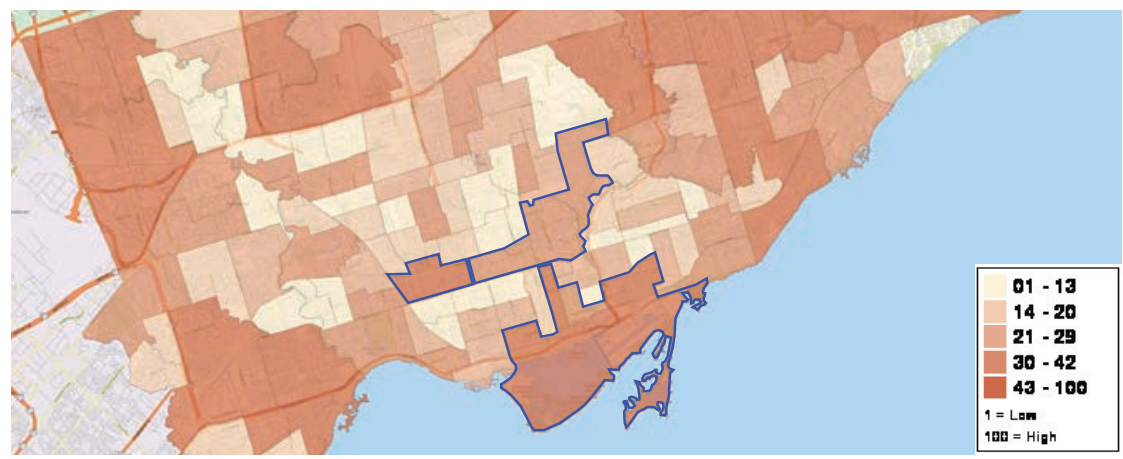

Fig. 5.07 - City of Toronto population concentration of age 45-54 years, Wellbeing Toronto 2013

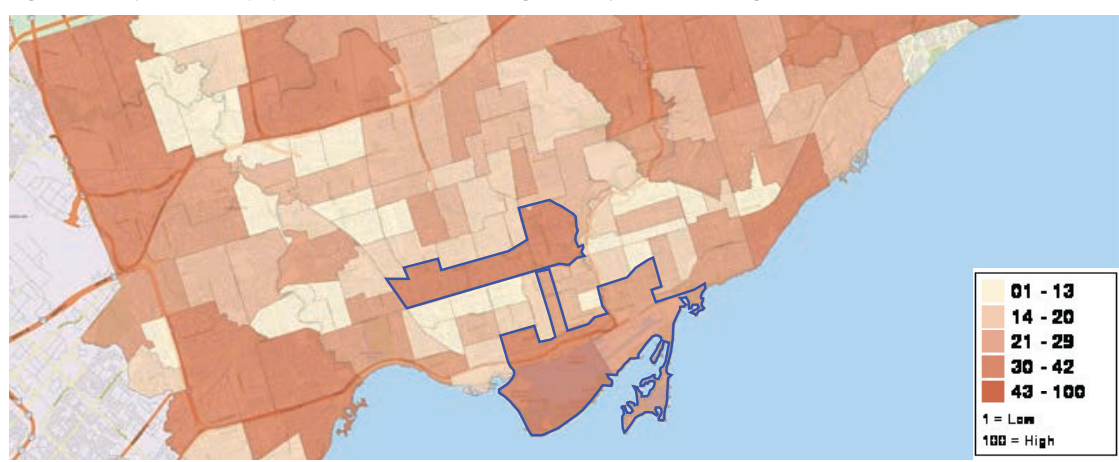

Fig. 5.08 - City of Toronto population concentration of age 55-65 years, Wellbeing Toronto 2013

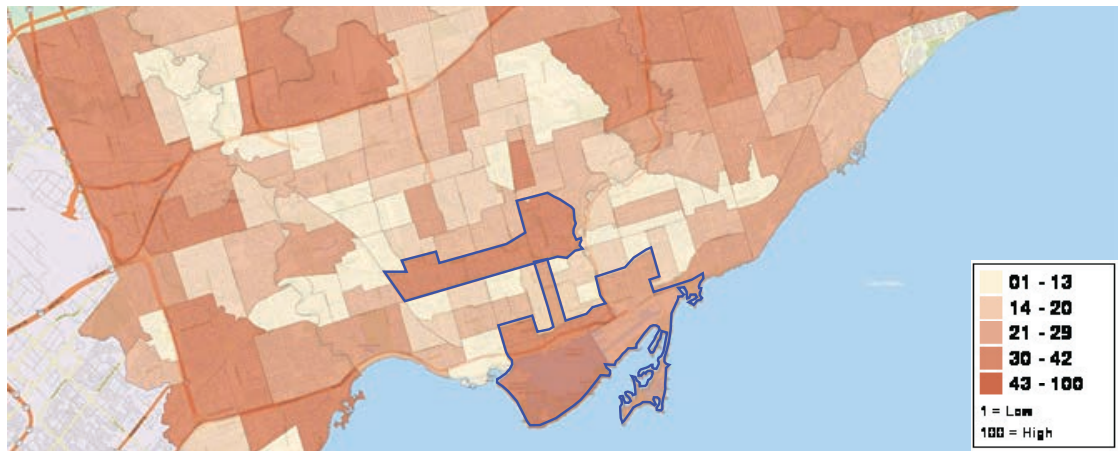

Fig. 5.09 - City of Toronto population concentration of age 65-75 years, Wellbeing Toronto 2013 


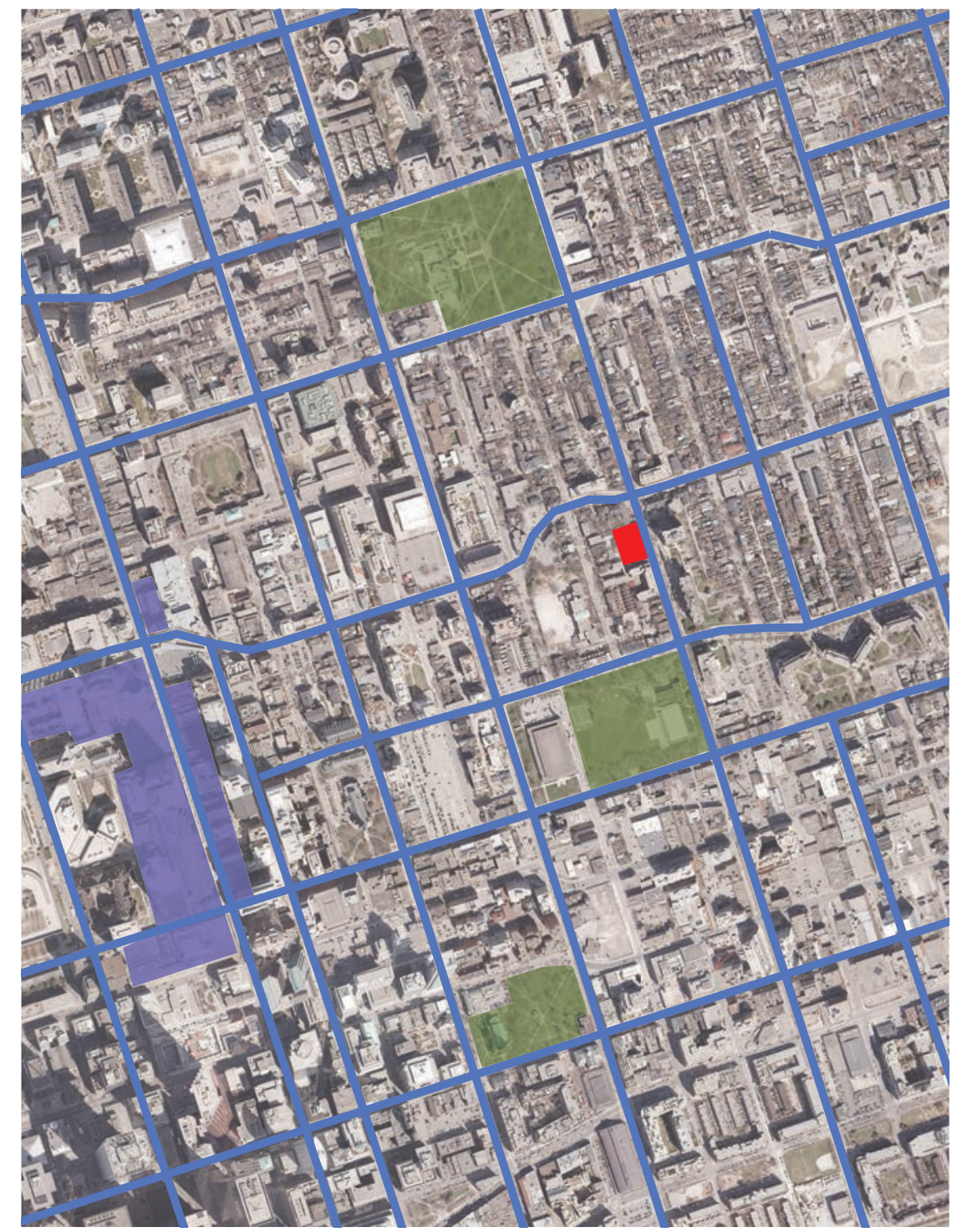

Fig. 5.10 - Proposed site location and neighbourhood context

coffee shops, etc. are other considerations that were accounted for.

The third step in the process in selecting a proper site was locating vacant or underdeveloped property within the selected area. The city of Toronto possesses many areas of potential land for development; surface parking lots, old industrial buildings, and vacated lots. The development of the size and nature of the building program responds with the selected site. As the proposed age demographic of 45 to 65 is intended for the Dementia Respite Care Centre, the utilization of the Canada Mortgage and Housing Corporation Guidelines for Markets Dealing with Housing Projects was part of the site selection process. 
The parcel of land that was selected is near the intersection of Dundas Street and Sherbourne Street. This parcel of land is currently vacant with an existing historical residential home.

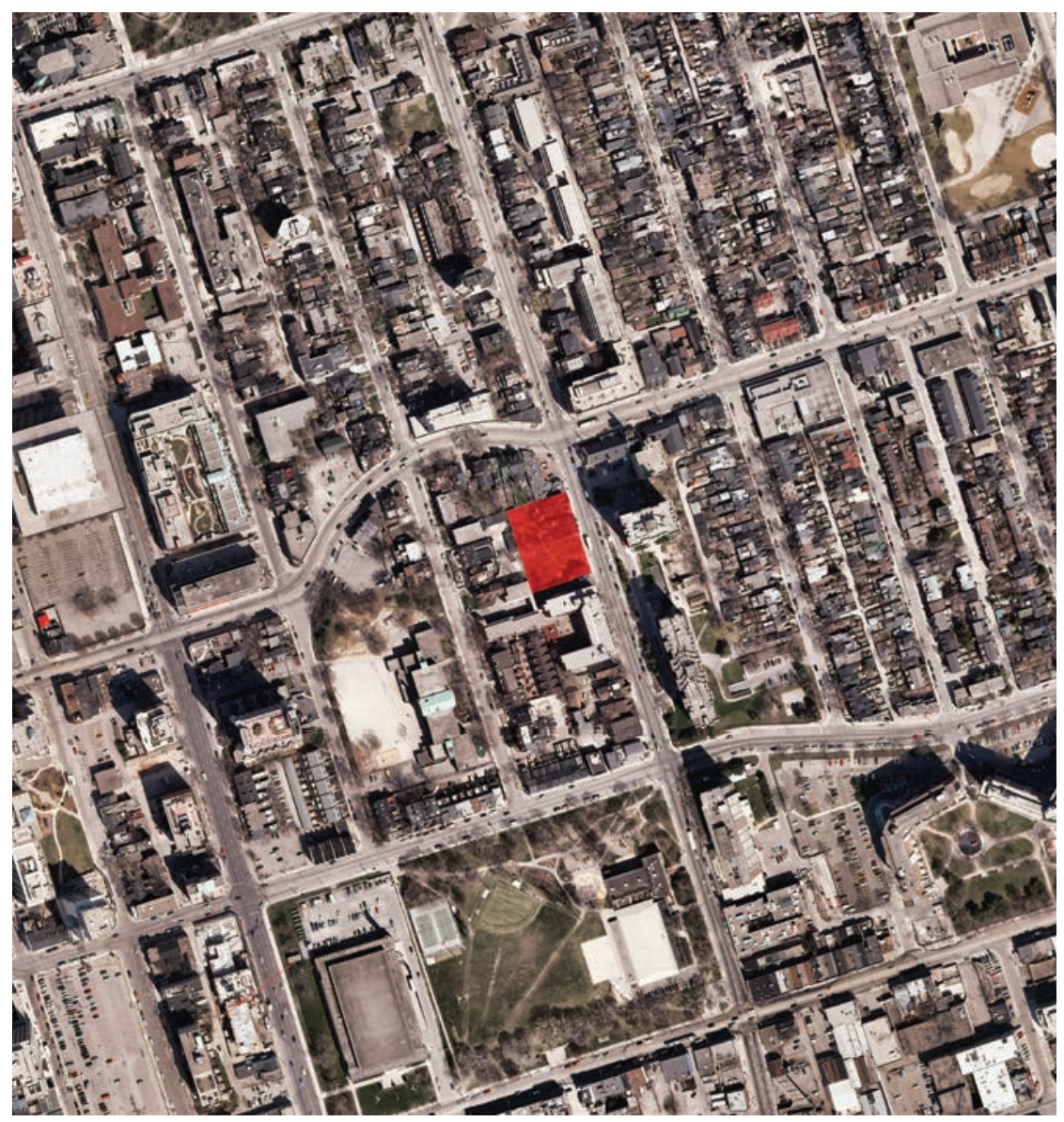

Fig. 5.11 - Proposed site location indicated in red

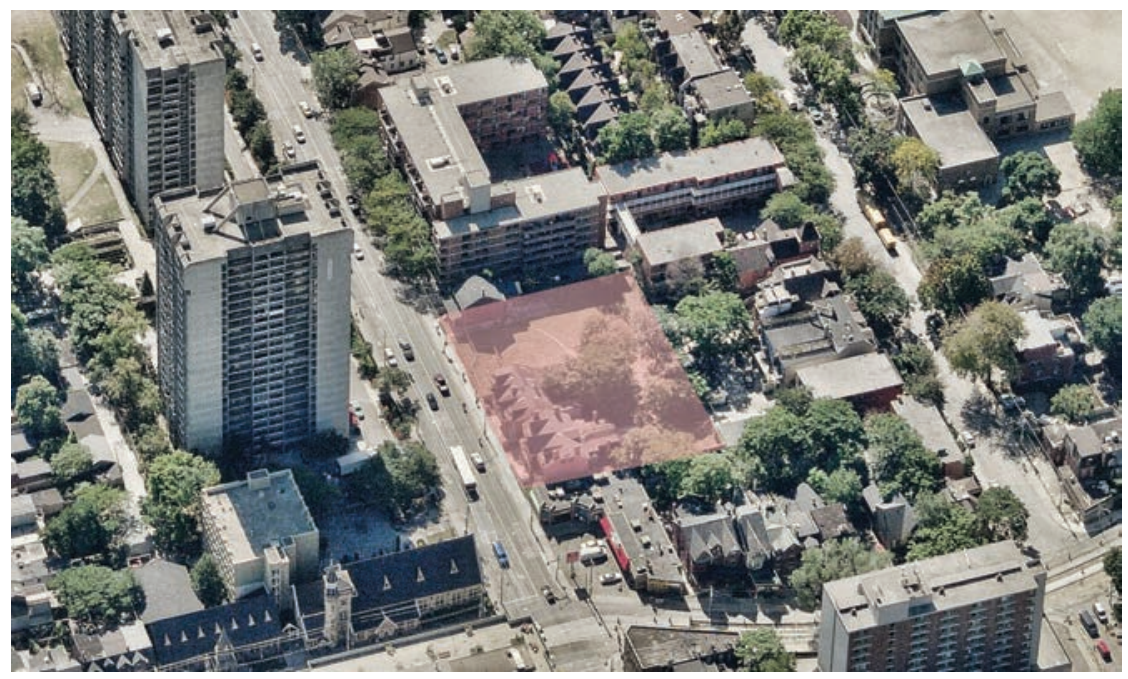

Fig. 5.12 - Proposed site location indicated in red 


\subsubsection{URBAN MORPHOLOGY}

A cities urban fabric is one that changes over time by different sets of external forces, be it economic or social elements. These forces morph and make neighbourhoods either permanent or temporary, integrated or erased from existence. Sherbourne Street is one of those streets in the city of Toronto that has been able to maintain most of the existing physical urban fabric. At the same time, the area developed new projects that responded to the character and scale of the neighbourhood.

This particular thoroughfare was home to some of the wealthiest people at one point. While the socio-economic class was changing within the area, and during an era in Toronto of providing high-density towers, large amounts of existing urban fabric, the cities traditional Victorian homes, were being demolished and erased from history to create space for these new towers. The amalgamated city property lots provided larger parcels of land, changing the scale and context of neighbourhoods. Some citizens were being displaced, having to relocate and move elsewhere. City renewal projects that seek to densify neighbourhoods should not erase past memory. Renewal projects should attempt at keeping the familiarity of the neighbourhood and innovate ways to integrate themselves within the existing urban fabric.

Looking at the historical property data maps from 1858-2013 (fig. 5.13-5.16), the urban form of the city had changed but didn't change drastically. This community maintained its identity, its familiarity and characteristic, through the density and scale of the homes and buildings constructed.

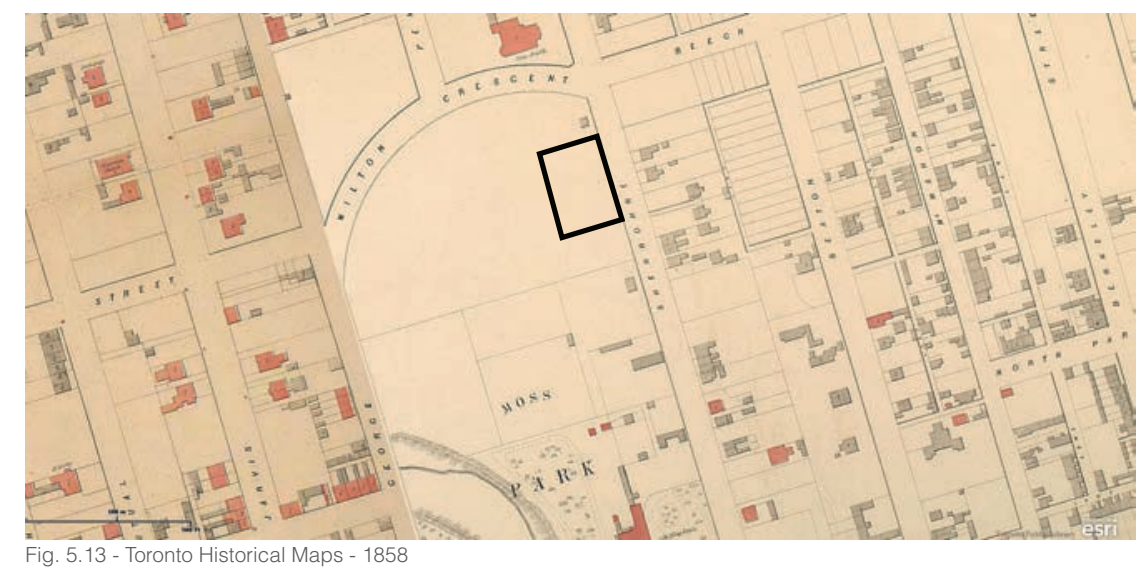




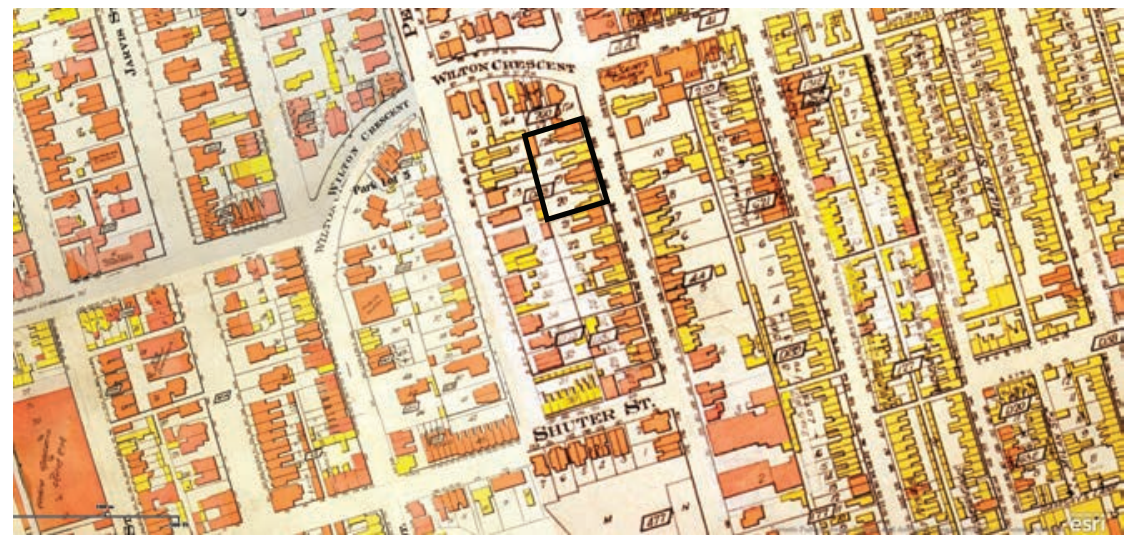

Fig. 5.14 - Toronto Historical Maps - 1913

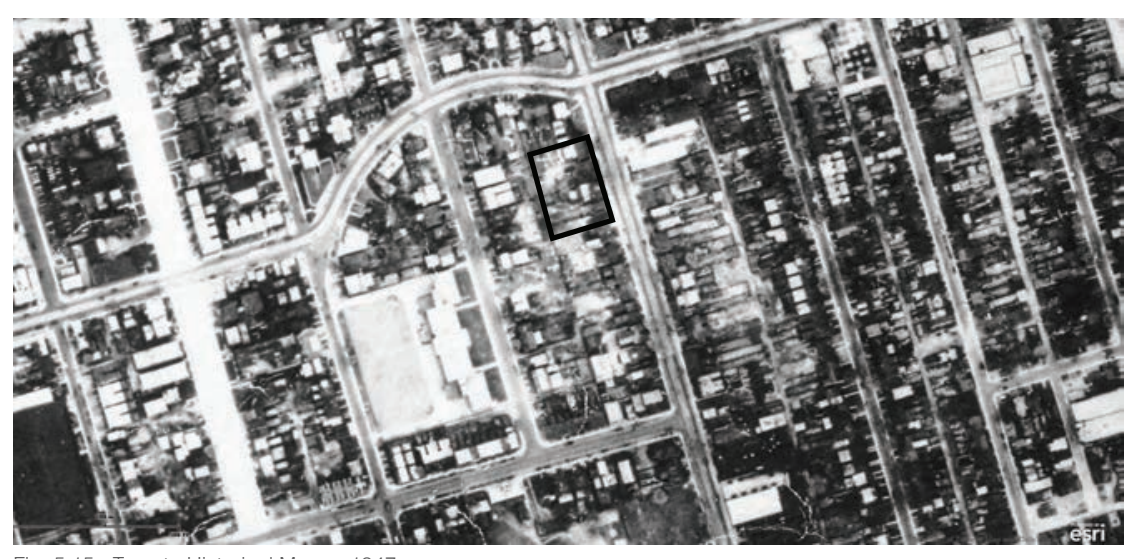

Fig. 5.15 - Toronto Historical Maps - 1947

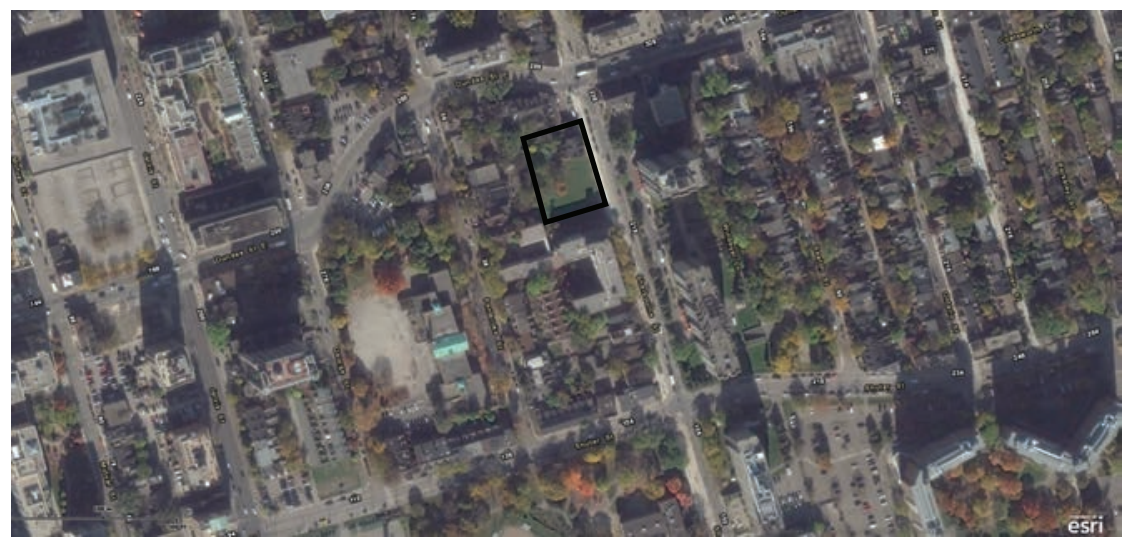

Fig. 5.16 - Toronto Historical Maps - 2013 
One project, in particular, that was completed in 1976 by architects A.J Diamond and Barton Myers is an example of this notion of maintaining existing fabric and adding to it. This development, named Sherbourne Lanes, was at that time seen as an innovative initiative in providing high-density housing within downtown Toronto. The initial development scheme called for the removal of all existing Victorian homes along the street in favour of a few towers for the scale and density the project was looking to obtain. However, the team of Diamond and Myers rejected that approach and decided that to infill the residential project carefully within the backed of the lots. The lots of the existing Victorian homes were very deep at $54 \mathrm{~m}$ (180ft). Infilling in behind the existing houses proved to be a useful method at inserting the new high density residential buildings without disrupting the scale, material qualities, and urban virtues of the existing fabric (fig. 5.17).
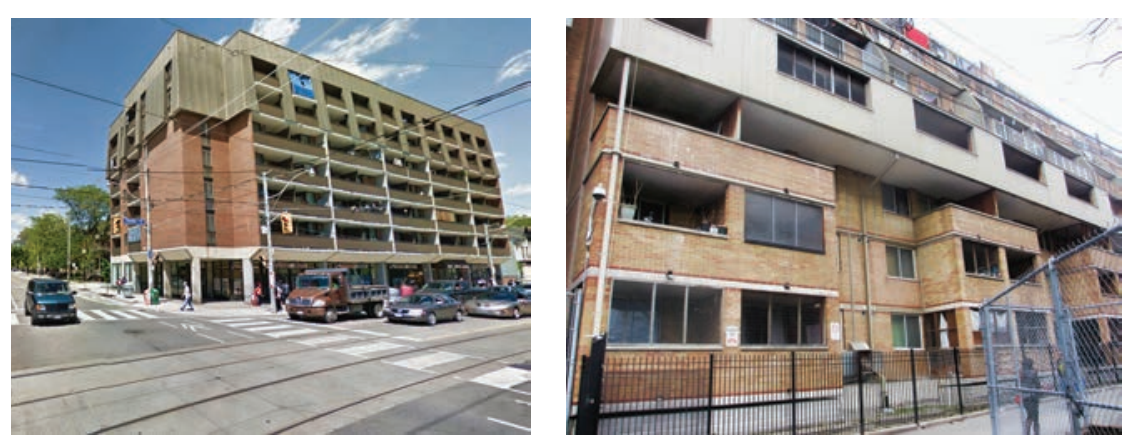

Fig. 5.17 - Sherbourne Lanes project at Sherbourne and Dundas (right) Back portion of project along lane way (right)

The Robertson House Crisis Care Centre project completed by Hairi Pontarini in 1998 is another example of an infill project that occurred along the street. The Robertson House Crisis Care Centre dotted in red in fig. 5.18, is a temporary shelter for women and their children. The design approach to this particular property was to maintain and renovate the two existing historic homes and add a new l-shaped addition along the properties perimeter in the back. Utilizing this type of massing form allowed the facility to be spatially organised around a courtyard for social gatherings. Due to the nature of spatial program associated with this building, the choice in materiality, design language and scale, does not stand out as "special housing", which successfully blends within the scale of the urban surroundings.

The l-shaped addition to the two existing historic homes, as seen in fig. 5.19 , draws on the notions of a single home, thus reinforcing the concept 


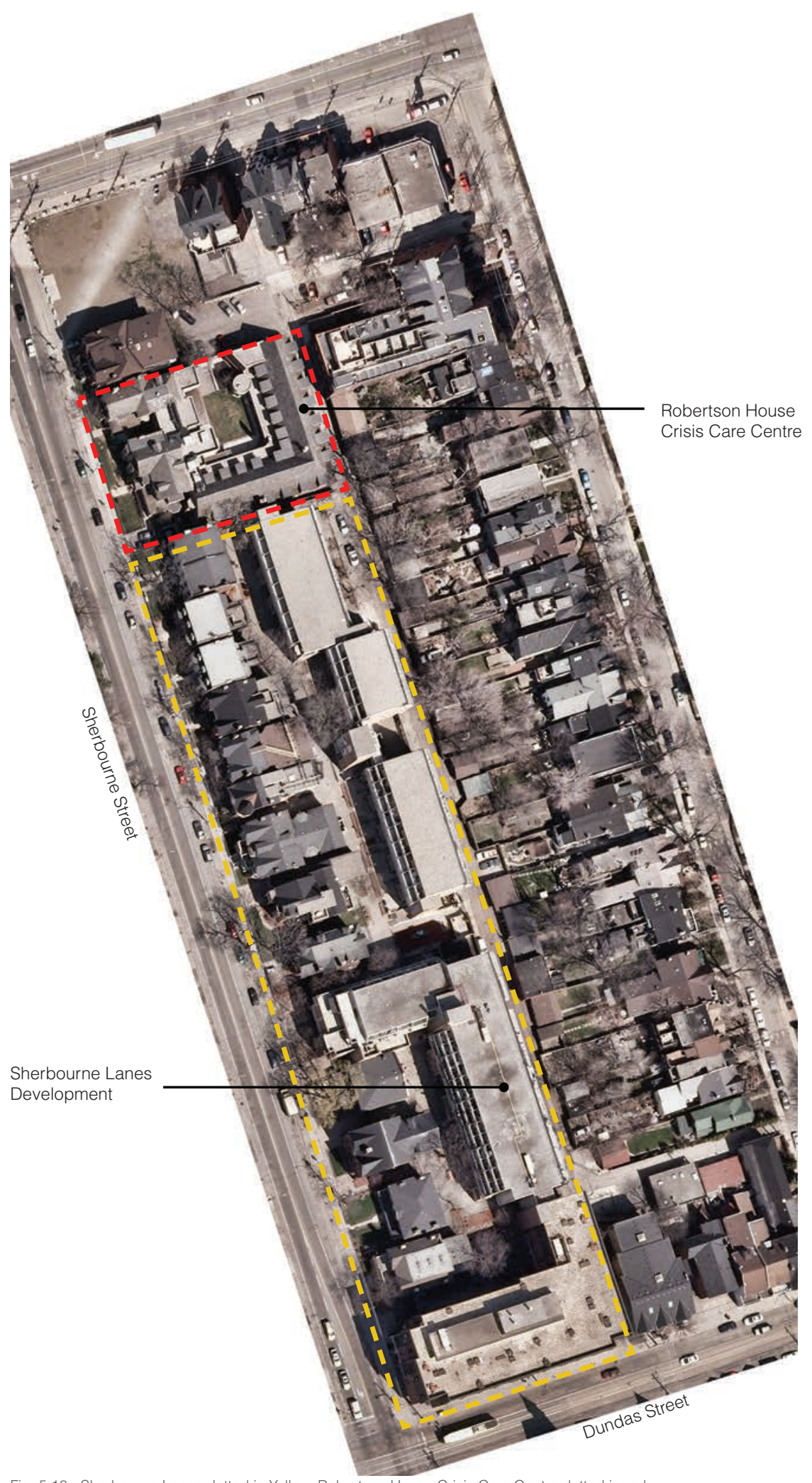

Fig. 5.18 - Sherbourne Lanes dotted in Yellow. Robertson House Crisis Care Centre dotted in red. 


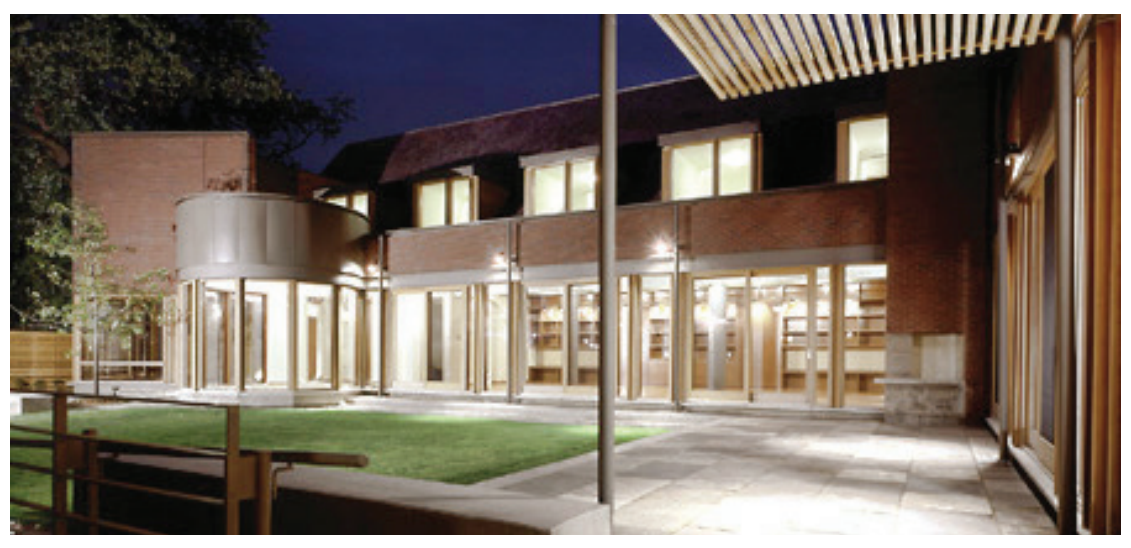

Fig. 5.19 - The Robertson House Crisis Care Centre interior courtyard

of a safe place for collective and individual living. This is accomplished by using the same type of residential language that is present within the neighbourhood; brick, wood window framing, sloped roofs and dormer windows.

The centres spatial programmatic functions occur within three elements: child-care, dining, and resident lounge area. These programmatic elements open directly onto the secure interior landscaped courtyard. Ground floor interior circulation occurs along the courtyard perimeter and provides spaces for casual encounters. This is one design element that is evidenced within the case studies presented in chapter 4 as well as one of the design fragments that is investigated as part of the development of design principles for this thesis-project.

These two projects illustrated different techniques at dealing with the required spatial programs for their respected buildings. However, similarities can be drawn from both as well; the scale and positioning of the buildings form, the bounding of the site as a means of infill, the choice in materiality in response to the neighbourhoods character, and maintaining continuity of people's lives within this neighbourhood.

The design of the Dementia Respite Care Centre is similar in the programmatic functions as the Robertson House Crisis Care Centre in that it provides adult day care and short-term housing. The Robertson House is a new form of housing within the context of the neighbourhood but is based on the typology of the area it is situated in. This form of design construct is also applied in the development of this thesis-project.

As a form of housing, the Dementia Respite Care Centre reinterprets 
the role of housing and its relationship to place. This design principle is premised on an analysis of the original typology of the neighbourhood block and necessitates a process of observation that emphasizes the current conditions of the streetscape as well as its forms and materiality. As a result, it is possible to provide a new form of housing that is both rooted in the local context and designed with the future in mind. The intent is not to imitate existing fabric, but to understand it, incorporate it, and augment the existing urban fabric with functions that are conducive to the needs of the users that are addressed in section 5.6.

Walking around the neighbourhood, you can quickly denote the historical style that is present there and new additions that blend in with the surrounding context. As seen in the images in fig. 5.20 to 5.27, this

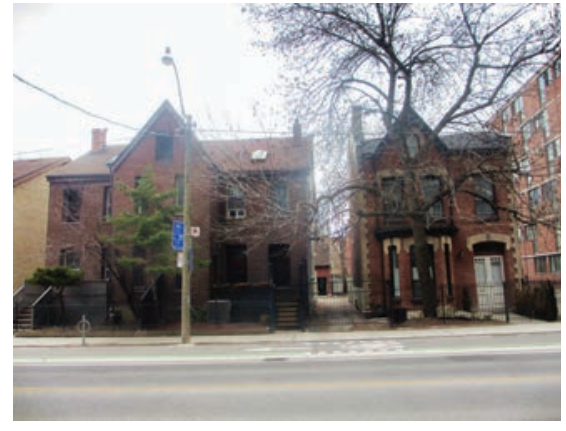

Fig. 5.20 - Neighbourhood context along Sherbourne

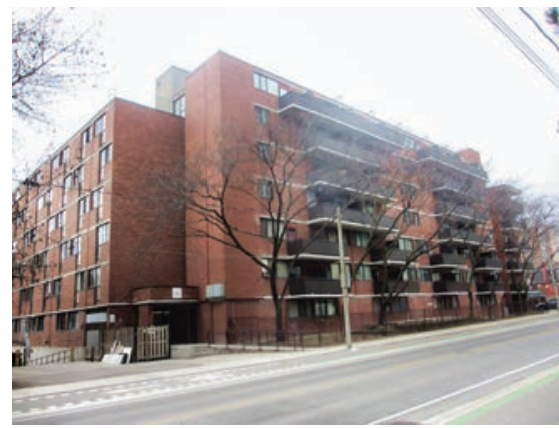

Fig. 5.22 - Neighbourhood context along Sherbourne

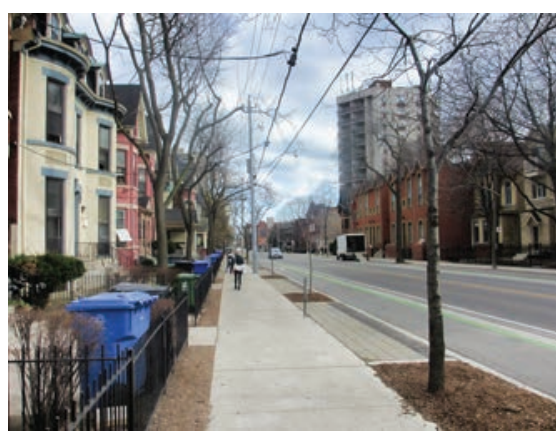

Fig. 5.24 - Neighbourhood context along Sherbourne

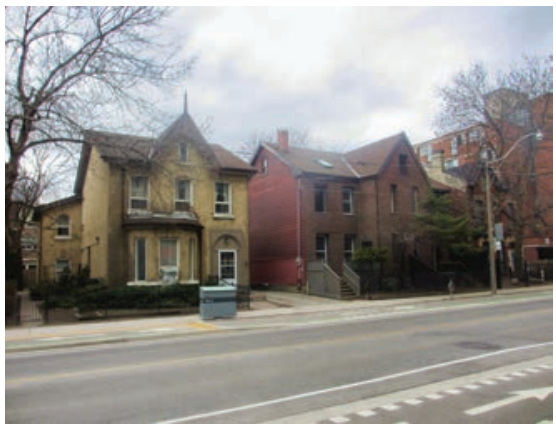

Fig. 5.21- Neighbourhood context along Sherbourne

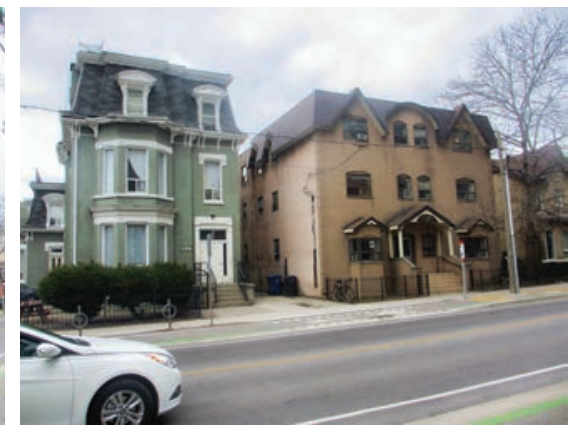

Fig. 5.23 - Neighbourhood context along Sherbourne

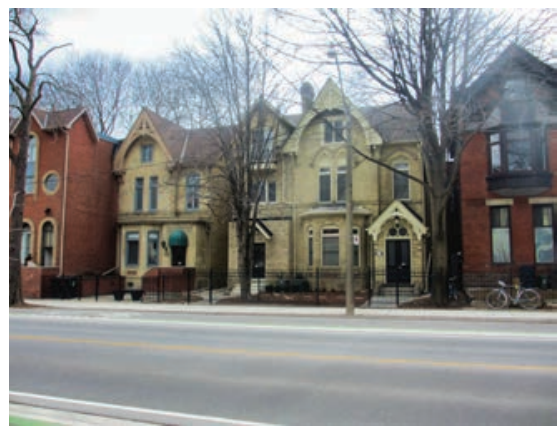

Fig. 5.25 - Neighbourhood context along Sherbourne 


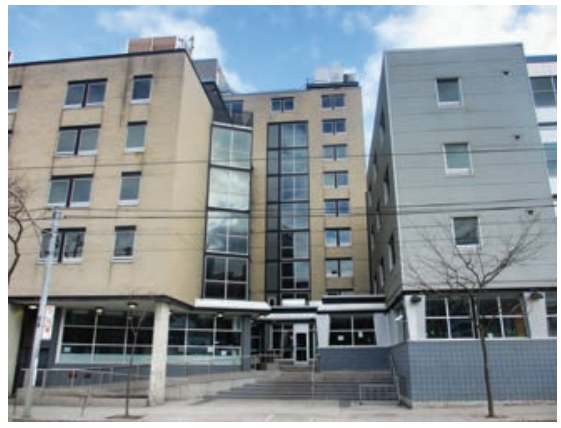

Fig. 5.26 - Neighbourhood context along Queen

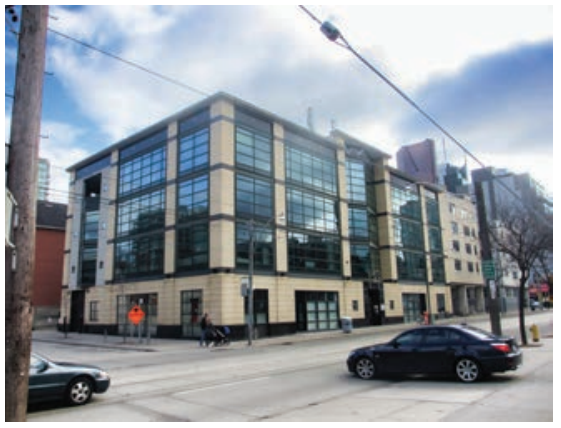

Fig. 5.27 - Neighbourhood context along Queen

is predominately evident in the choice of material, however, the scale for some of these buildings is much larger than the existing homes.

Scale and massing are two elements that are significant in exploring and will be examined in the design of the Dementia Respite Care Centre. When looking at the site, and building typologies within the area, what are possible massings that can be considered for this thesis-project?

This type of care centre examines several massing options as part of its development. Reason being that today's current living conditions, people not only are living in single detached homes, but also in several story condos and small rise apartments. Fig. 5.28 starts to analyse the possible massing's concepts as hybridized versions of each other. One possibility is to have the site completely bound with an internal courtyard and other massing options look at the "point tower" with 2 - 3 story sections bounding the site.

Looking closer at the chosen site, the historical property lines of 1924 and the property lines of today, (fig. 5.29 and 5.31) indicate that the property lot sizes have stayed the same during the course of 90 years. Projecting the property lines vertically in elevation, the overall massing for these sites can be hypothesized (fig. 5.30 and 5.32). What this allows

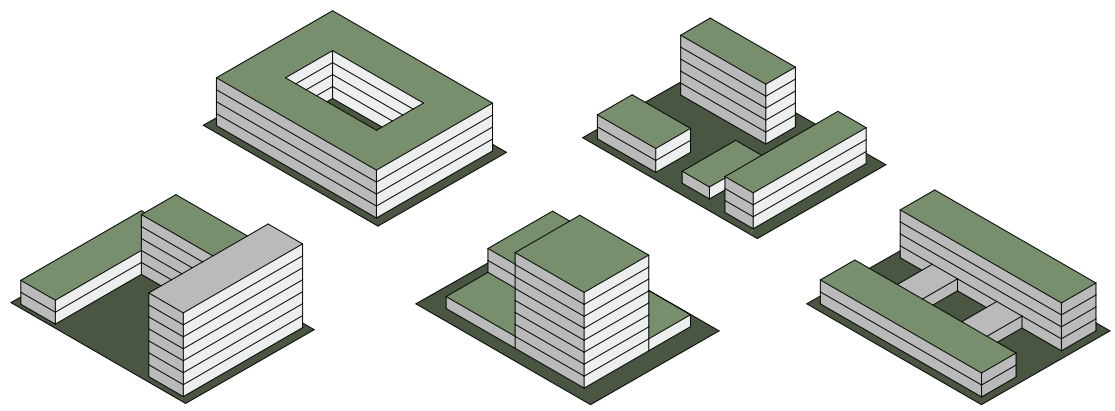

Fig. 5.28 - Site Massing Typology Study 


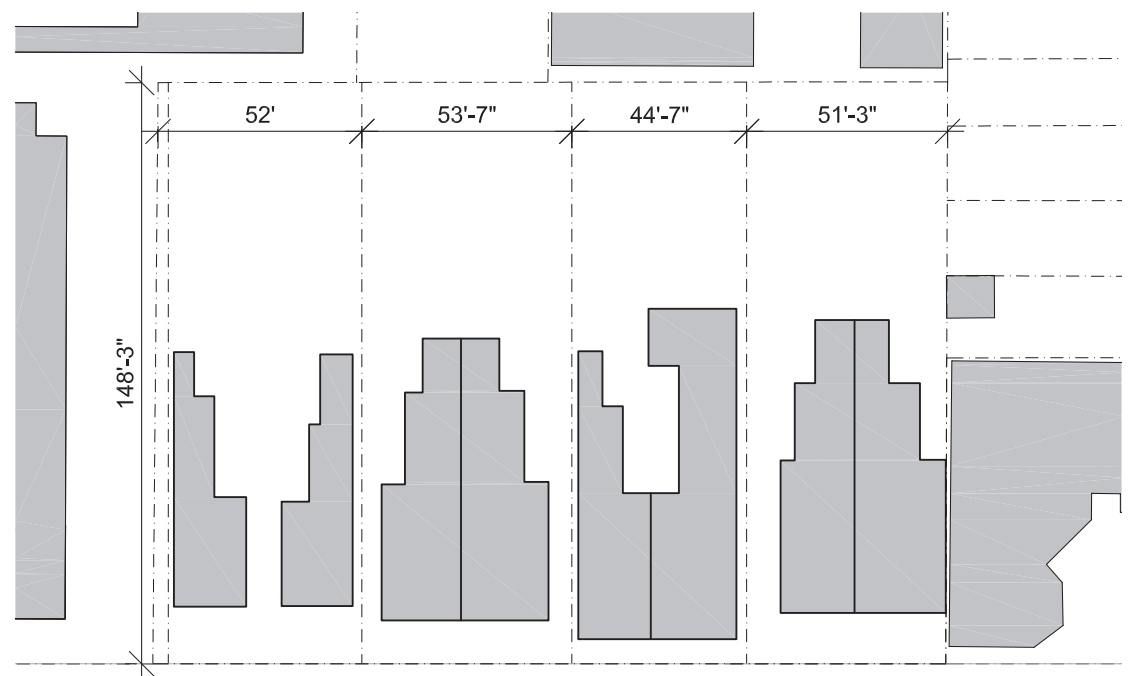

Fig. 5.29 - 1924 Property line division in plan

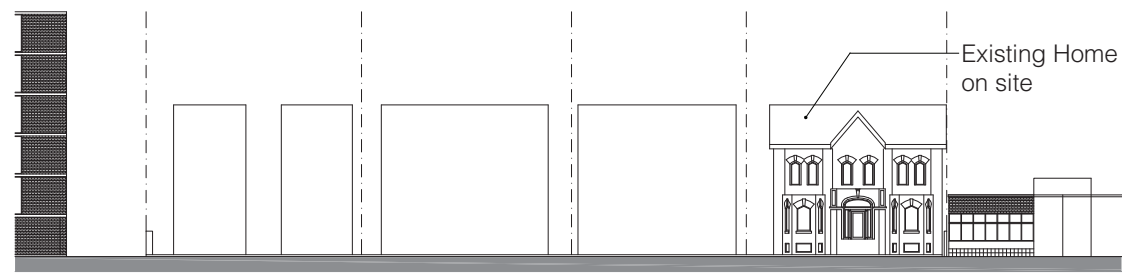

Fig. 5.30 - 1924 Property line division in elevation

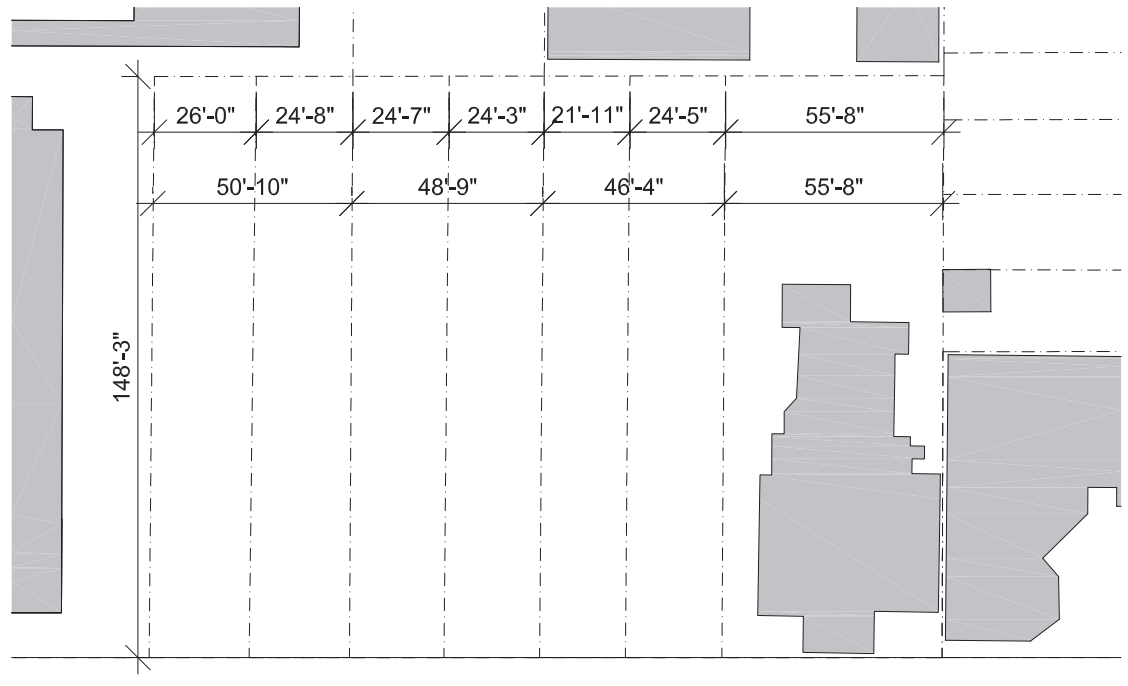

Fig. 5.31 - 2012 Property line division in plan

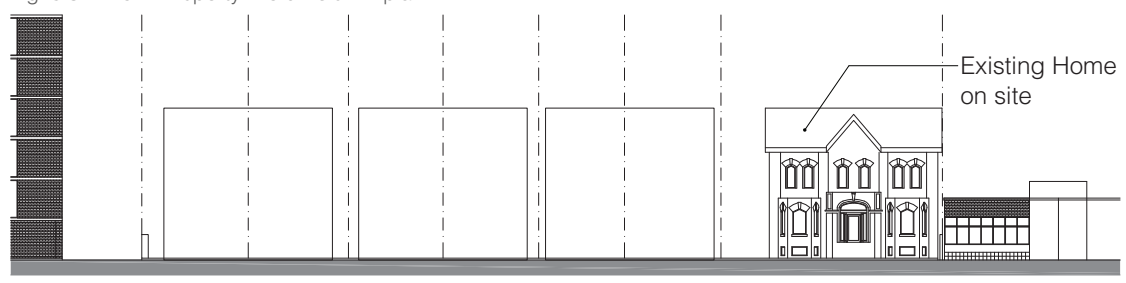

Fig. 5.32 - 2012 Property line division in elevation with existing home as reference for scale 
for is an understanding and projection in determining the right massing and breakdown of the scale of the building so that the main elevation of the building is not interpreted as one facade, but composed of several elevations that have a dialogue with one another.

\subsubsection{SITE CONDITIONS / BUILDING CONSIDERATIONS}

This section examines site conditions and the main features and characteristics of the selected site and context. The total site area is approximately 30,000 sqft (2,790sqm) with the existing historical Victorian home.

The proposed site's current zoning designation falls under two different zoning by-laws, both of which are categories for residential use (fig. 5.34). For this thesis-project, the zoning for this parcel would be required to be rezoned to allow for a Respite Care Facility to be developed under the city of Toronto's zoning by-laws.

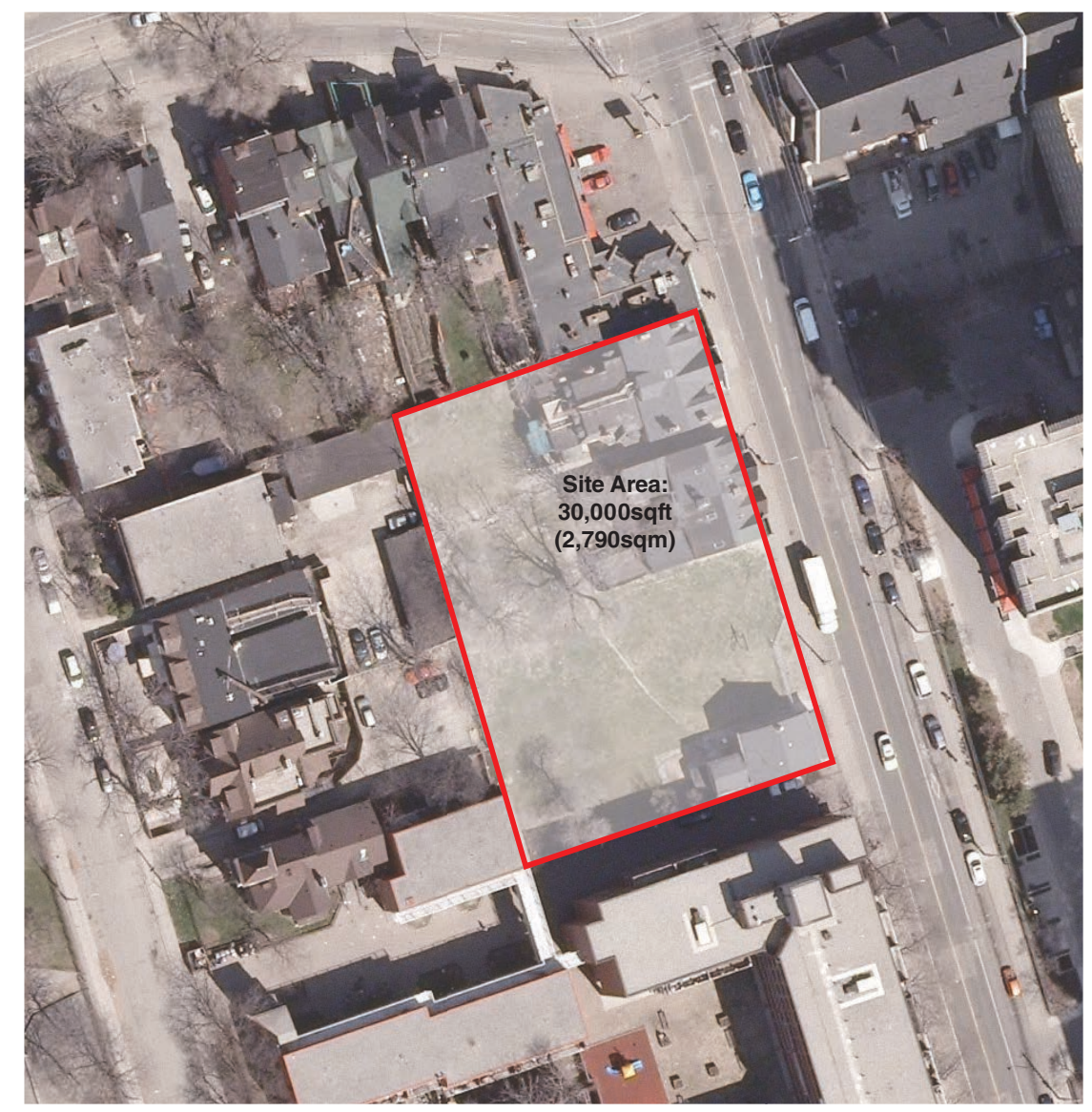

Fig. 5.33 - Proposed site boundary and area 


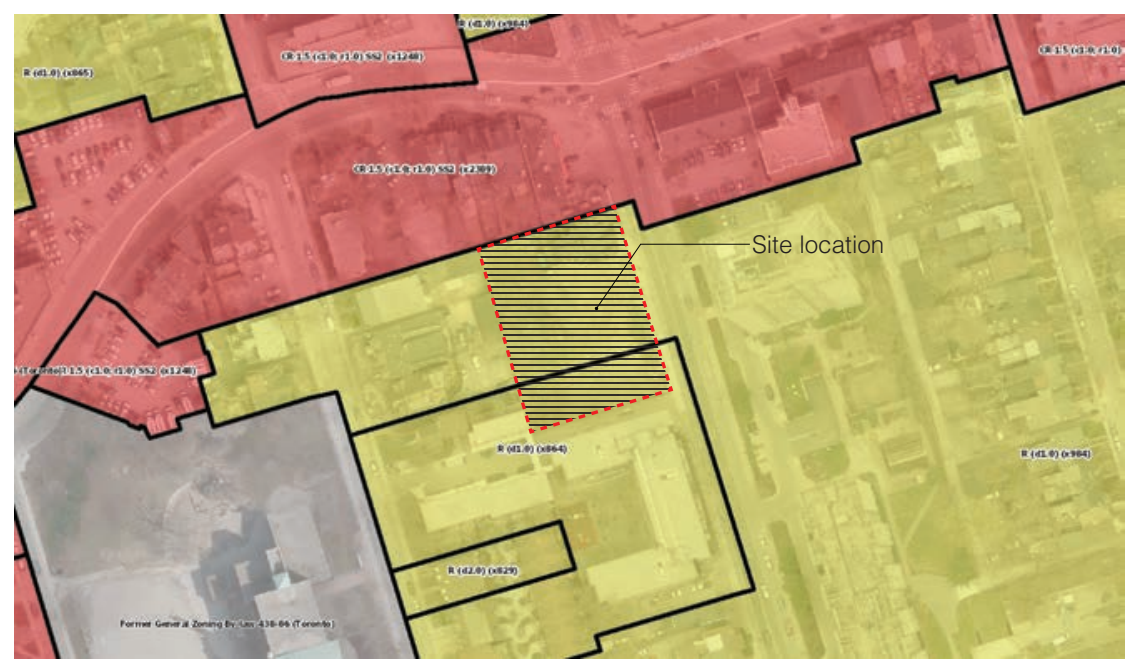

Fig. 5.34 - Site selected zoning designation

The appropriate zoning designation for this type of facility that would provide the most flexibility for design would fall under the CR - Commercial Residential 40.10.20 - Shared Housing / Residences. This permits the facility to be a standalone residential respite centre without having to be combined with other shared housing categories like nursing homes and retirement homes. According to the city of Toronto by-laws, this respite facility is permitted and regulated by section 40.5.1.10(3)(A)(ii).

According to this zoning bylaw, key lot requirements for this parcel of land that need to be taken into consideration are as follows:

Lot Frontage:

Lot Coverage:

Height:

Building Setbacks:
- 30'-0" (9m) minimum

- not applicable to this site

- 34'-6" (10.5m) minimum

- 3 storeys minimum

$-75 \%$ of main wall of building facing a front lot line to be between front lot line and a maximum of 9'-10" (3m)

- 15'-0"min (4.5m) from rear lot line

- 15'-0"min (4.5m) from side lot lines where windows and openings are located - 0'-0" from side lot lines where no windows and openings are located

The proceeding figures, 5.35 and 5.36 , illustrate the above stated zoning by-law requirements and set the starting platform for the development of the form explorations for the Dementia Respite Care Centre. 


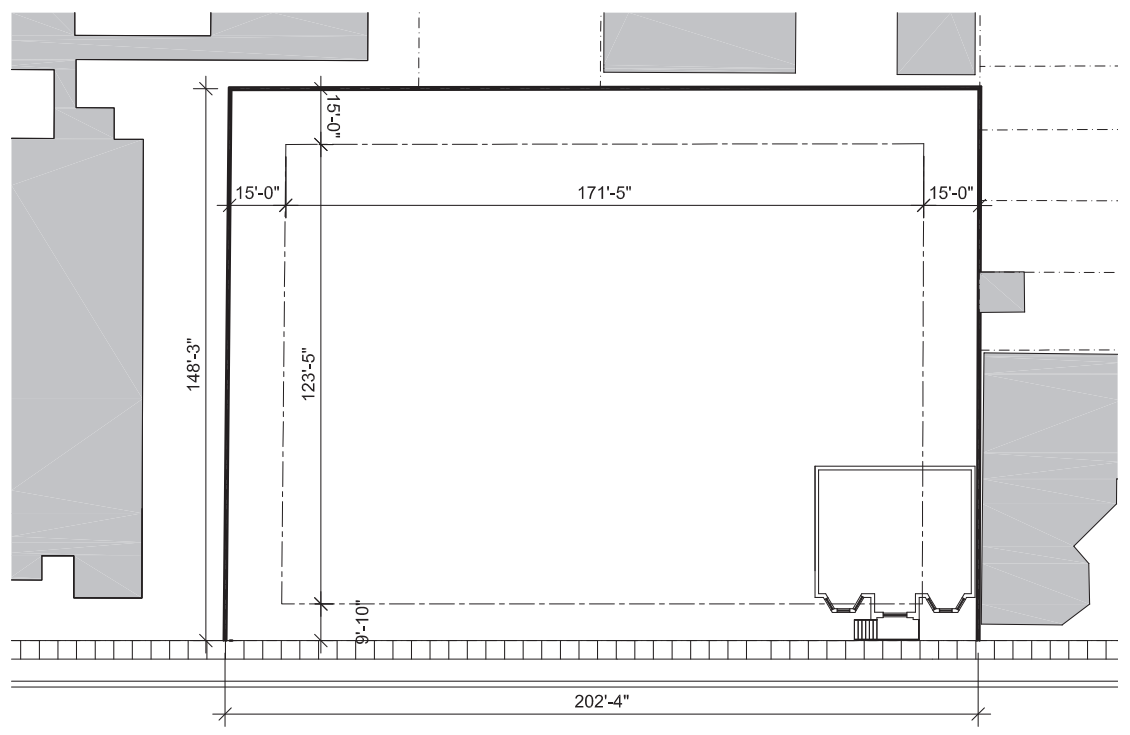

Fig. 5.35 - Zoning setback requirements in plan
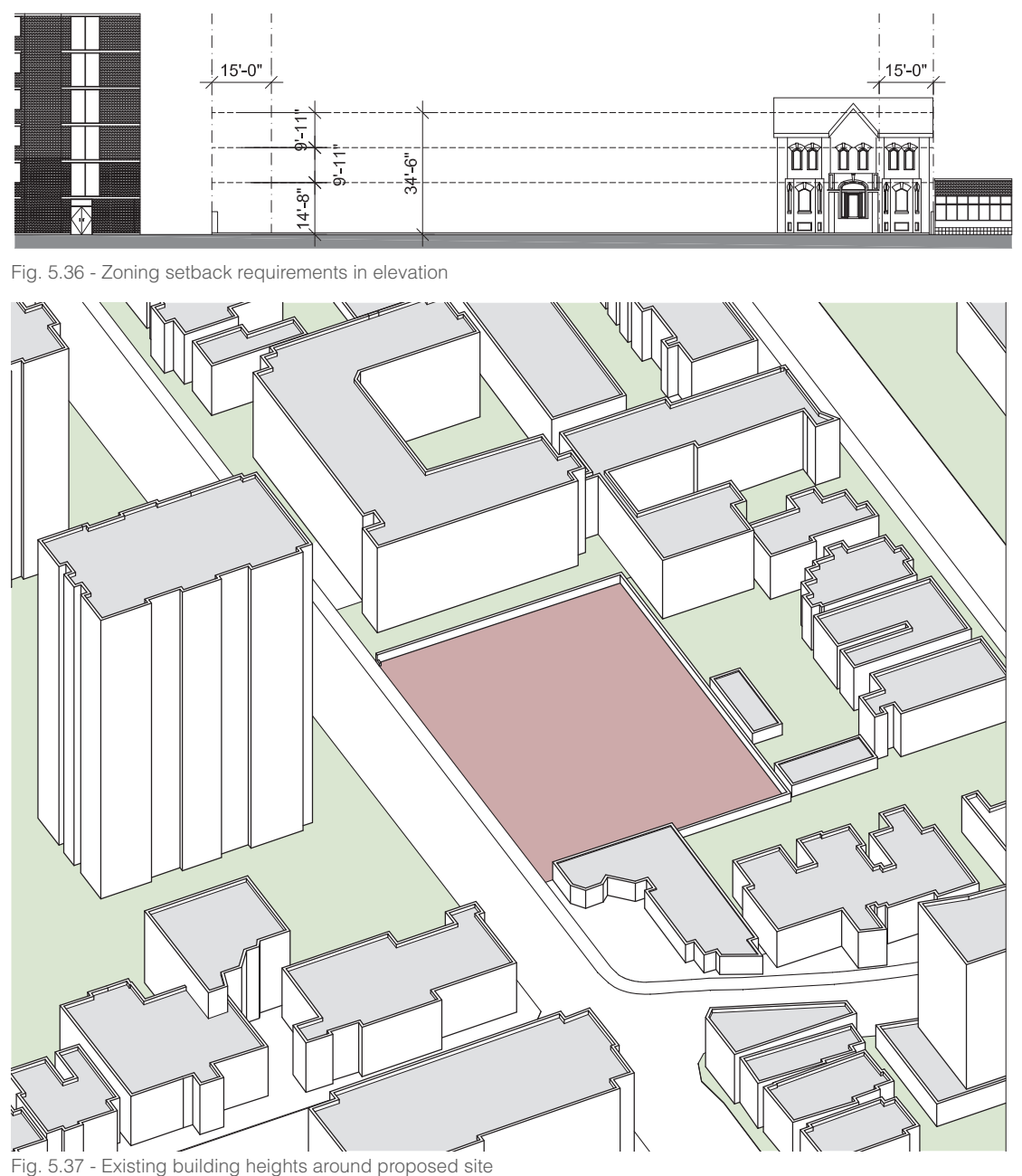

79 | sebastian lubczynski master of architecture ryerson university 


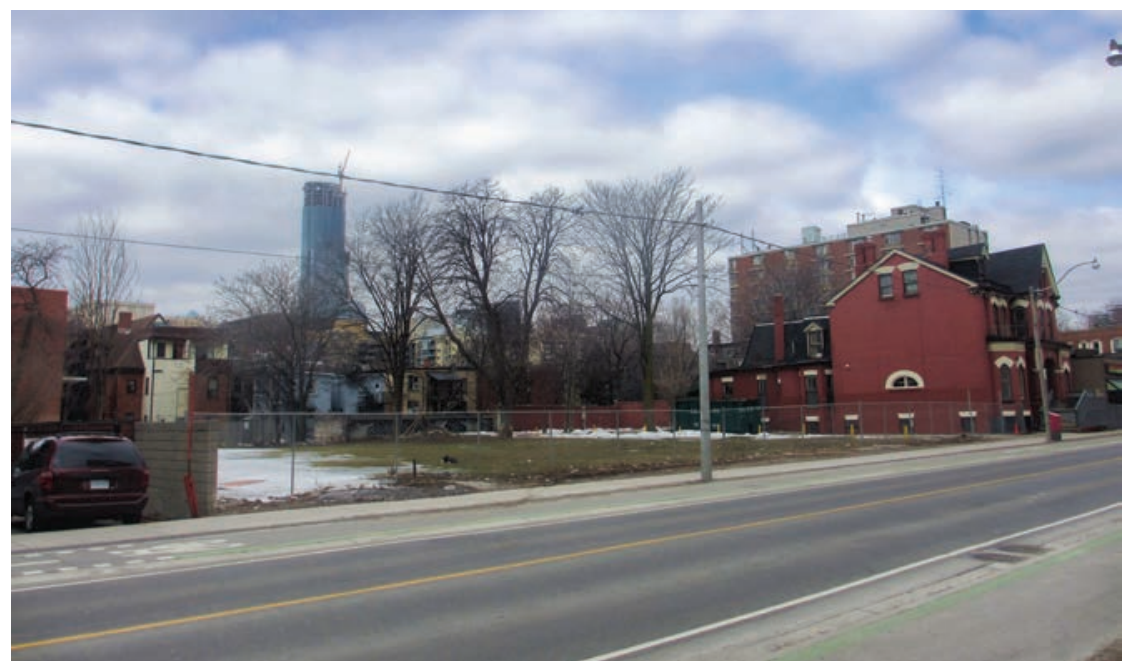

Fig. 5.38 - Selected site perspective looking north-west
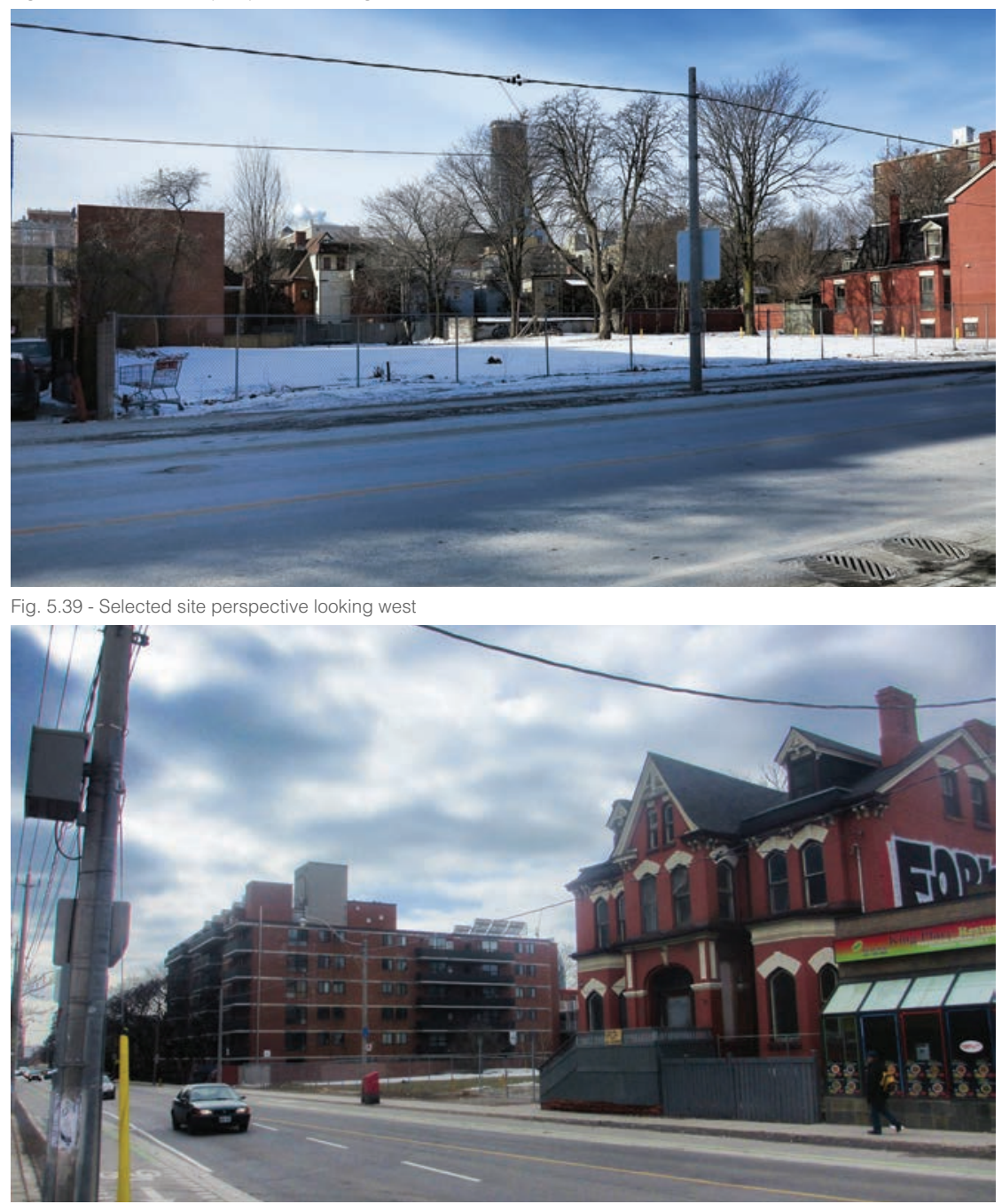

Fig. 5.40 - Selected site perspective looking south-west 


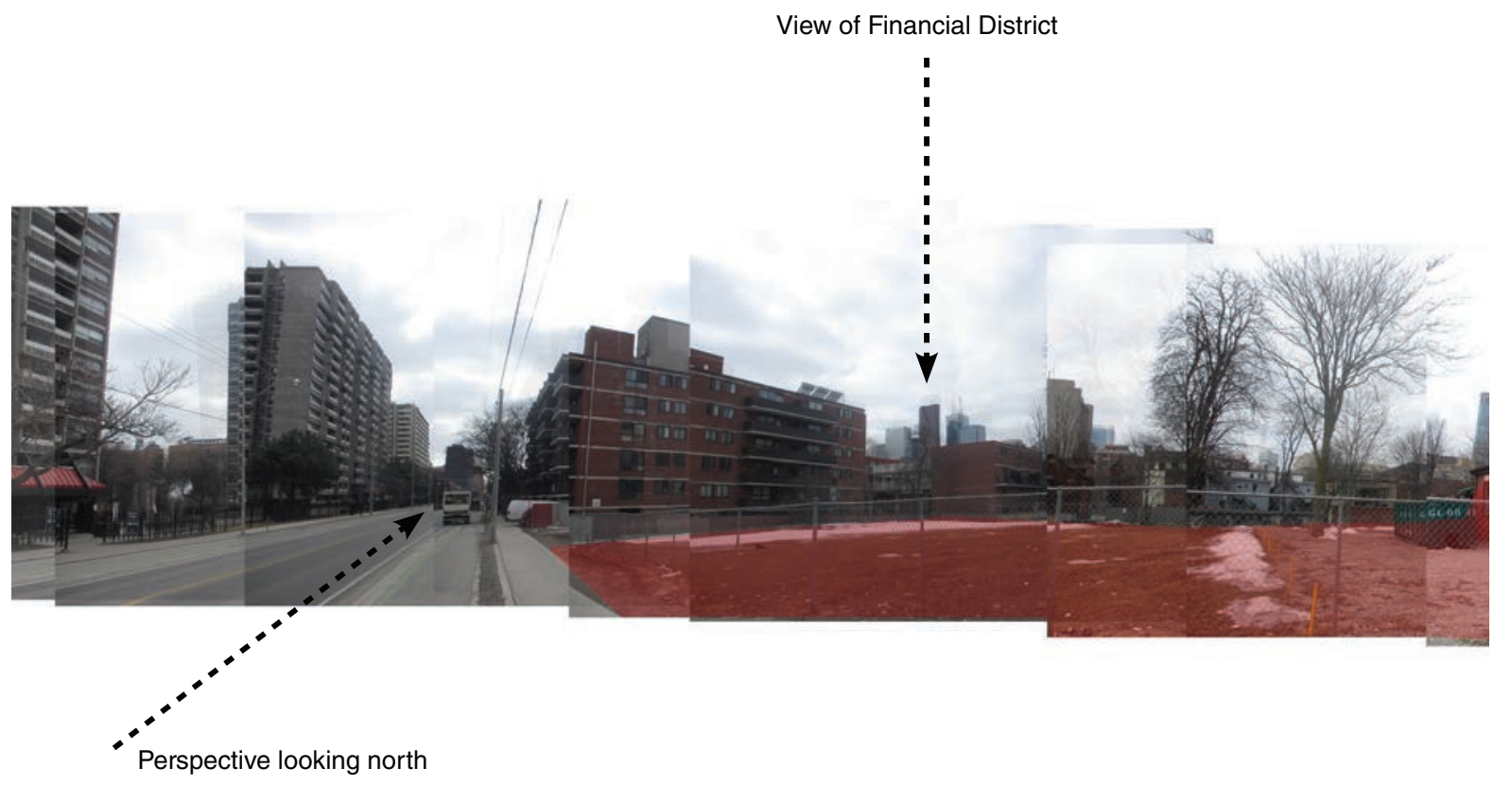

Fig. 5.41 - Selected site perspective

81 | sebastian lubczynski master of architecture ryerson university 


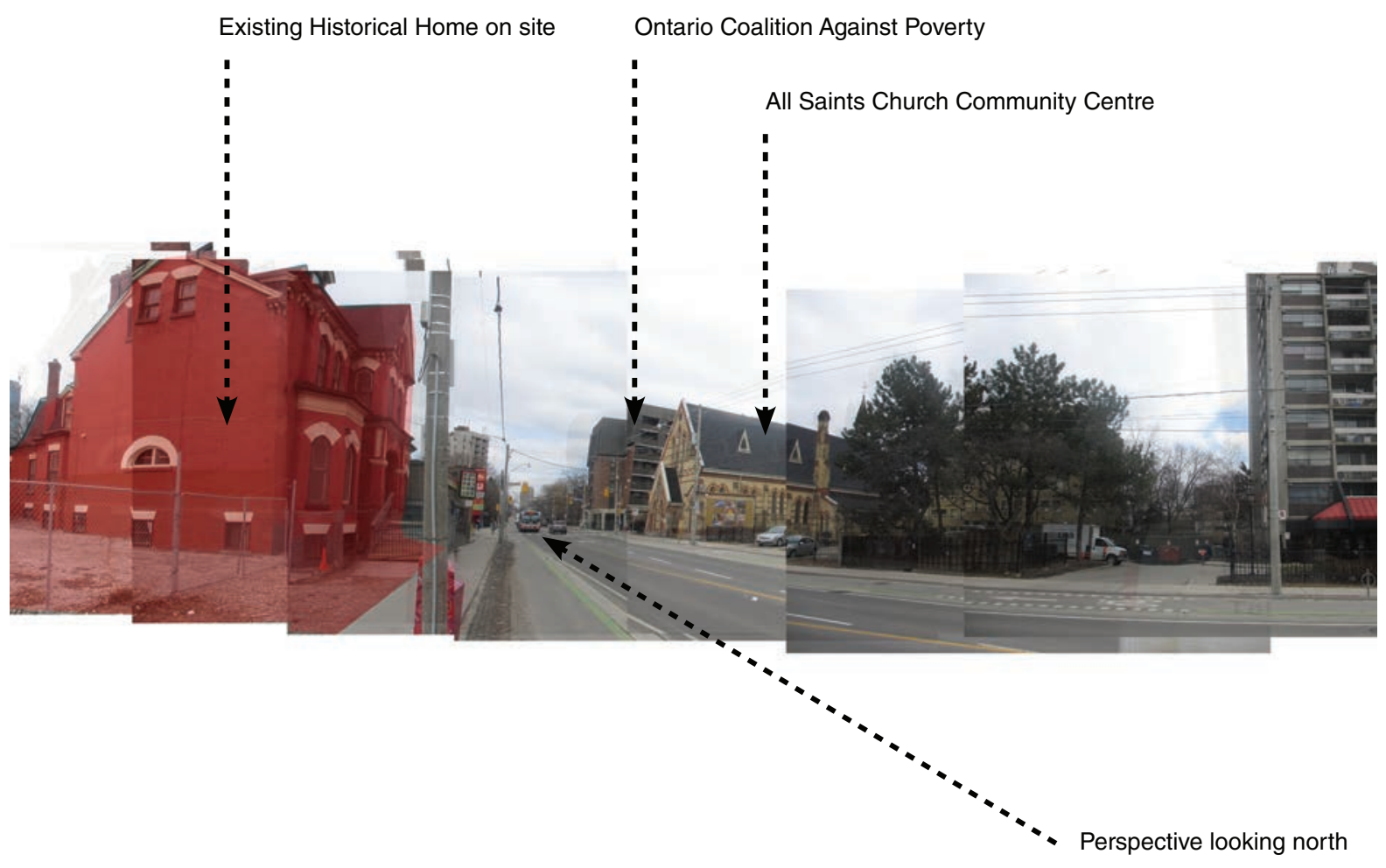




\subsection{SPATIAL PROGRAM DEVELOPMENT}

The lives we lead consist of a series of discrete interconnected set of activities. The elements that compose our life such as eating, sleeping, working, playing, provide everyone a set of goals to strive towards that give meaning to our life. These elements become ever more important as we get older. They become our reference points for time and direction, a reference point for reality. How can these elements be brought forth in the development of a Dementia Respite Care Centre that blends normality with medical practices?

In most cases when dealing with assisted living, nursing homes, or long-term care homes, the problem faced with providing an adequate program and living conditions lies in balancing the need of the patients, the staff, the family, and the developer. The aim is to provide the patients with the best care for their well-being, yet, maximized supervision, streamlined care operations, and sanitized materiality tend to dominate the requirements for these types of places. The aim here is to provide a humanistic approach over a medical one in setting the program and their spatial relationships. The intent thus is to foster a caring community, eliminating discrepancies between the needs of the patients and that of the caregivers.

Unlike many other care facilities, the Dementia Respite Care Centre is dedicated to one particular condition. As the intent is to be a flexible, parttime care centre, the spatial program fosters a different kind of dialogue between staff, user and family. What sets this dialogue apart from other care facilities is that most care facilities are full-time stay, creating a sense of separation and possible guilt between the family member and the user. There tends to be a negative perception at times with long-term care or nursing homes when families decide to send their loved ones to be taken care of by someone else, even though the family itself is illequipped to provide the proper care for them. With a care centre that is flexible with the durations of stay and its day program, the possibility of fostering a sense of autonomy over one's life and commonality between the users is an element to strive toward. This factor also extends to the family by alleviating the relationships with the immediate family, their friends and relatives, by not completely removing them from their home and communities. Without a community, the sense of personhood is lost. In the words of philosopher Martin Buber "all real living is meeting". 
Fostering community between all individuals involved becomes marginal when efficiency of procedures and staff take precedence.

Creating a community and activity program for these individuals becomes a vital aspect for their mental well-being. There are multiple factors that influence the spatial program and should therefore be accounted for; current and projected abilities of the user, the training and number of staff, and the physical constraints of the building. The composition of the Dementia Respite Care Centre is of two distinct programmatic aspects that makeup the spatial program; life as activity and health and rehabilitation. Life as activity are indicated as the most therapeutically beneficial activities for people with dementia because these types of activities play an essential role in defining who we are as people. The intent of Health and Rehabilitation activities is on helping individuals with monitoring their health and assist in providing physical, occupational, lighting, and speech therapies that prolong the lives of the individuals.

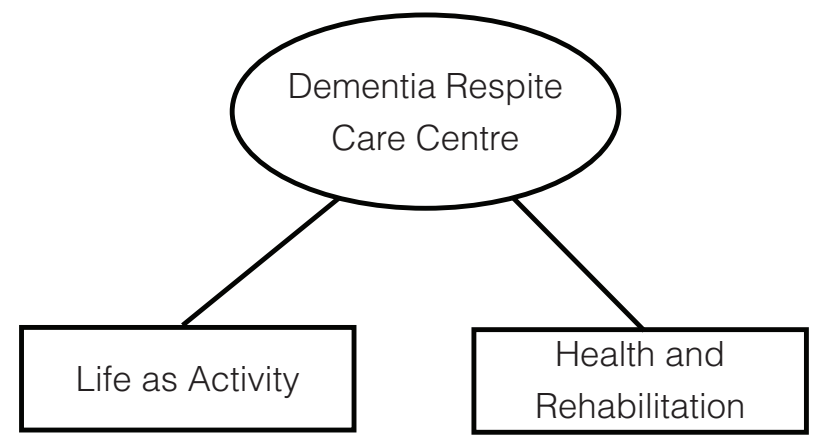

Fig. 5.42 - Dementia Respite Care Centre Program Breakdown 


\section{Spatial Program Development}

The spatial program for this building has developed throughout the course of the design process. The following is the final spatial program that was developed as part of the final design iteration.

Building designed for 40 people (20 daycare / 20 respite)

Site Size: 18,908 sqft usable as per zoning setbacks

Total Program: Respite $(12,890)+$ Day Centre $(17,276)+$ Admin $(3,855 \mathrm{sqft})$

$=34,021$ sqft $\times 1.15$ circulation $=39,125 \mathrm{sqft}$

\section{Day Centre Program}

Total: 17,276 sqft

Foyer (565sqft)

Cafe (1000sqft)

Main Lounge (910sqft)

Activity / Workshop (600sqft)

Communal Kitchen (320sqft)

Dining ( 3 @ 290sqft)

Semi-Private Living Room (570sqft)

Activity / Library (700sqft)

Beauty Room (140sqft)

Hairdressing Room (90sqft)

Treatment Room (170sqft)

Medicine Storage (130sqft)

Spa Bath (235sqft)

Phisio Therpay (880sqft)

Therapy Pool (1350sqft)

Winter Garden (490sqft)

Change Rooms (2 @ 275sqft)

Linen Storage (25sqft)

Sitting Areas (180sqft)

Outdoor Gardens (6120sqft)

Outdoor Sitting Area (875sqft)

Washrooms (6@ 45sqft)

Semi-Private Lounge (236sqft)

\section{Respite Area}

(2 Floors @ 6,445sqft, Total: 12,890sqft)

10 - Single Private Rooms (@ 300sqft)

2 - Private Dining Room (@ 290sqft)

Kitchen (200sqft)

Living Room (1100sqft)

Resident Laundry (120sqft)

Spa Bath (160sqft)

Nurses' Station (280sqft)

Activity Room (530sqft)

Treatment Room (115sqft)

Quiet Room (160sqft)

Private Lounge (200sqft)

\section{Administration}

Total: 3,855 sqft

Reception (100sqft)

Interview Room (240sqft)

Training Room (210sqft)

Information / Gallery Space (690sqft)

Staff Meeting Room (240sqft)

Staff Kitchen / Lounge (430sqft)

Lockers (80sqft)

Directors Office (215sqft)

Assistant Office (170sqft)

Office (125sqft)

Storage (120sqft)

Outdoor Staff Area (1110sqft)

Staff Washrooms (2 @40sqft)

Public Washroom (45sqft) 
The complexities of the spatial program were required to be broken down to further comprehend the spatial relationships between each program. Fig. 5.43 were initial program relationship groupings and connections. Within this program iteration each cluster grouping of functions start to breakdown the spatial programs that will be closer together and provide direct access in each space.

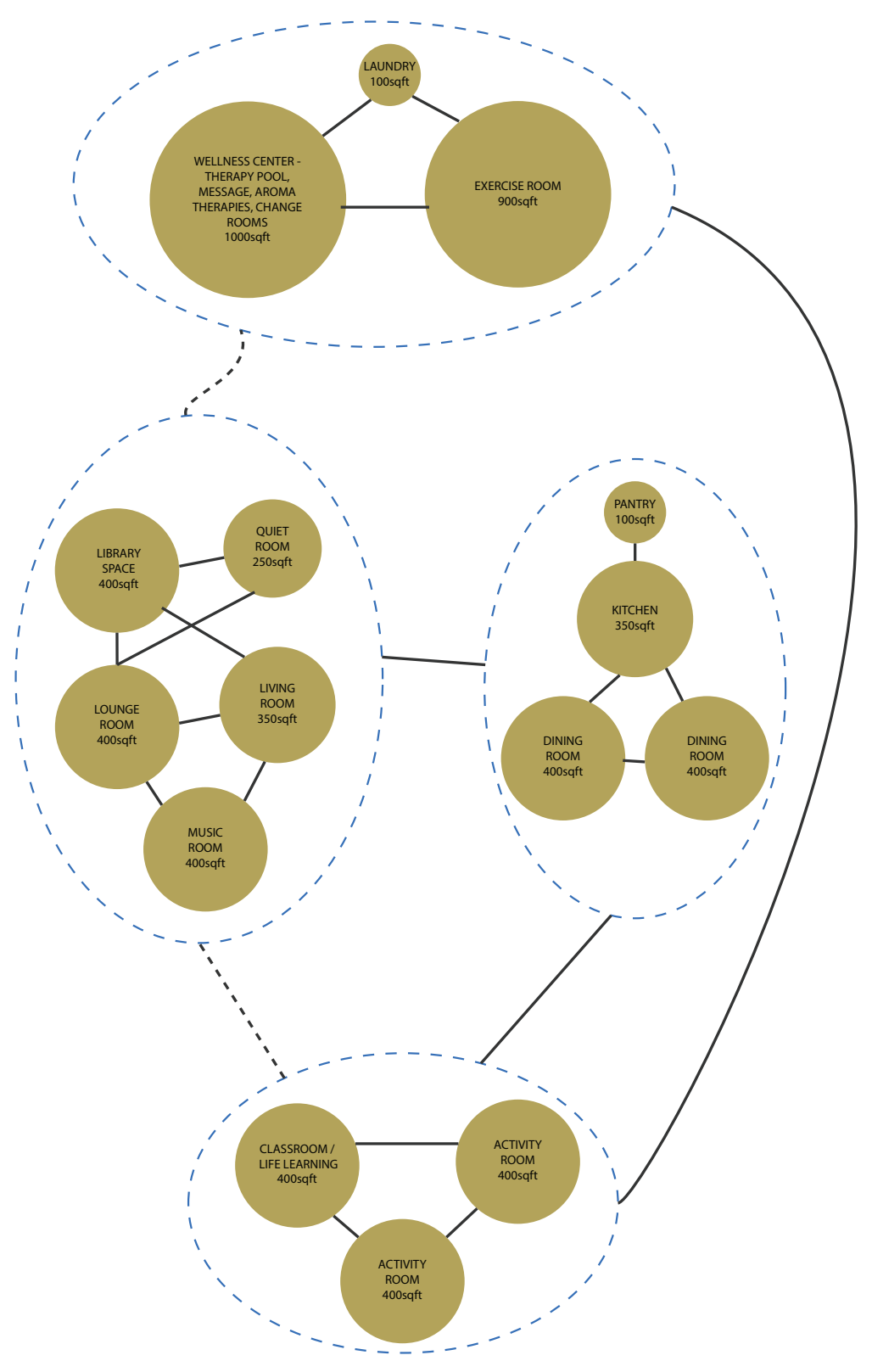

Fig. 5.43 - Spatial Program Relationship Analysis 


\subsection{DESIGN PROCESS}

\section{Building Form}

With a site selected and a preliminary program established, initial design concepts on building form is formulated as a response to site context and design goals set out for this design exploration. Elements of street frontages, density of adjacent blocks, and previous site property boundaries are utilized as part of organisational strategies for the development of the building form.

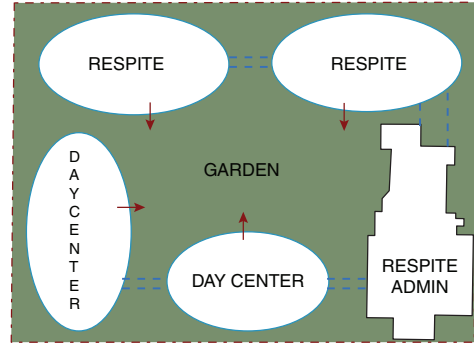

SHERBOURNE STREET

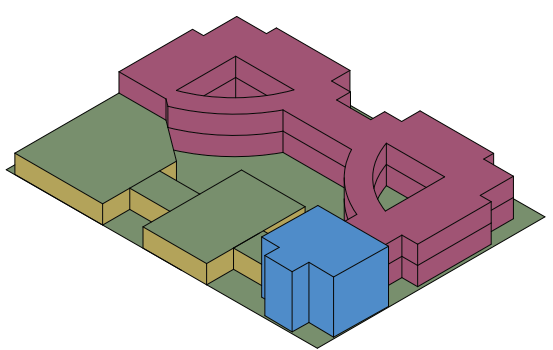

Fig. 5.44 - Building form strategy 1

The first approach as illustrated in fig 5.44 establishes discrete volumetric forms for each programmatic type. The day centre program is located on the ground floor along Sherbroune Street as part of creating activity along the street and a gradient of public to private areas of the site. The west portion of the site houses two storeys of the respite program, providing internally looped circulation and private courtyards. This scheme introduces legibility, transparency, and orientation to all parts of the building by breaking down the volumetric forms, creating smaller floor plates, resulting in visual access to all areas of the site.

The second design approach as illustrated in fig 5.45 establishes a long volumetric bar along Sherbroune Street with a recessed entry into the building adjacent to the existing home on site. The main entry into the site for each scheme is situated adjacently to the existing home to utilize the home for the administration portions of the program. In this scheme, 3 internal courtyards are created by the respite portion of the program creating a continuous circulation on the first and second floor denoted by the purple colour.

The third design approach to the building's massing as illustrated in fig. 5.46 is similar to the second iteration but with the respite program 

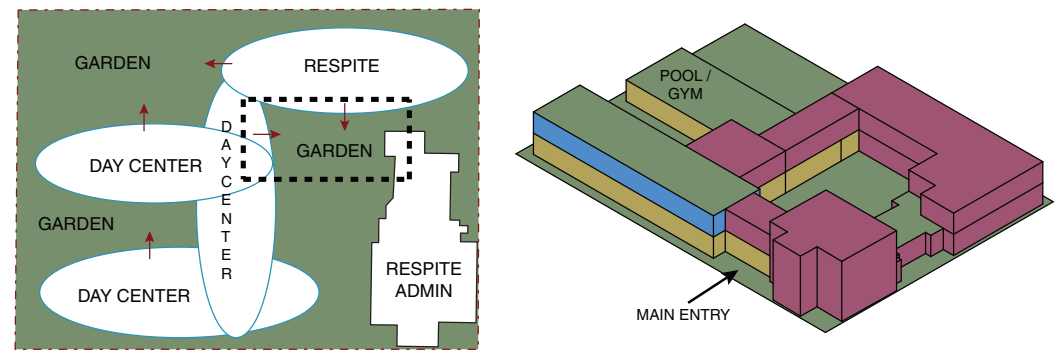

SHERBOURNE STREET

Fig. 5.45 - Building form strategy 2

located on the second floor only. The west-east connection between the volumes is re-orientated towards external neighbourhood vistas of the downtown core and Sherbourne Lanes project. Within this scheme, the respite program is divided into two "homes" accompanied with discrete circulation looping along the bedroom units and other programmatic functions.
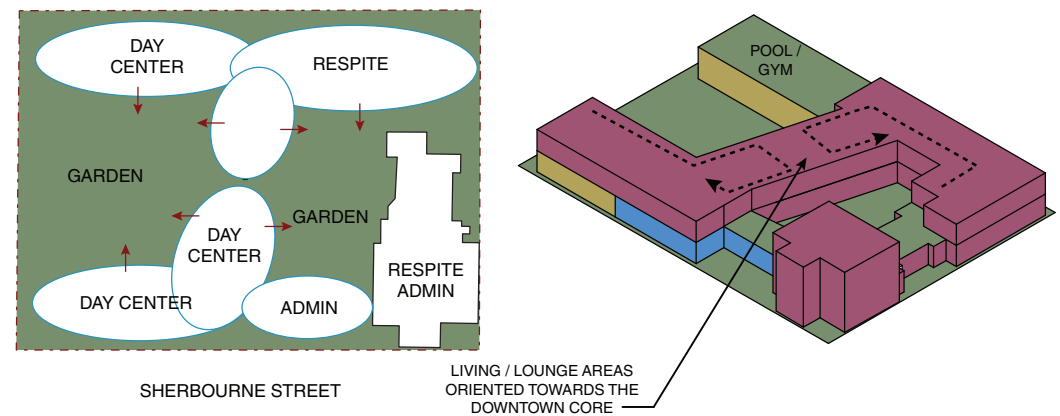

Fig. 5.46 - Building form strategy 3

As part of the building massing development and general organization, strategies for the respite program are also conceptualized. Each iteration is composed of the same essential programmatic functions. These design explorations were completed independent of the massing development and plan development, as a means of establishing conceptual thinking towards ideal program relationships and functions. These concepts were then applied to the realities of the site, and the chosen massing was further developed as a response these explorations.

The first exploration of the respite program is to break down individual "clusters" into groups of 6-10 bedroom units. Fig. 5.47 cluster diagram illustrates internal circulation wrapping around daily living program with bedroom units along the perimeter. In this scheme transparency is provided by having direct access to programmatic functions directly from 
the bedroom units, directly affecting the orientation within the spaces.

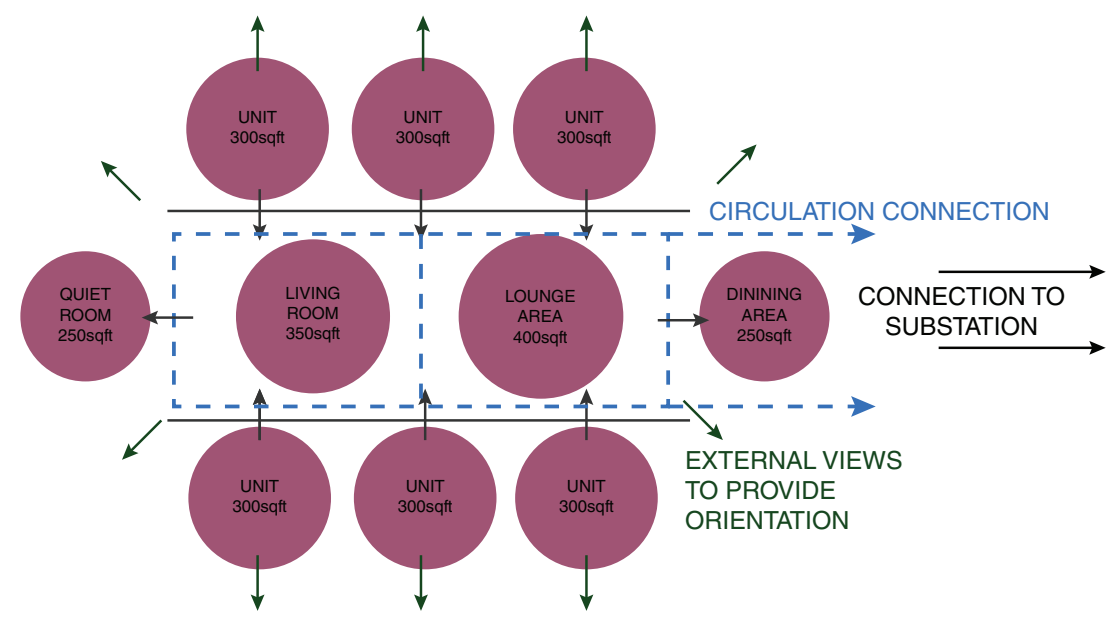

Fig. 5.47 - House Cluster Strategy 1

The second exploration investigated the spatial layout as a single loaded corridor overlooking an interior courtyard. This scheme provides a continuous looped interior circulation that provides transparency and orientation within the floor plan. All programmatic functions have access to natural light and natural ventilation. Particular program spaces are inserted in between the bedroom units as destination spaces, altering the typical design of the bedroom and daily living areas.

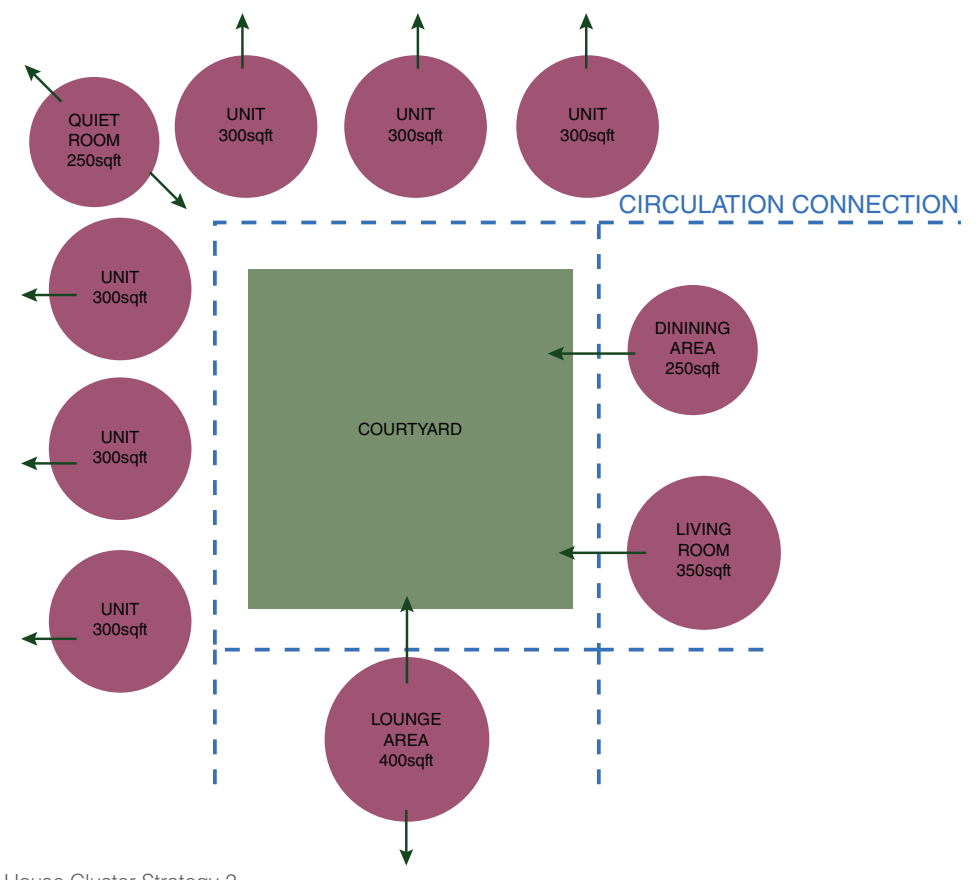

Fig. 5.48 - House Cluster Strategy 2 


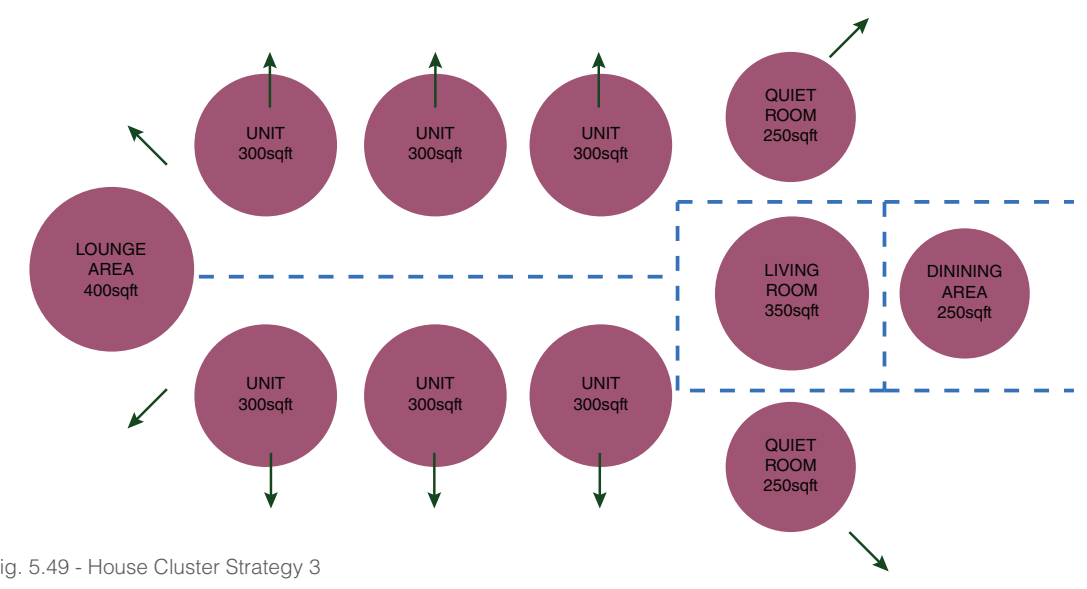

The third scheme investigated a double loaded corridor with program functions at the ends of the corridor. However this scheme is not as successful at providing meaningful daily experiences. Spaces and interactions between users his very much one-dimenstional.

\subsection{DESIGN ITERATION ONE PROCESS DEVELOPMENT}

The first iteration that was conducted illustrates the design constructs of the research and design goals that were established for this thesisproject.

The process that was undertaken in the first design iteration initiated from the existing and historical urban morphology. Laying out the previous property boundaries allowed for creating setbacks at each property line with the intent of developing separate volumetric forms. These volumetric forms were further developed with the programmatic functions required and the creation of an interior courtyards.

The following figures, 5.50 to 5.58 document the design process undertaken in developing the first iteration of the Dementia Respite Care Centre. 


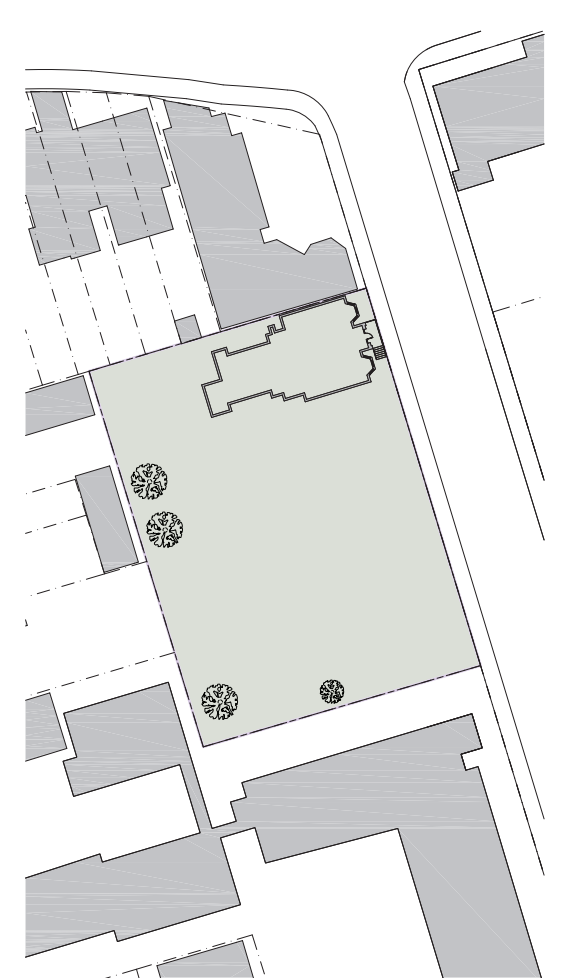

Fig. 5.50 - Existing site conditions

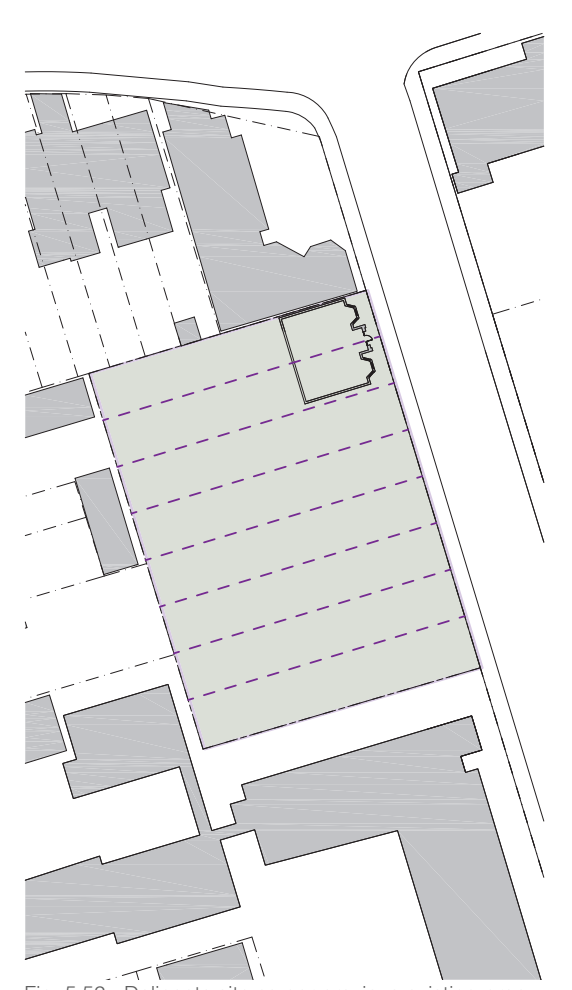

Fig. 5.52 - Delineate site as per previous existing property lines on site

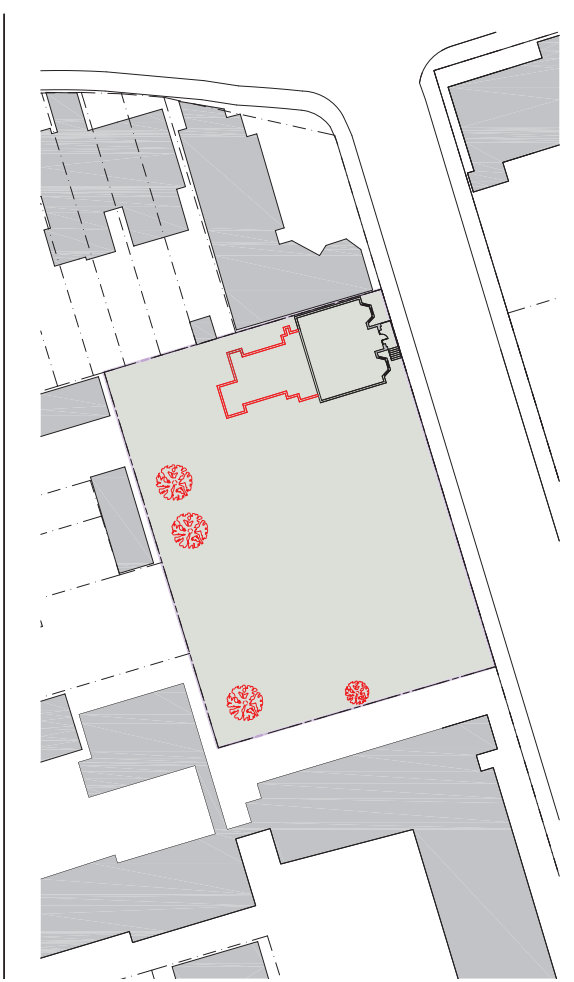

Fig. 5.51-Removal of back of existing house and trees

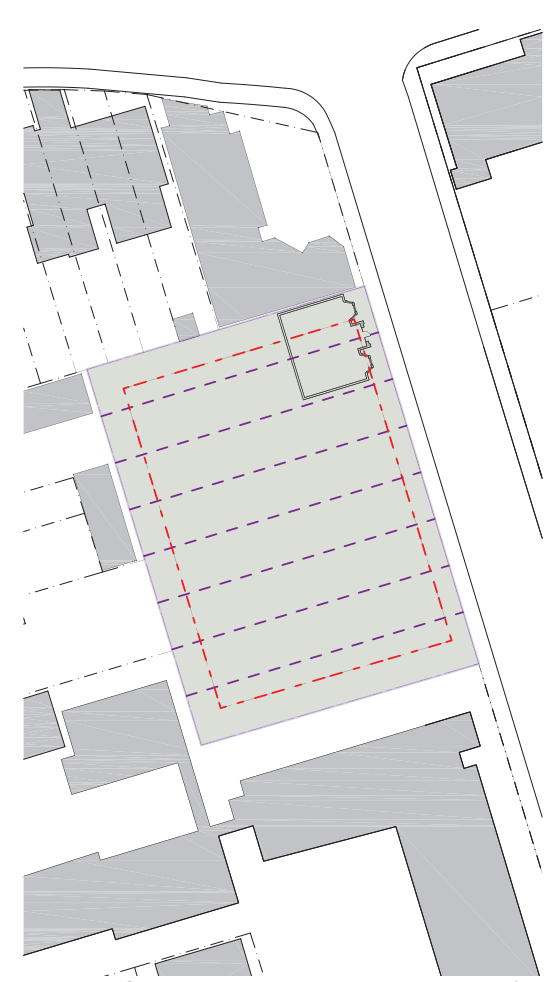

Fig. 5.53 - Setbacks: 4.5 meters back and side yard for glazing. Face of wall allowed to be to property line if no glazing. 3 meters set back at front yard 


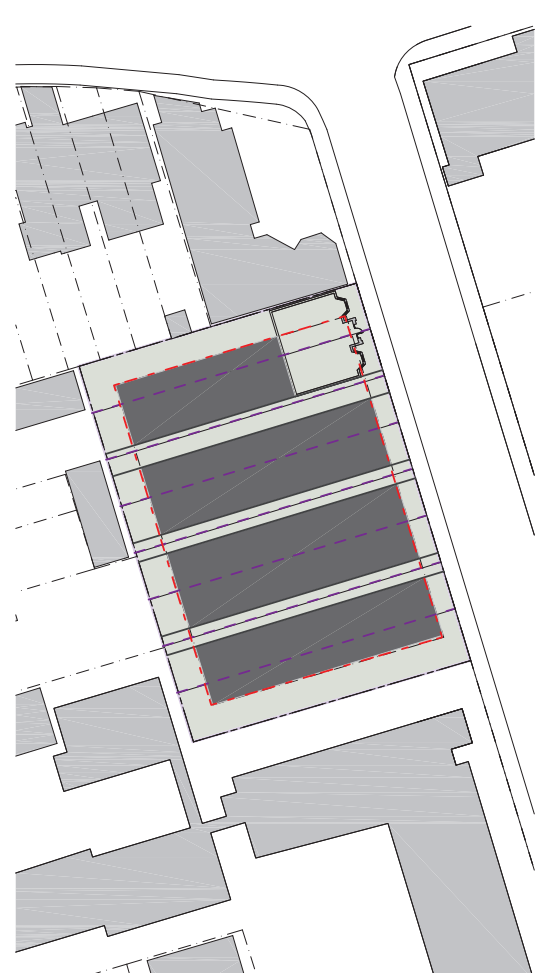

Fig. 5.54 - 3 meter setbacks from each property line provides 4 volumetric forms on site

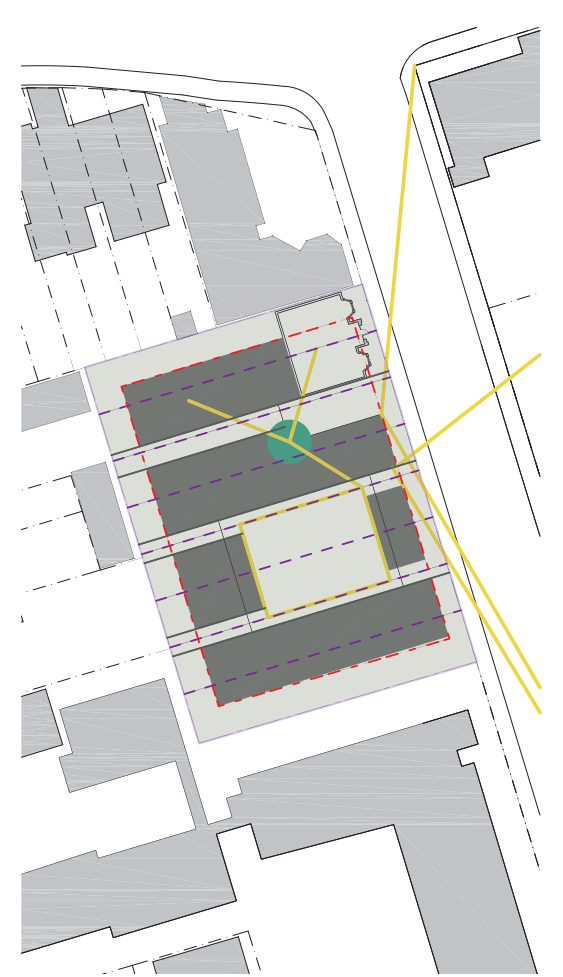

Fig. 5.56 - Remove area within site to create 2 nd courtyard. Node at entry to provide orientation to external landmarks and city scape

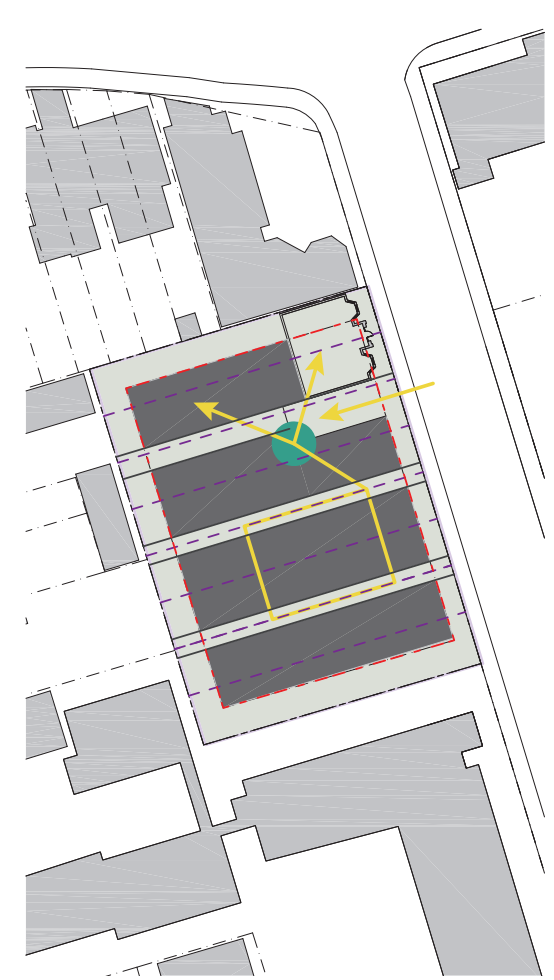

Fig. 5.55 - Entry court yard as transition space between public and building. Secondary space between volumes becomes internal circulation space

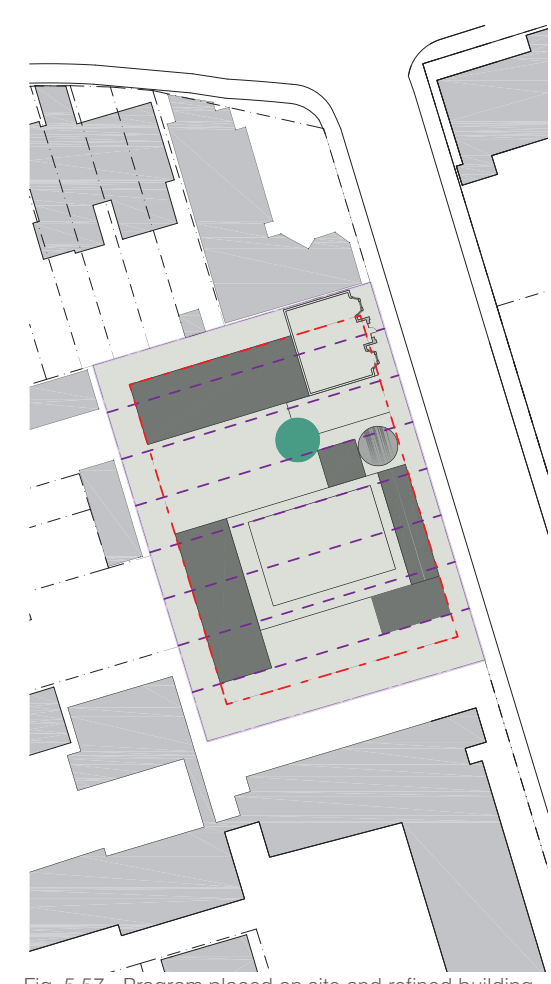

Fig. 5.57 - Program placed on site and refined building boundaries. Activity court yard is provided at north end of site. 


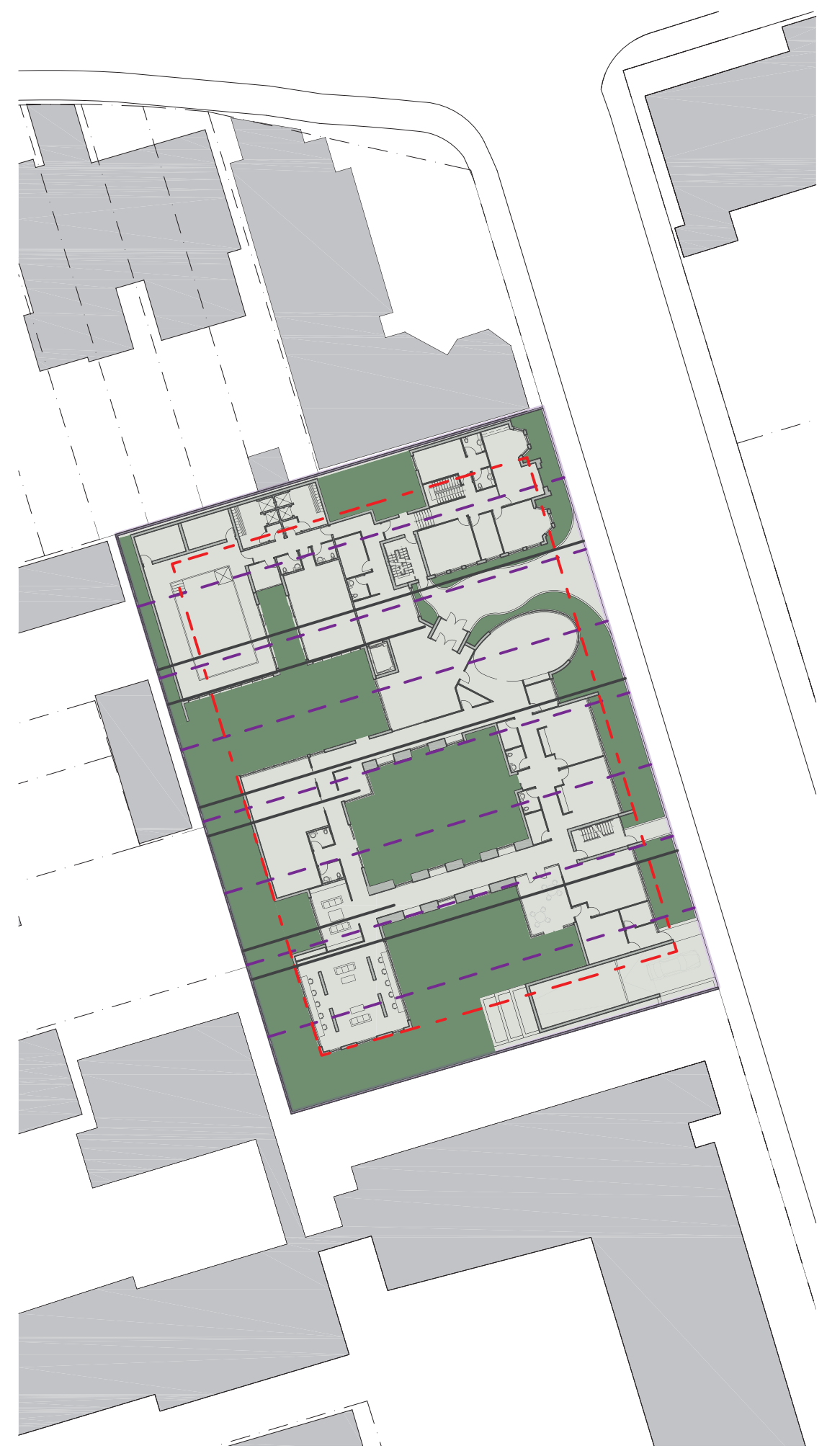

Fig. 5.58 - Final design outcome of day centre on ground floor 


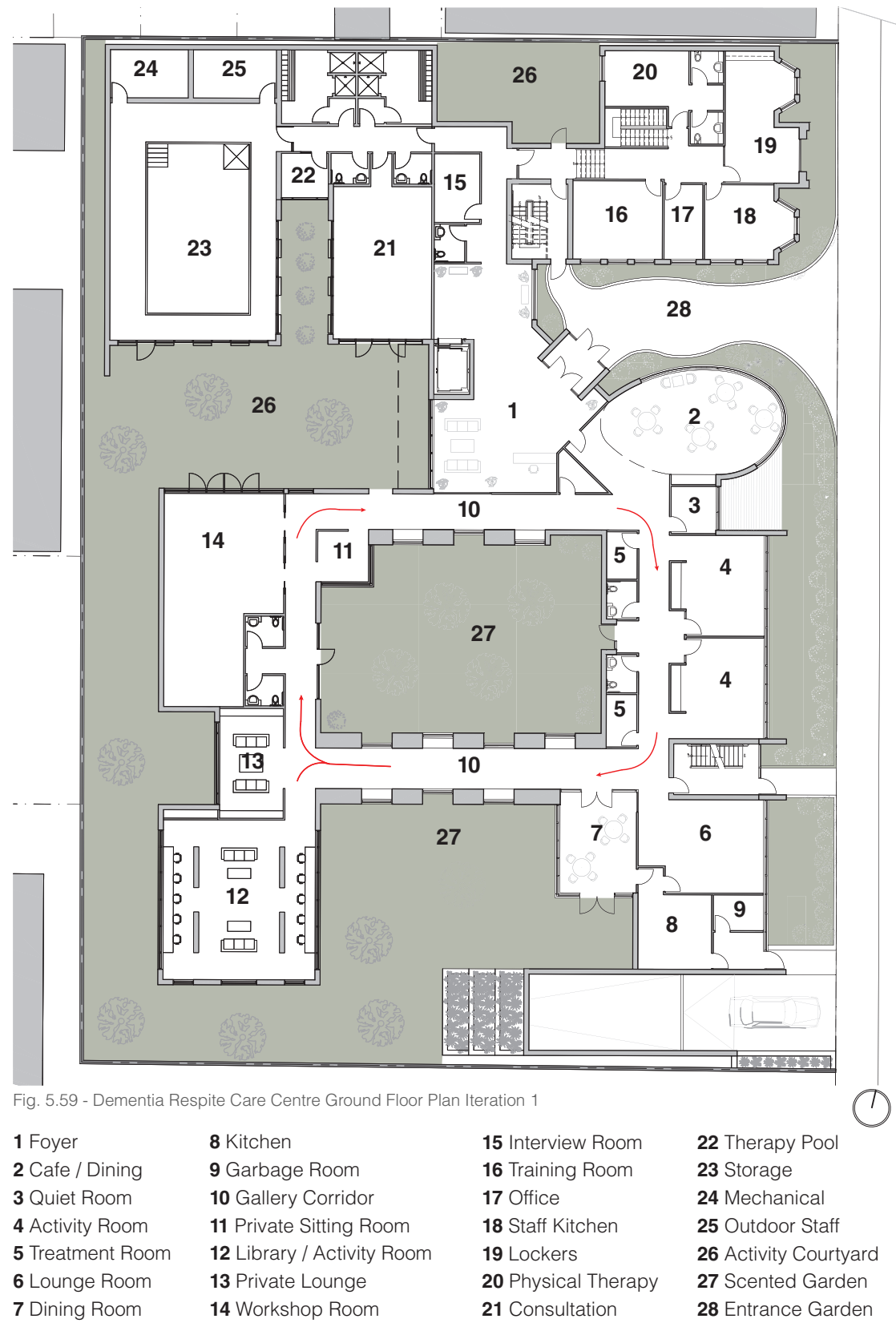

The design of the ground floor in iteration one (figure 5.59) is composed of three separately contained areas. The foyer is the main transition space between the administration, wellness area, and day centre of the program at grade. The day centre portion, composed of a single loaded corridor, allows for direct visual and physical access to two scented gardens and activity courtyard. This provides a high level of transparency and orientation from within the program spaces. 


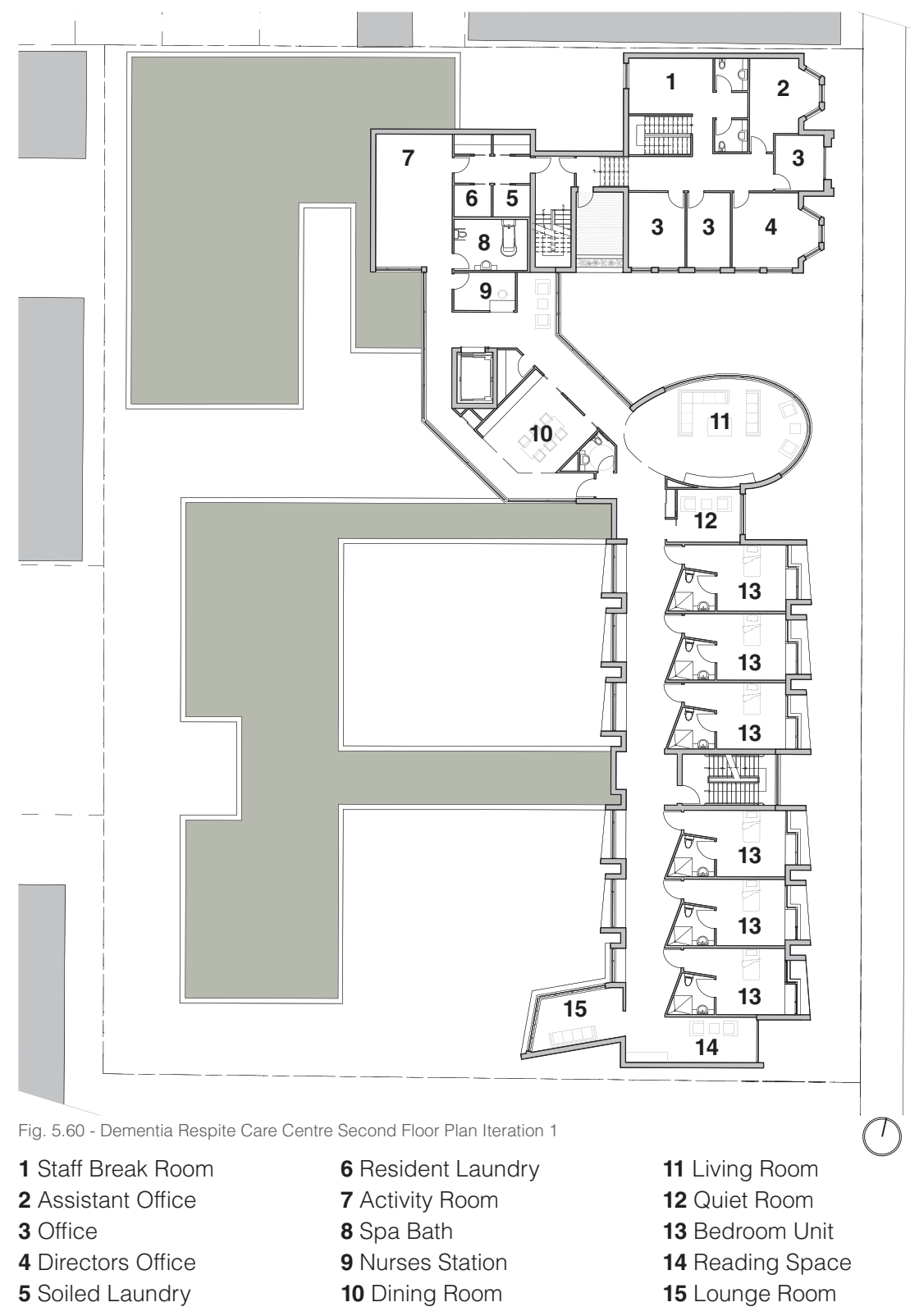

The design of the second and third floor respite portion of the facility is comprised of a small cluster groupings of six bedroom units. Organizing residents into smaller family-sized groups allows for communal spaces to remain familiar and home-like in scale. Bedroom units are located along the east portion the site and are serviced by a single loaded corridor. The resident corridor has direct visual access to the courtyards below and day centre program allowing residents to oversee potential activities they can partake in. 


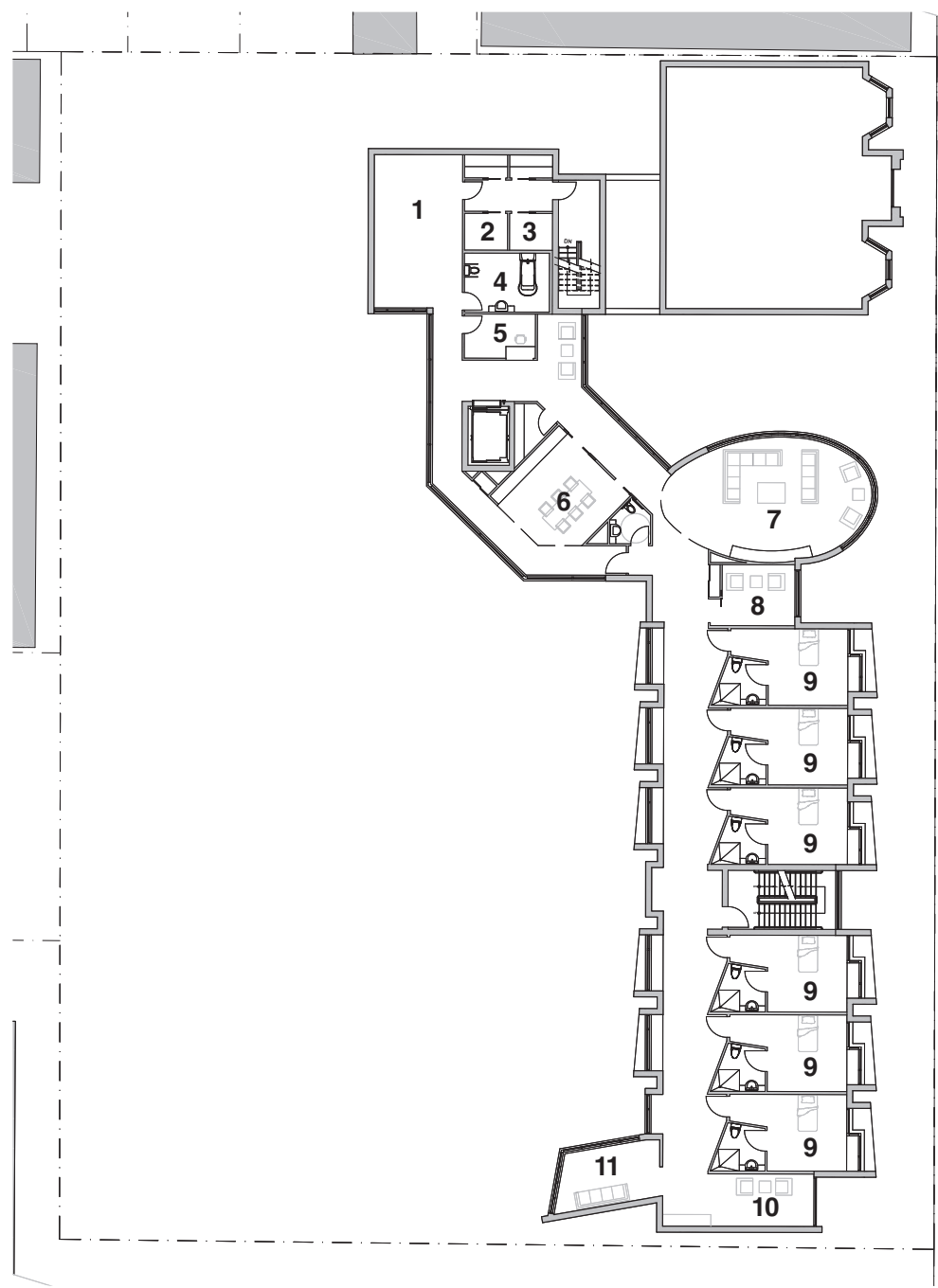

Fig. 5.61 - Dementia Respite Care Centre Third Floor Plan Iteration 1

1 Activity Room

2 Resident Laundry

3 Soiled Laundry

4 Spa Bath
5 Nurses Station

6 Dining Room

7 Living Room

8 Quiet Room
9 Bedroom Unit 10 Reading Space 11 Lounge Room 
The south elevation of the building along Sherbourne Street depicted in figures 5.62 and 5.63 is intended to express the programmatic functions of the interior spaces. Within this elevation iteration there is a clear distinction between the bedroom units, the living lounges in the oval space, and the day create activity spaces on the ground floor. All programmatic spaces are provided with a high level of transparency to maximise natural light.

An essential design element that was explored within this iteration, and further developed in the final design proposal, is the identification walls for the resident units (figure 5.64 - figure 5.67). Private entryways are created by angling the walls outward toward the resident as they are walking along the corridor. The angled walls are, therefore, clearly seen to each resident and provide an surface area for each resident to privatize their walls with personal images.

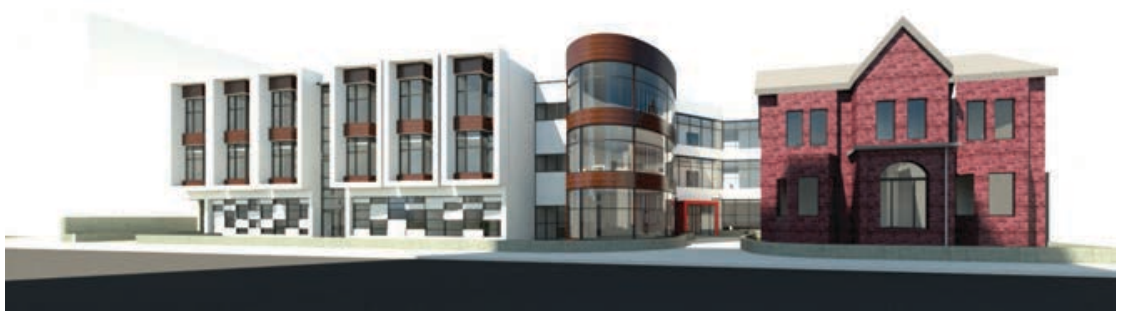

Fig. 5.62 - Iteration 1 Building Elevation

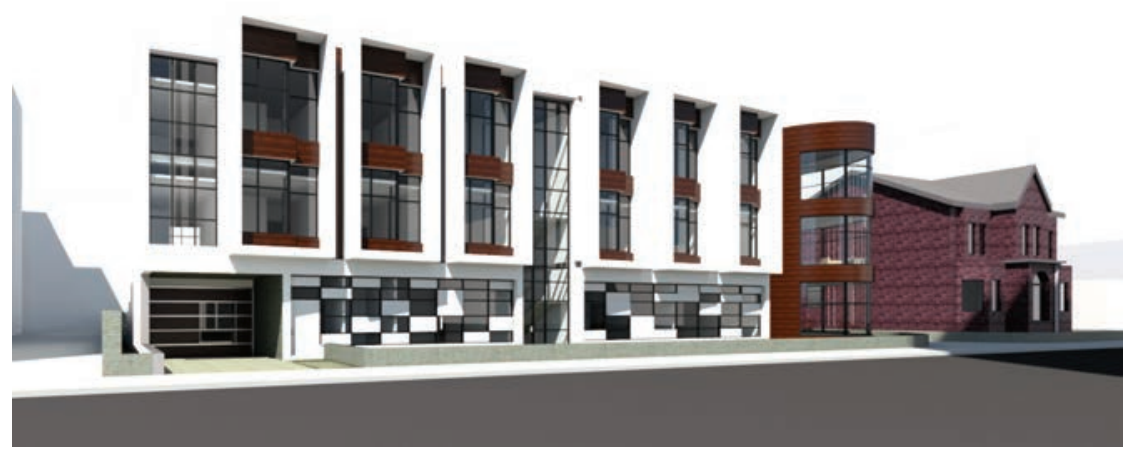

Fig. 5.63 - Iteration 1 Building Elevation

97 | sebastian lubczynski master of architecture ryerson university 


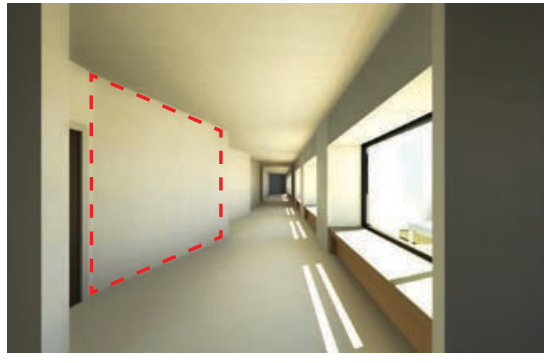

Fig. 5.64 - Resident corridor identification wall design

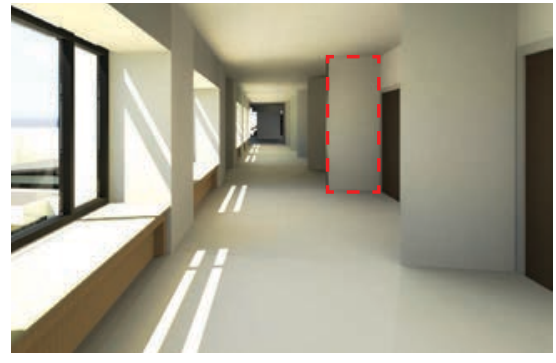

Fig. 5.65 - Resident corridor identification wall design

ANGLED WALLS TO PROVIDE AREA FOR MEMORY ITEMS TO BE LOCATED ON IN ASSISTING IN ORIENTATION AND VISUAL CUES FROM BOTH DIRECTIONS

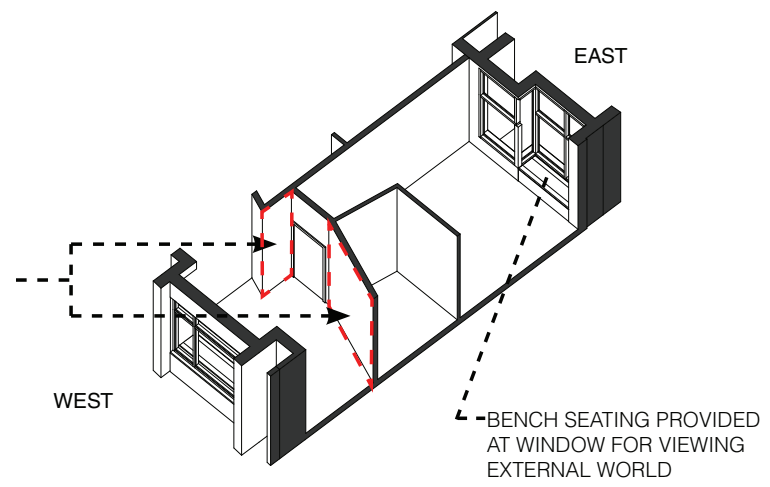

Fig. 5.66 - Resident corridor identification wall design

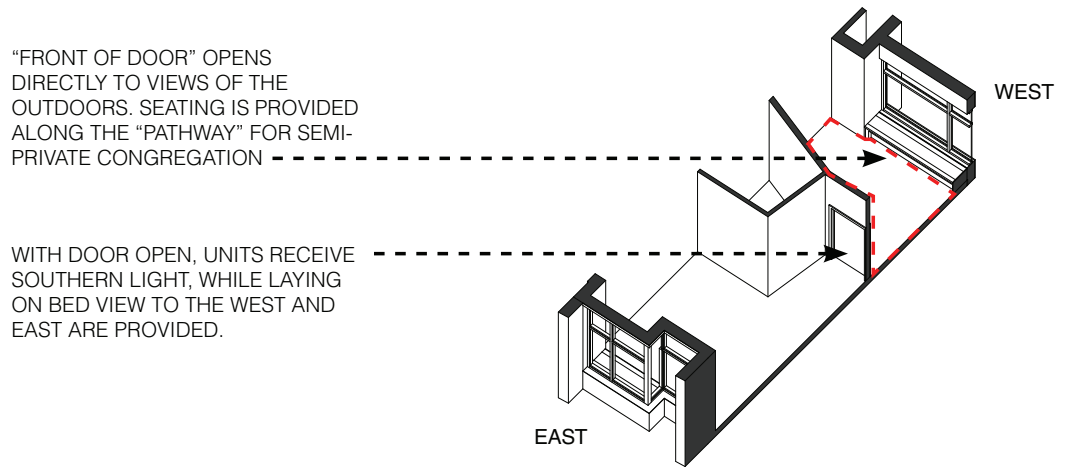

Fig. 5.67 - Resident corridor identification wall design 


\subsection{THESIS-PROJECT DESIGN PROPOSAL}

The concept for the thesis-project design proposal for this thesis-project is illustrated through figures 5.68 to 5.75 . There are three formal design approaches that were developed. First, the creation of the internal sensory garden courtyard for the day centre and residents, a private courtyard for staff members, and a winter garden atrium that is the anchor for the site. The design intent here is to provide visual and physical access to outdoor spaces for both users as it is noted in previous chapters that sensory gardens have proven to be therapeutic. The second design approach is responding to the historic urban morphology of the site and area. This design approach of utilizing previous property line boundaries of the site provided the opportunity to breakdown the massing of the overall building and provide a scale that is present within the contextual neighbourhood. The third formal design approach is the use of a single loaded corridor for both, the day centre program and resident program spaces as the main horizontal circulation. The design intent here is to provide a high level of transparency and orientation for the users of each space.

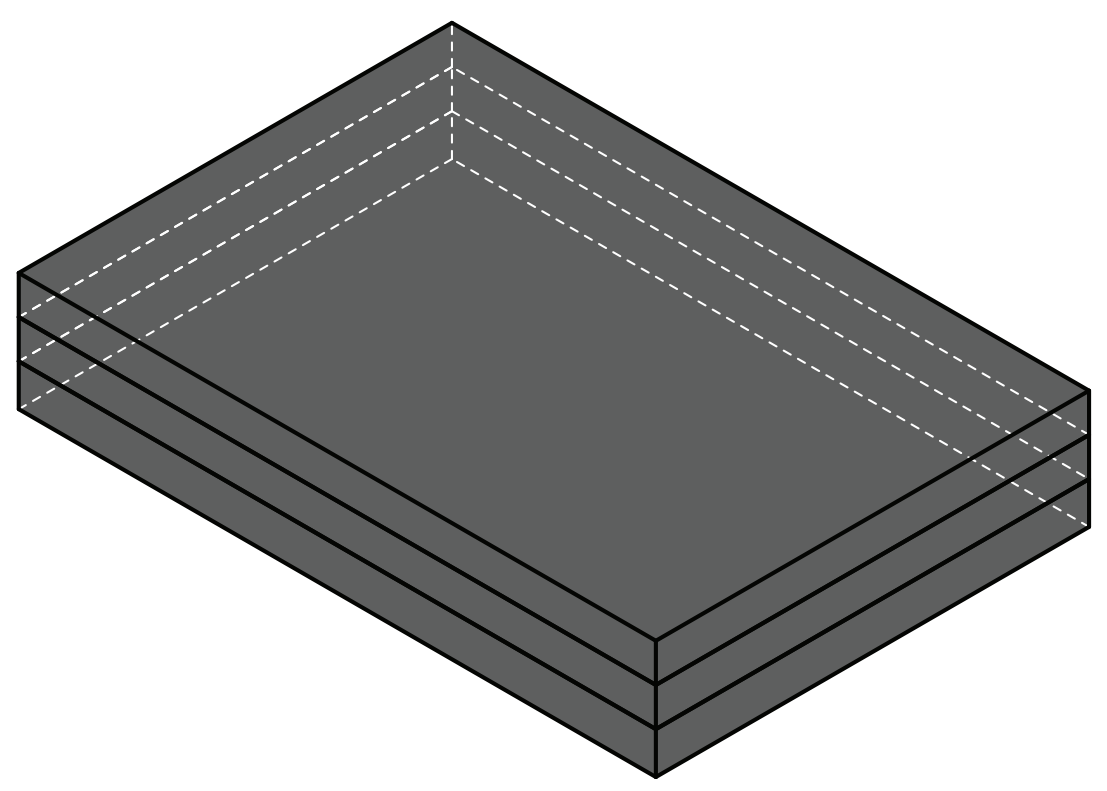

Fig. 5.68 - Available footprint massing on site 


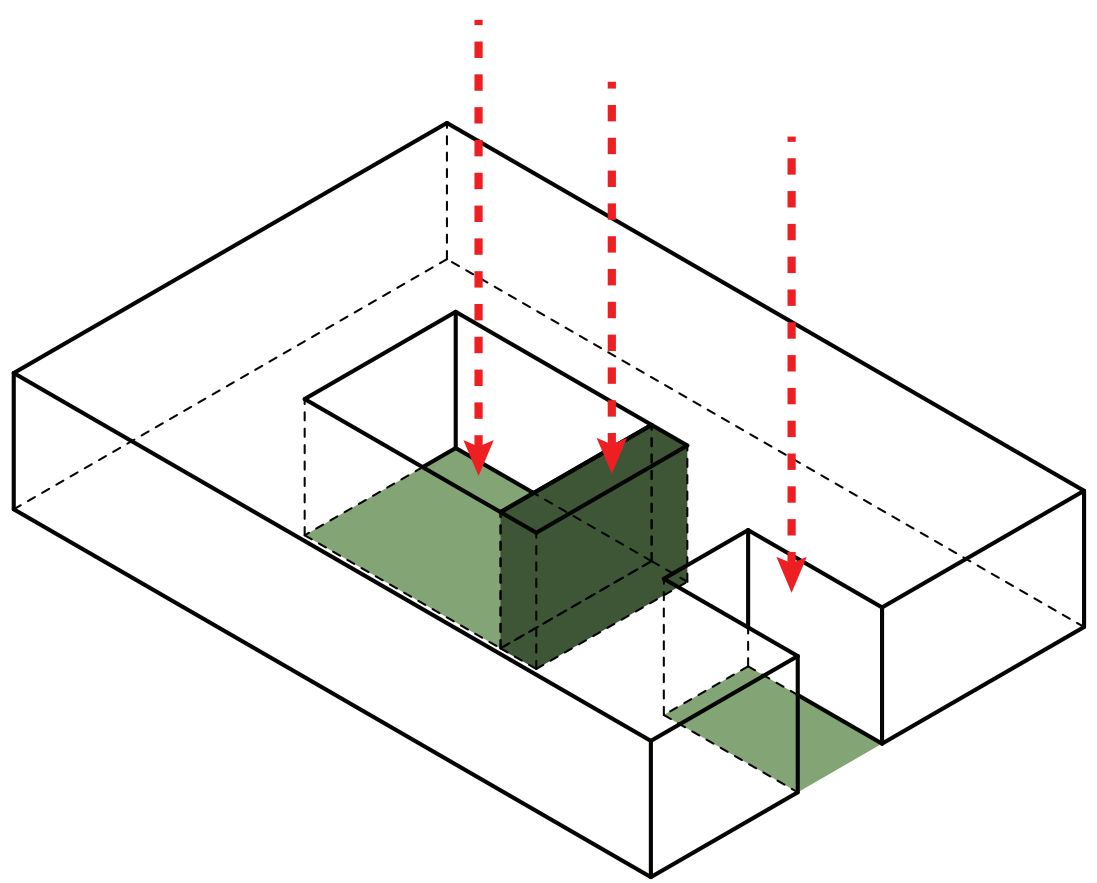

Fig. 5.69 - Internal courtyard to provide sensory garden and natural daylight into single loaded interior corridor. Winter garden atrium space as extension of courtyard indicated in dark green. Staff courtyard provided at north side of site.

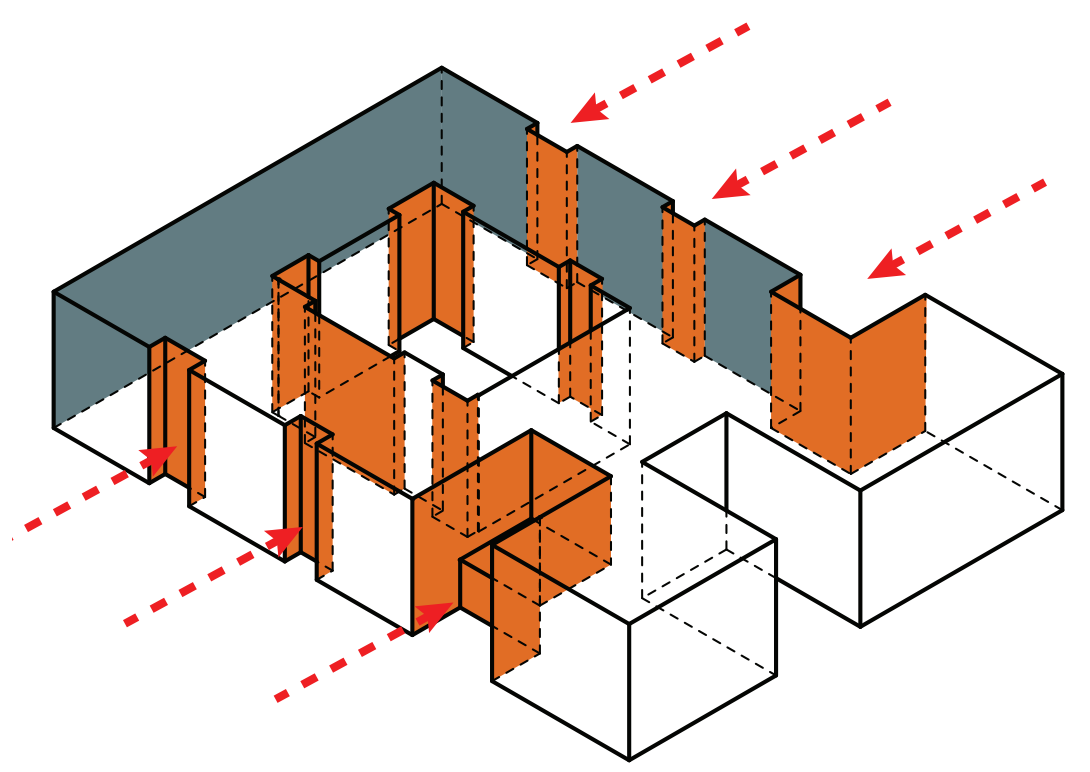

Fig. 5.70 - Recess building planes to breakdown massing in response to existing Victorian streets cape 


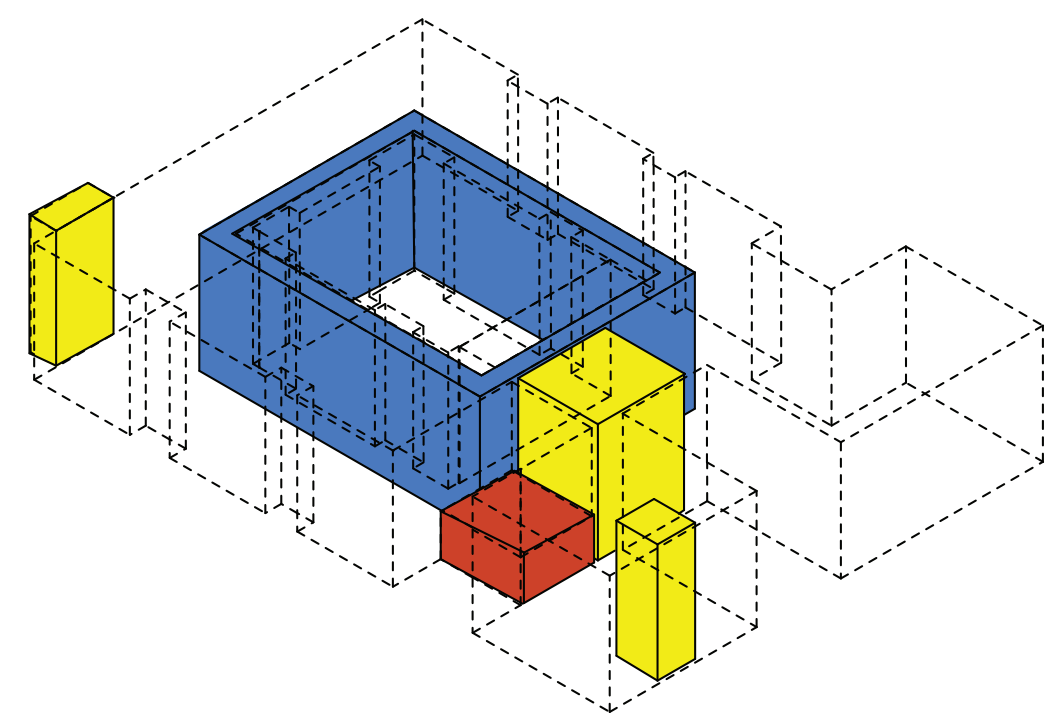

Fig. 5.71 - Vertical circulation (yellow), Horizontal circulation (blue), Entry into facility (red)

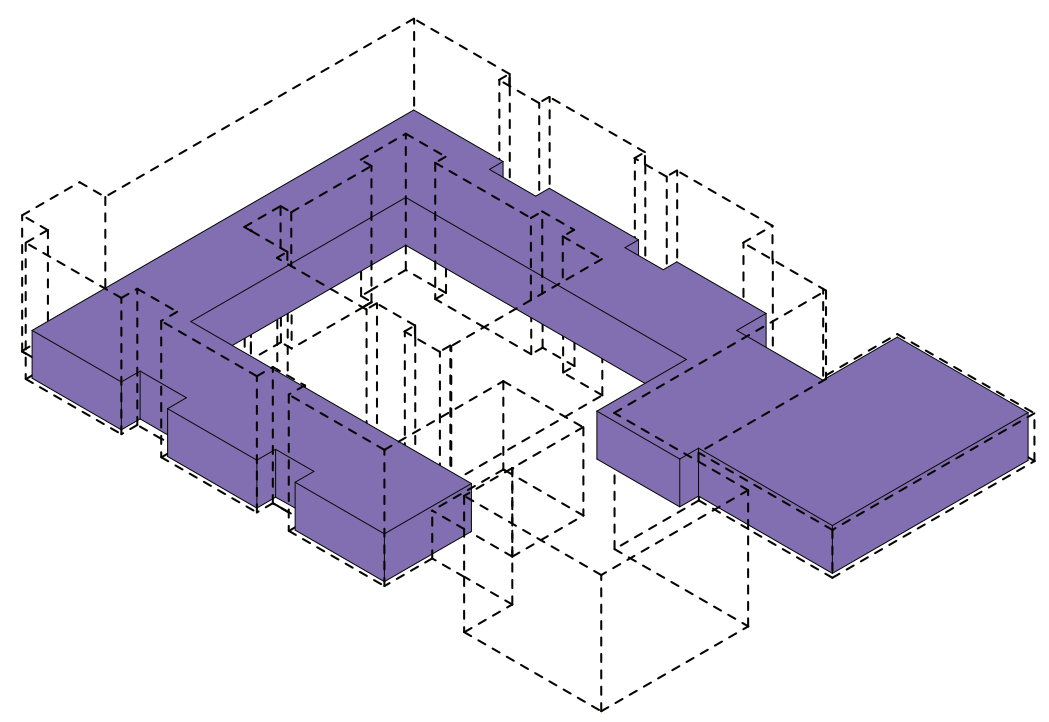

Fig. 5.72 - Dementia Respite Day Centre program on ground floor

101 | sebastian lubczynski master of architecture ryerson university 


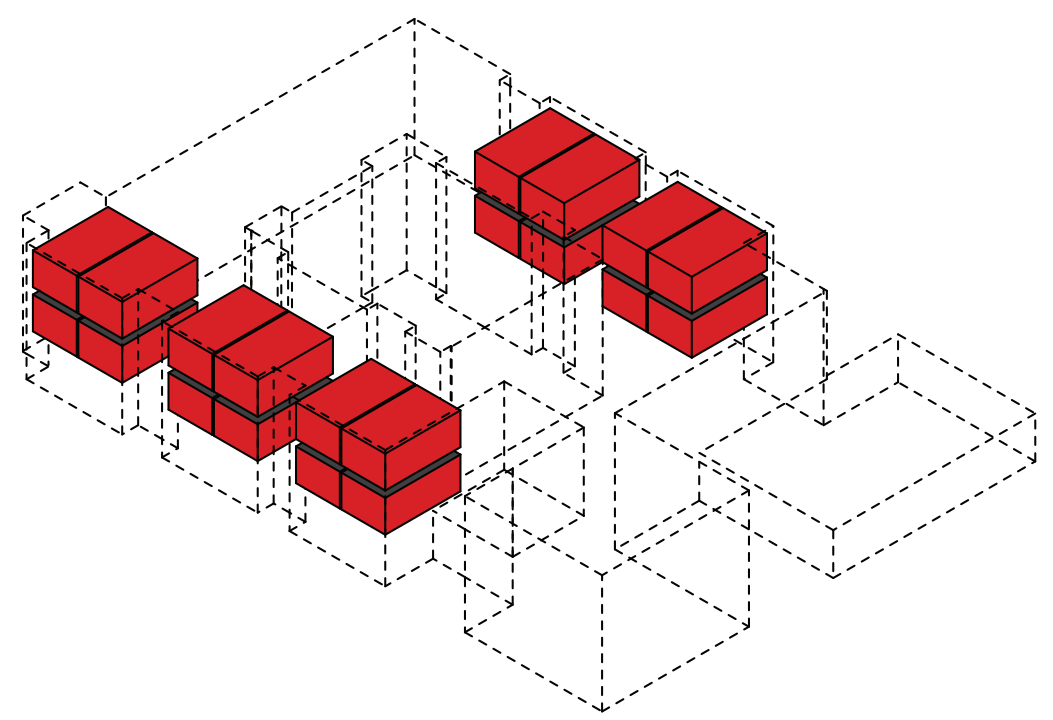

Fig. 5.73 - Bedroom unit locations on second and third floor

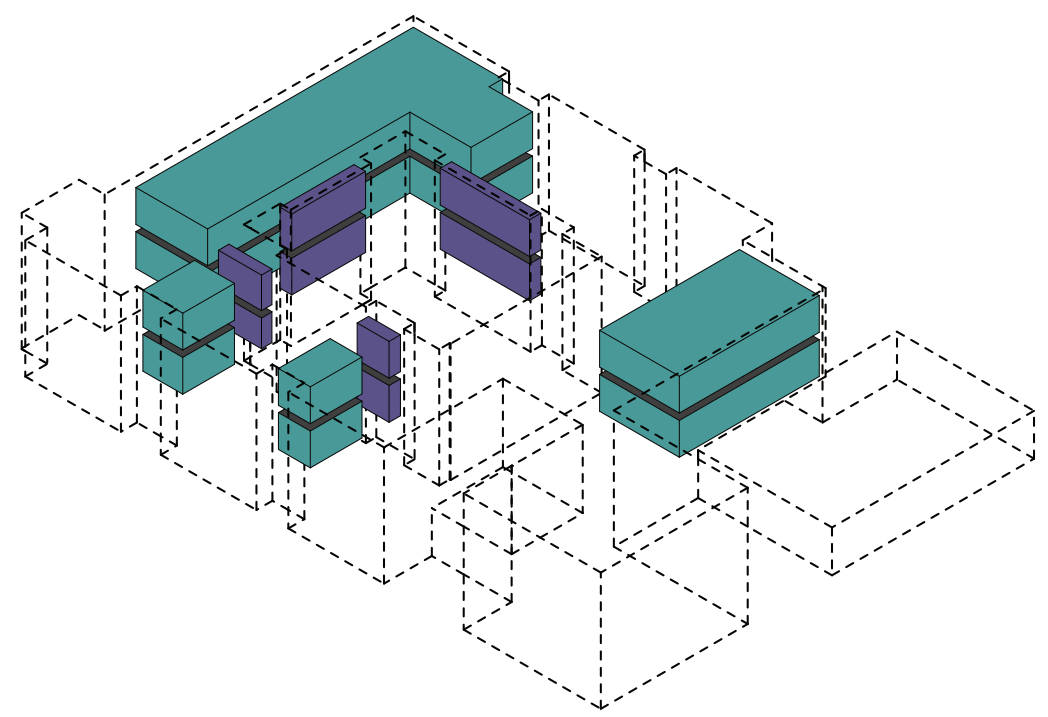

Fig. 5.74 - Respite daily living program on second and third floor 


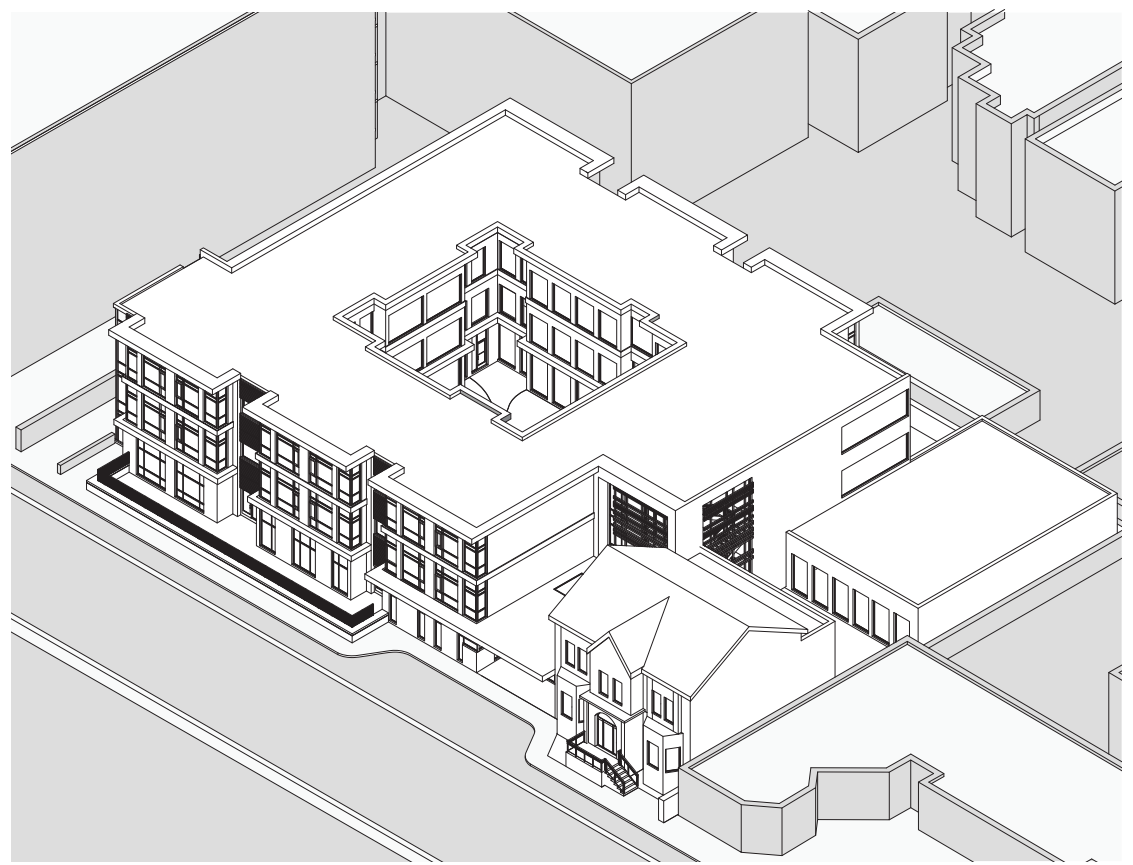

Fig. 5.75 - Resultant building form in context 
The ground floor plan design is featured diagrammatically in figure 5.76 and illustrated in figure 5.77. Access to the facility is provided through the drop-off area along Sherbourne Street, where the foyer is located adjacently to the existing residential house. The foyer provides controlled access to all areas of the facility. The administration portion of the program indicated in purple is located within the existing residential building, which has the interview and training rooms for incoming residents. From here, access is provided to the upper floors through the convenience stair and resident elevator. The third access that is provided is into the day centre. The receptionist, indicated with a red dotted circle, has visual oversight of who is coming and going at any given time to ensure a safe environment for the users.

The day centre program is distributed into three distinct areas, public spaces, semi-private spaces, and wellness area. Along Sherbourne Street, the public spaces are comprised of the cafe, shared living space and main activity room. The semi-private spaces are located along the south and west side of the site and are comprised of the communal kitchen, dining, living room, and library. The wellness portion of the program is located within the north-west area of the site, where the therapy pool, physiotherapy, beauty room, spa bath, hairdressing and beauty room are located. The essential feature for the facility is the winter garden that becomes an extension of the sensory courtyard. The winter garden is, therefore, utilized as a landmark that all users can see from any given space, which aids in orientation within the building.

The design goals of transparency and orientation are clearly evident in the overall design of the ground floor. The single loaded corridor that loops around the sensory garden provides maximum natural light and air access to the programmed spaces adjacent to the corridor. As a user engages with each space, they are given the opportunity to oversee their next possible destination as most rooms are not closed off from each other by doors, but with sliding doors. This changes the atmosphere of each room in that the users are not feeling confined. Legibility of spaces is expressed, for example, in the scale and size of the dining rooms. The dining room is familiar in scale to home-settings. Therefore, the understanding of expected behaviours is evident to each resident. 


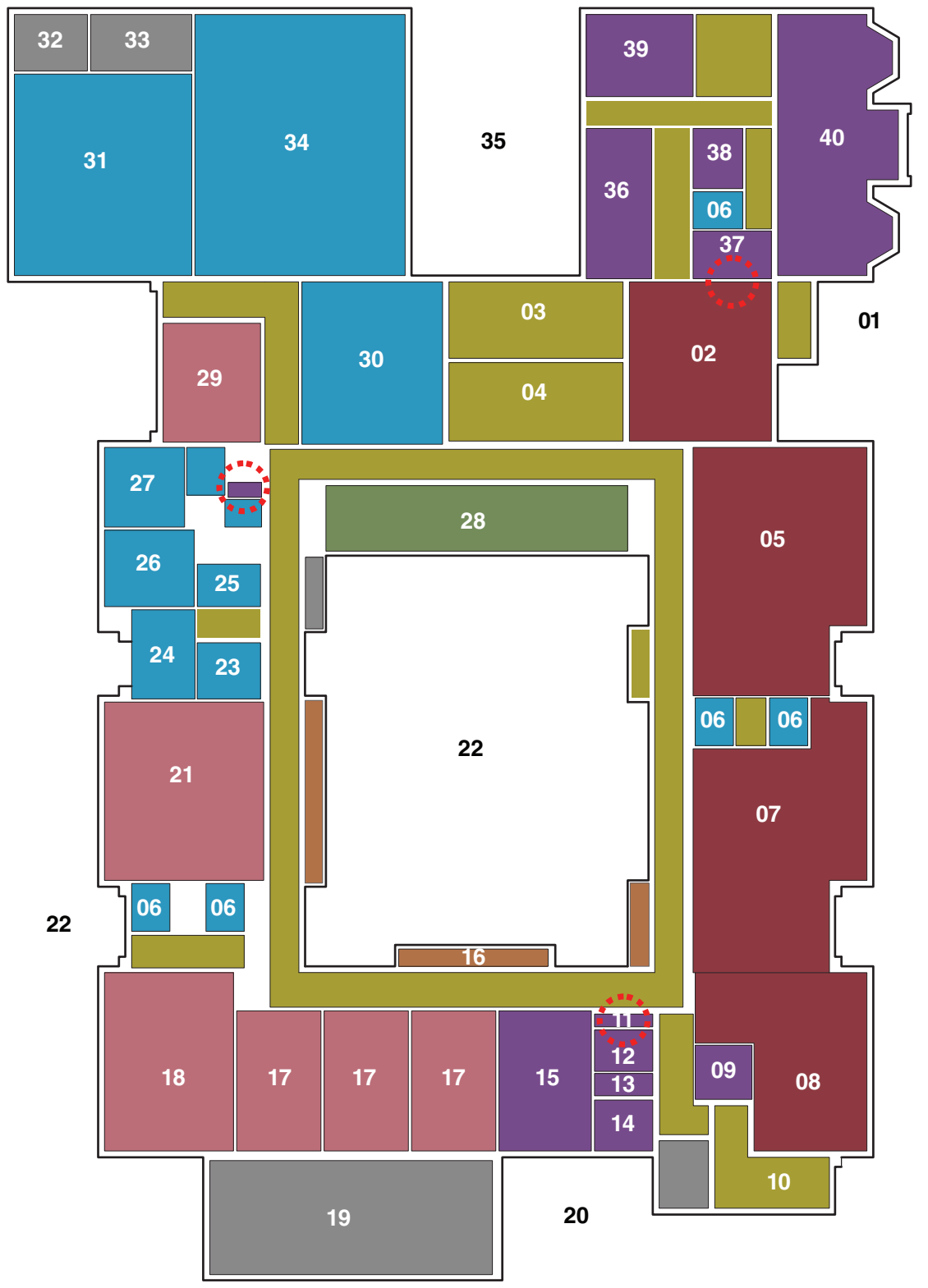

Fig. 5.76 - Ground floor spatial program layout diagram

01 Drop off area

02 Foyer

03 Resident Stair

04 Resident Elevator

05 Cafe / Dining

06 Washroom

07 Common Living Room

08 Activity Room

09 Cleaner Storage

10 Fire Exit Stair

11 Nurse's Station

12 Medicine Storage

13 Storage

14 Loading Room
15 Common Kitchen

16 Sitting Area

17 Private Dining

18 Private Living Room

19 Underground Parking

20 Loading Area

21 Library / Activity Room

22 Scented Garden

23 Hairdressing Room

24 Beauty Room

25 Medicine Storage

26 Treatment Room

27 Spa Bath

28 Winter Garden Atrium
29 Wellness Lounge

30 Change Rooms

31 Physiotherapy

32 Storage

33 Mechanical

34 Therapy Pool

35 Staff Garden

36 Interview Room

37 Reception

38 Staff Storage

39 Training Room

40 Information / Gallery Space 


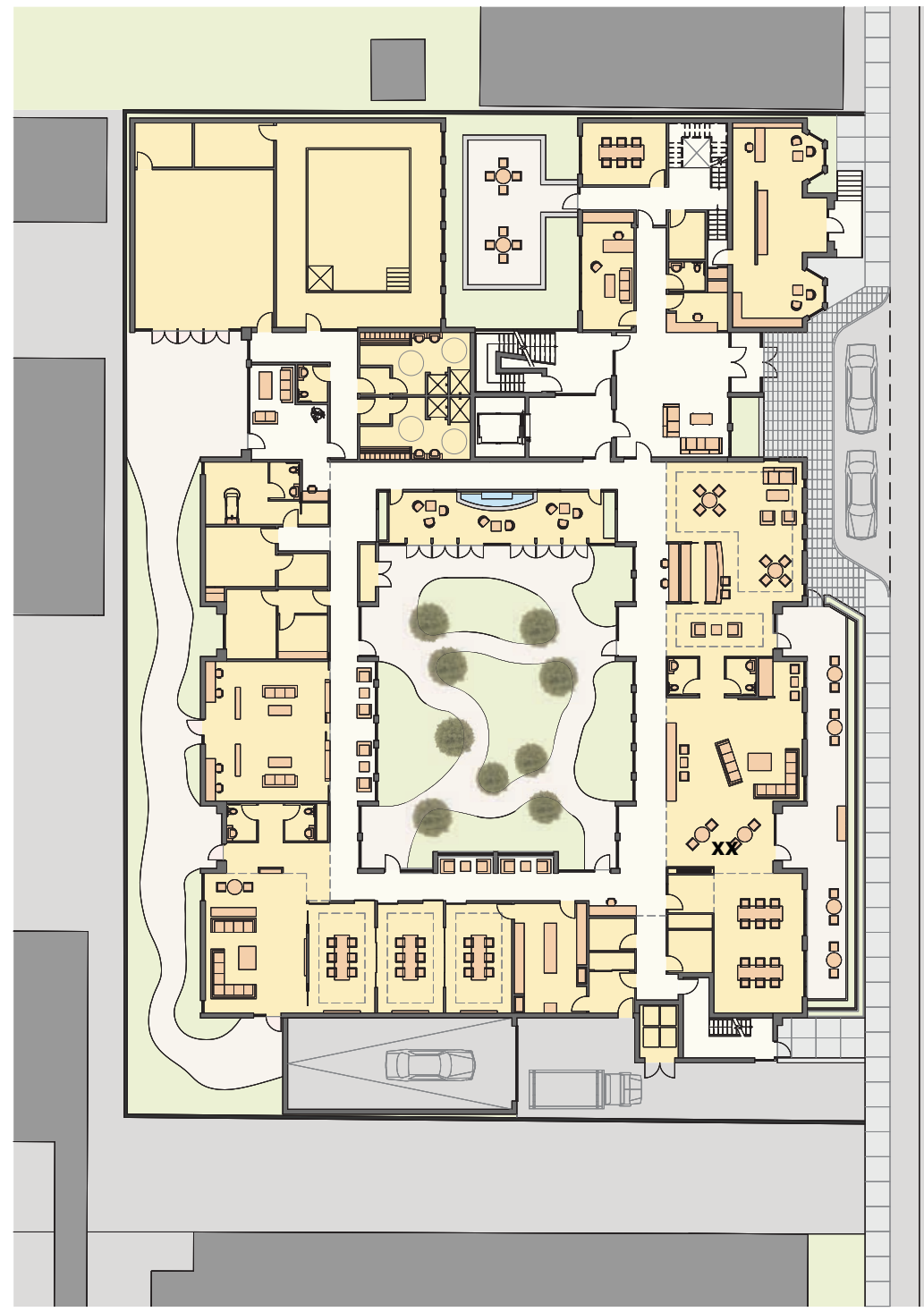

Fig. 5.77 - Day Centre Ground Floor Plan 


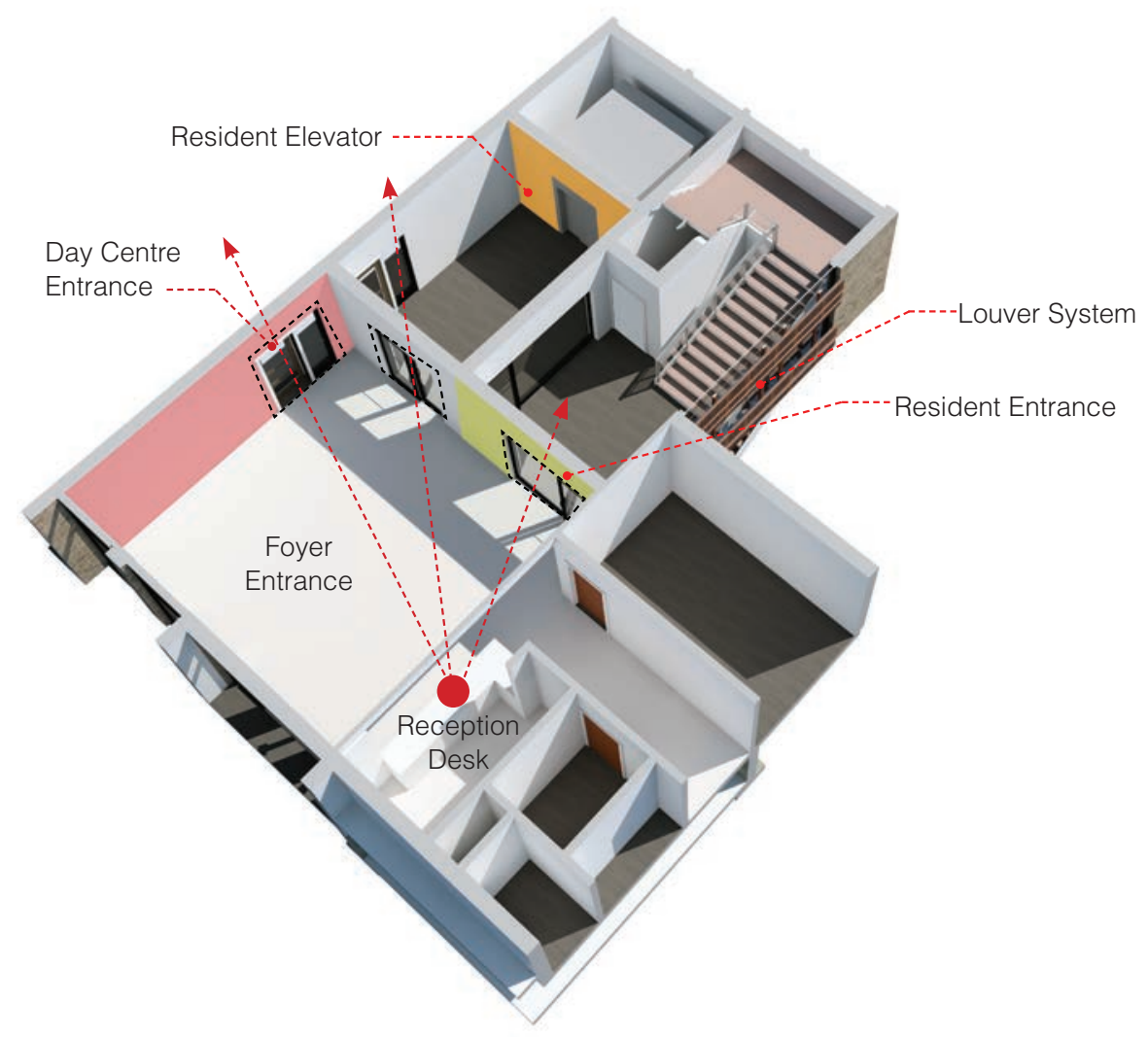

Fig. 5.78 - Entrance foyer security design

As mentioned previously, the design of the foyer (fig. 5.78) and reception area is two-fold. The first, the foyer as transition space between all the spatial programs on the site and secondly, visual and physical overview of those engaged with the day centre and respite area. The main walls for the day centre, elevator, and resident stair is clearly defined by their wall colour, aiding in legibility and orientation. Additionally, the door type to each of those spaces are different to distinguish each space from one another. Furthermore, doors that are not meant for users are designed as a solid door, and the frame and door are painted the same colour as the wall they are located on.

The design of the library/activity room (fig 5.79) provides a form of landmarking by utilizing the bookcase as separator between the public corridor and the space itself. The resting sitting spaces along the perimeter of the corridor become an extension of the library. 

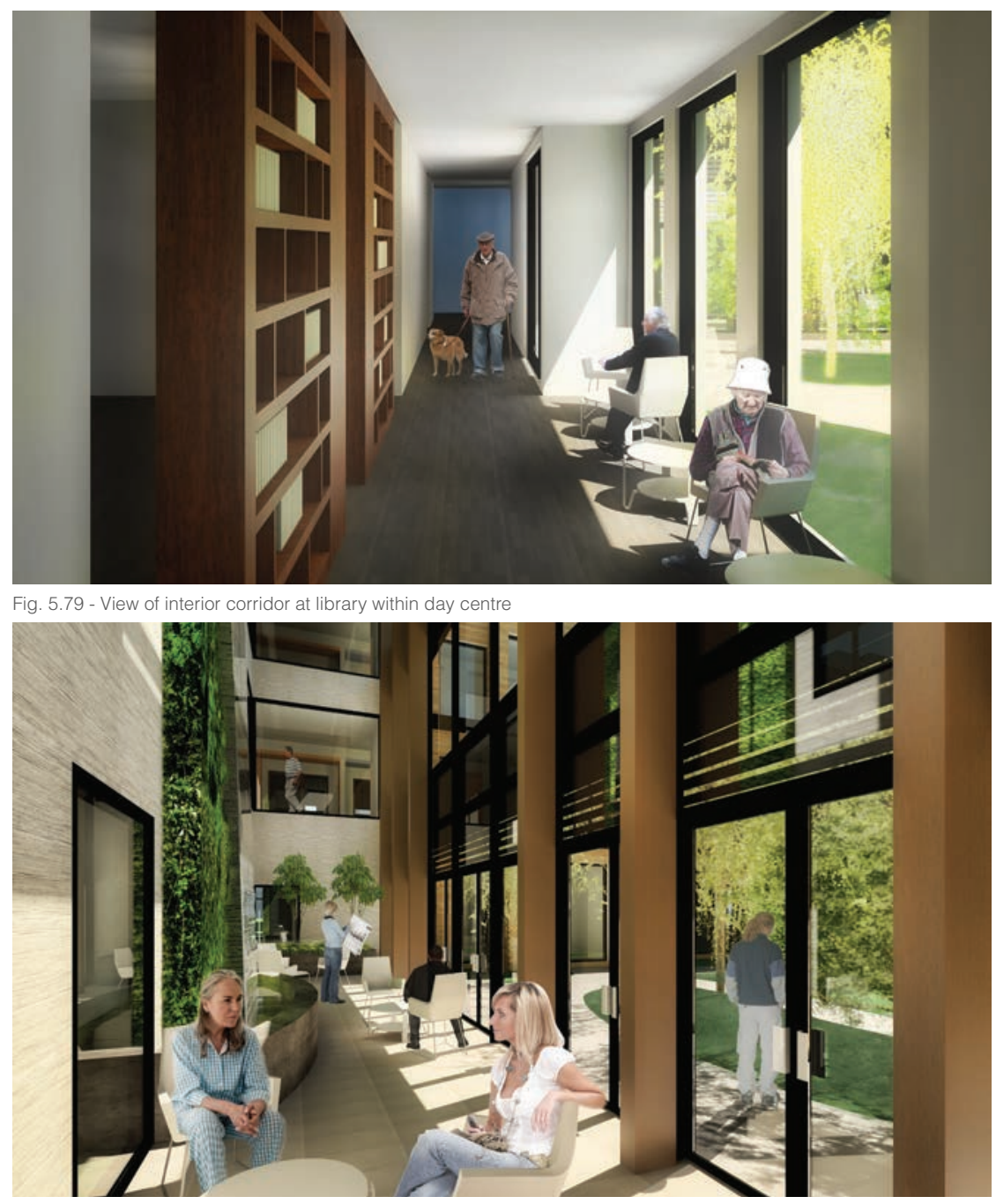

Fig. 5.80 - View of interior winter garden atrium space

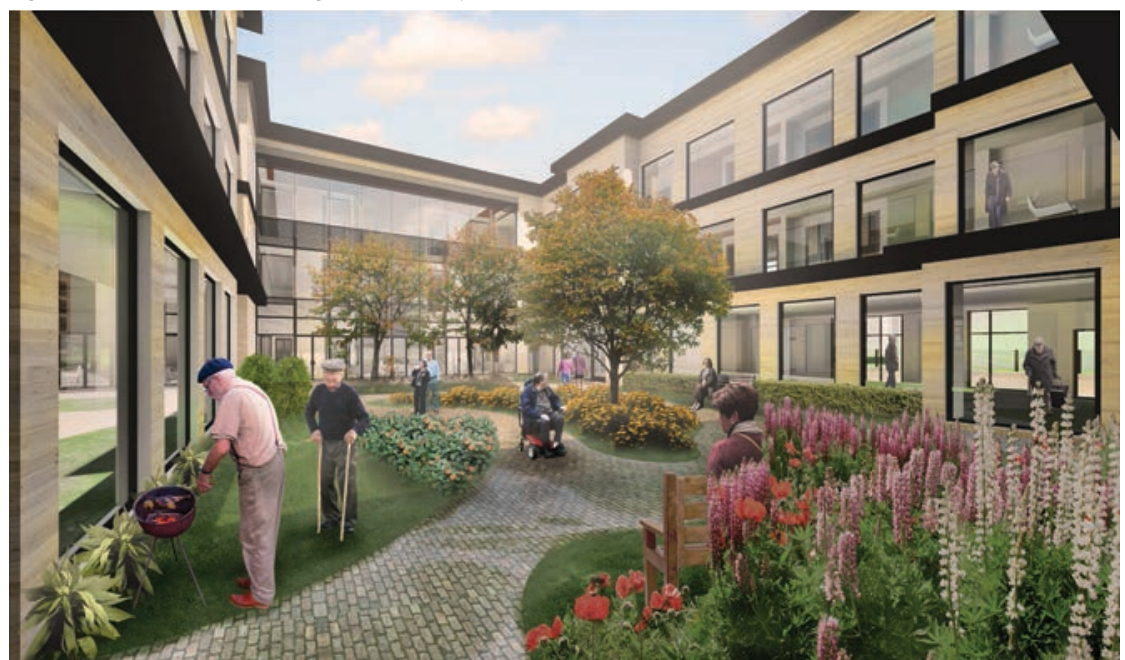

Fig. 5.81 - View of outdoor courtyard 


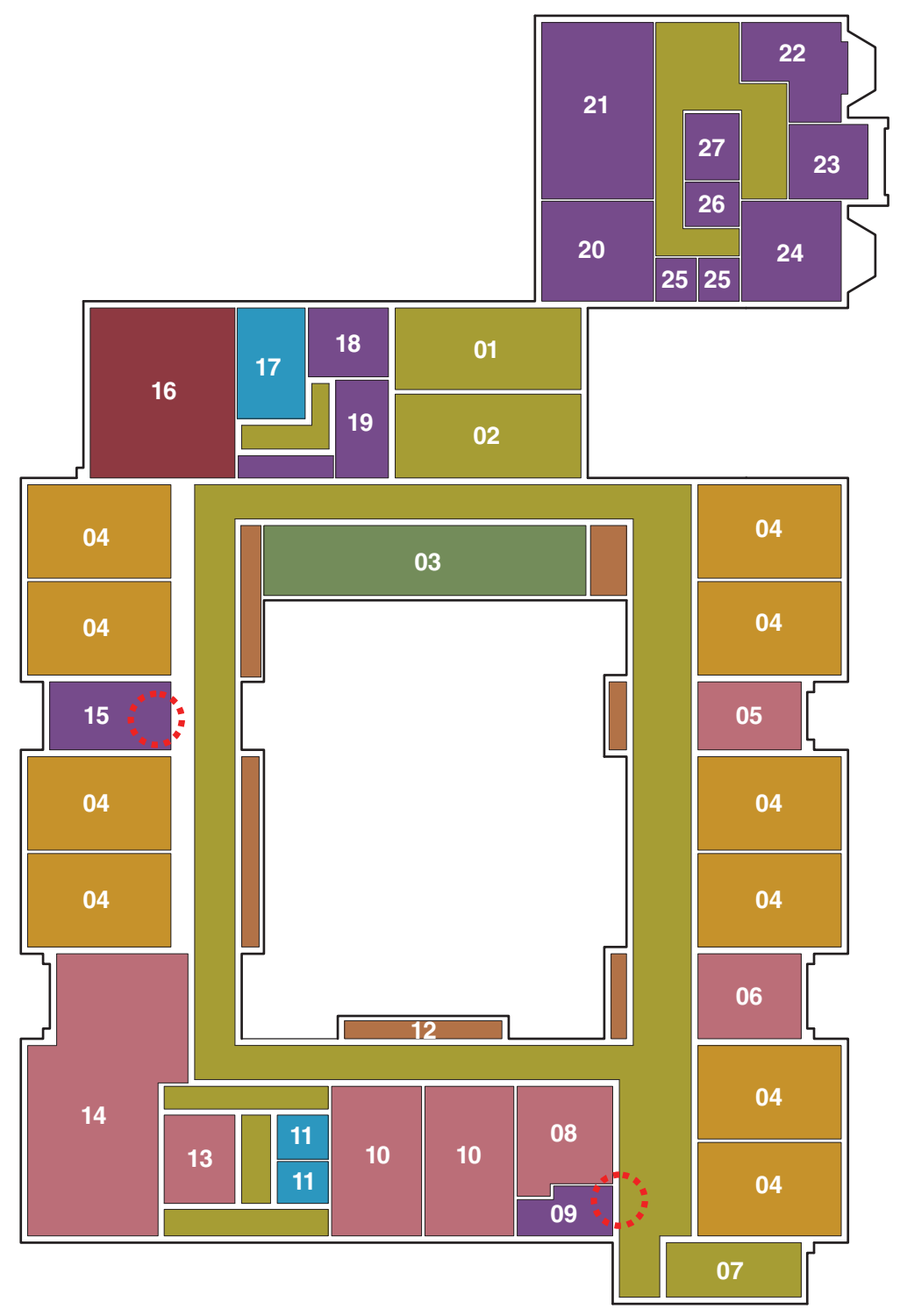

Fig. 5.82 - Second and Third Floor spatial program layout diagram

01 Resident Stair

02 Resident Elevator

03 Winter Garden Atrium

04 Single Bedroom Unit

05 Quiet Room

06 Private Lounge

07 Fire Exit Stair

08 Communal Kitchen

09 Nurse's Station
10 Private Dining

11 Washroom

12 Sitting Lounge

13 Meeting Room

14 Living Room

15 Nurse's Office

16 Activity Room

17 Spa Bath

18 Resident Laundry
19 Treatment Room

20 Staff Meeting Room

21 Staff Kitchen Lounge

22 Assistant Office

23 Office

24 Director's Office

25 Staff Washrooms

26 Staff Storage

27 Staff Lockers 


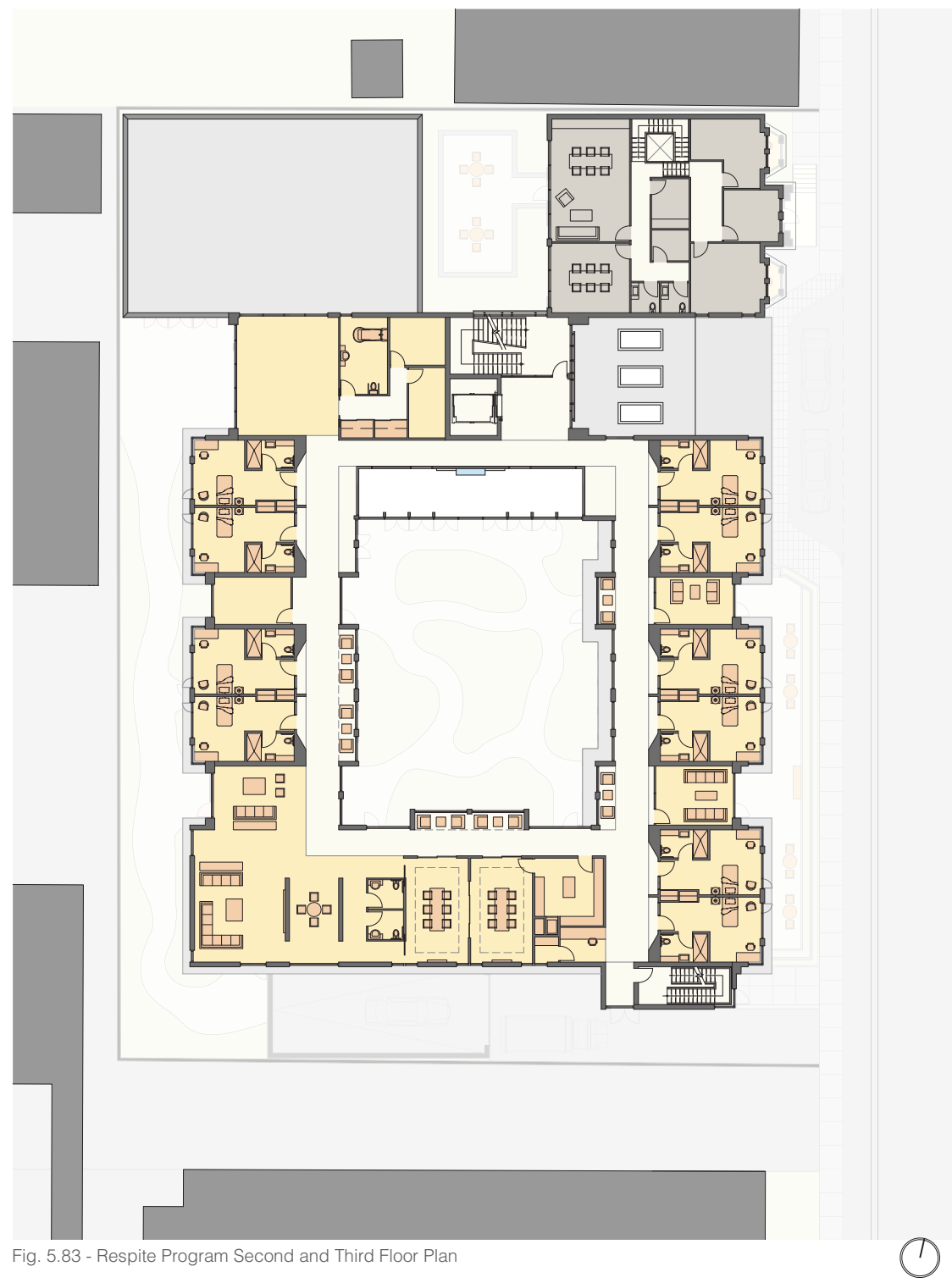

The second and third floor for the respite program is designed such that each level is considered to be its own "house cluster." Each floor plate provides ten bedroom units, private dining, communal kitchen, and living room. This design approach is similar with the first iteration, whereby the spaces are familiar in scale to that of private residential living, providing a clear understanding of behavioural intent for each space. A quiet room and private living room are interjected in-between the bedroom units, providing a gradient of public to private spaces for the residents of the area. The element of choice gives the users the sense of autonomy of their space, allowing them to either engage with everyone or have private moments with their family members. 
One of the primary components of the "cluster house" is the individual private room. The design of these rooms is capable of adapting to each resident's needs and preferences. The three design goals of legibility, transparency, and orientation is highly integrated with the overall design of these private rooms. The use of the angled walls in the final layout (fig 5.84 - 5.86) provides a private entryway for each room. Individuals can personalize their entry wall with images to aid in identification. Each entryway has lower ceilings than the corridor and colour is used to distinguish each room from one another.

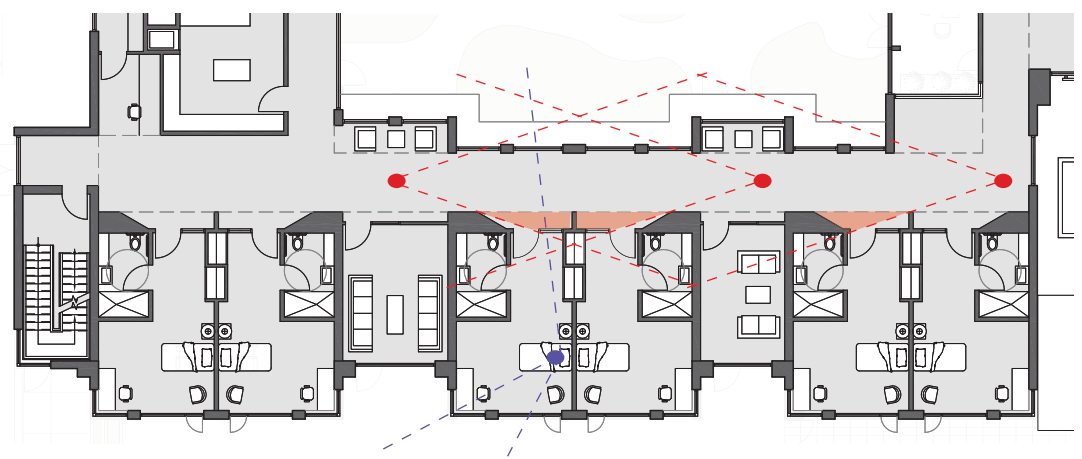

Fig. 5.84 - Resident corridor wall entry angle design

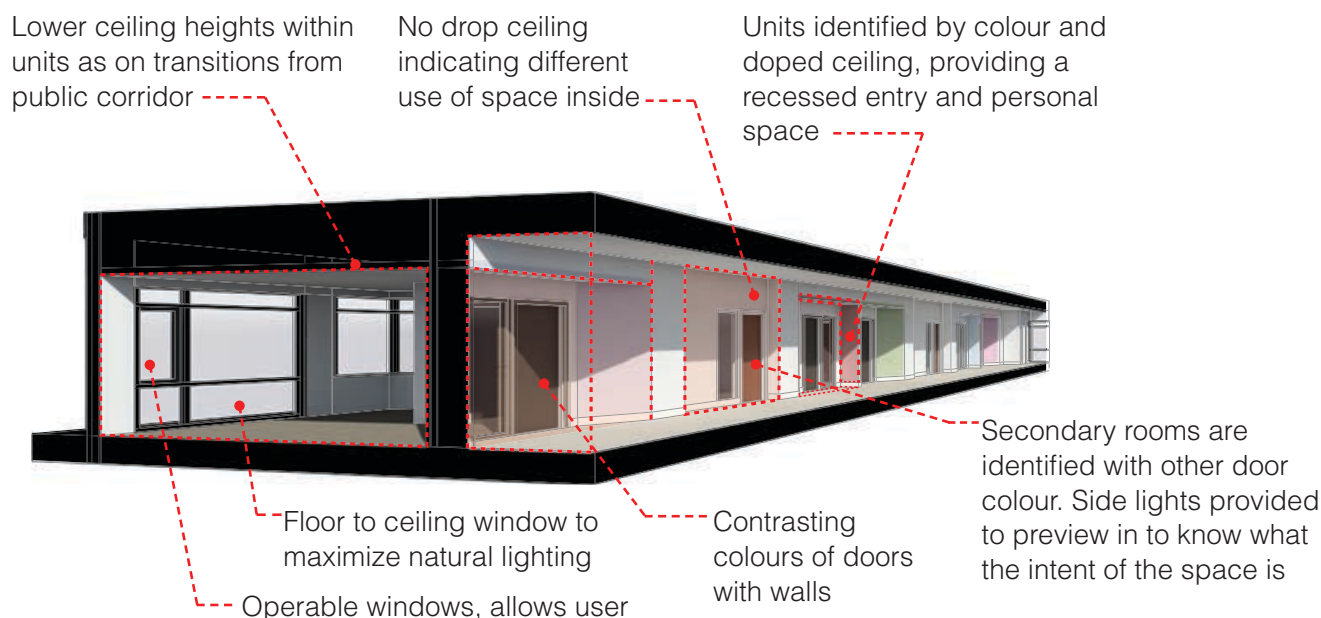
control of their environment and ventilation 

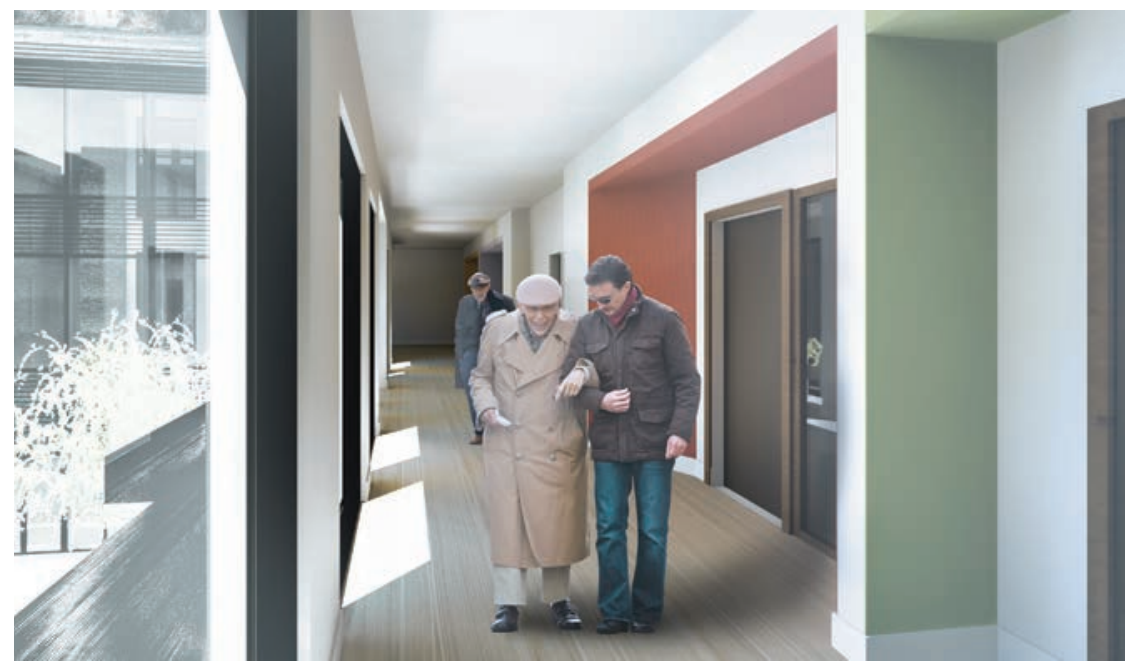

Fig. 5.86 - View of resident corridor
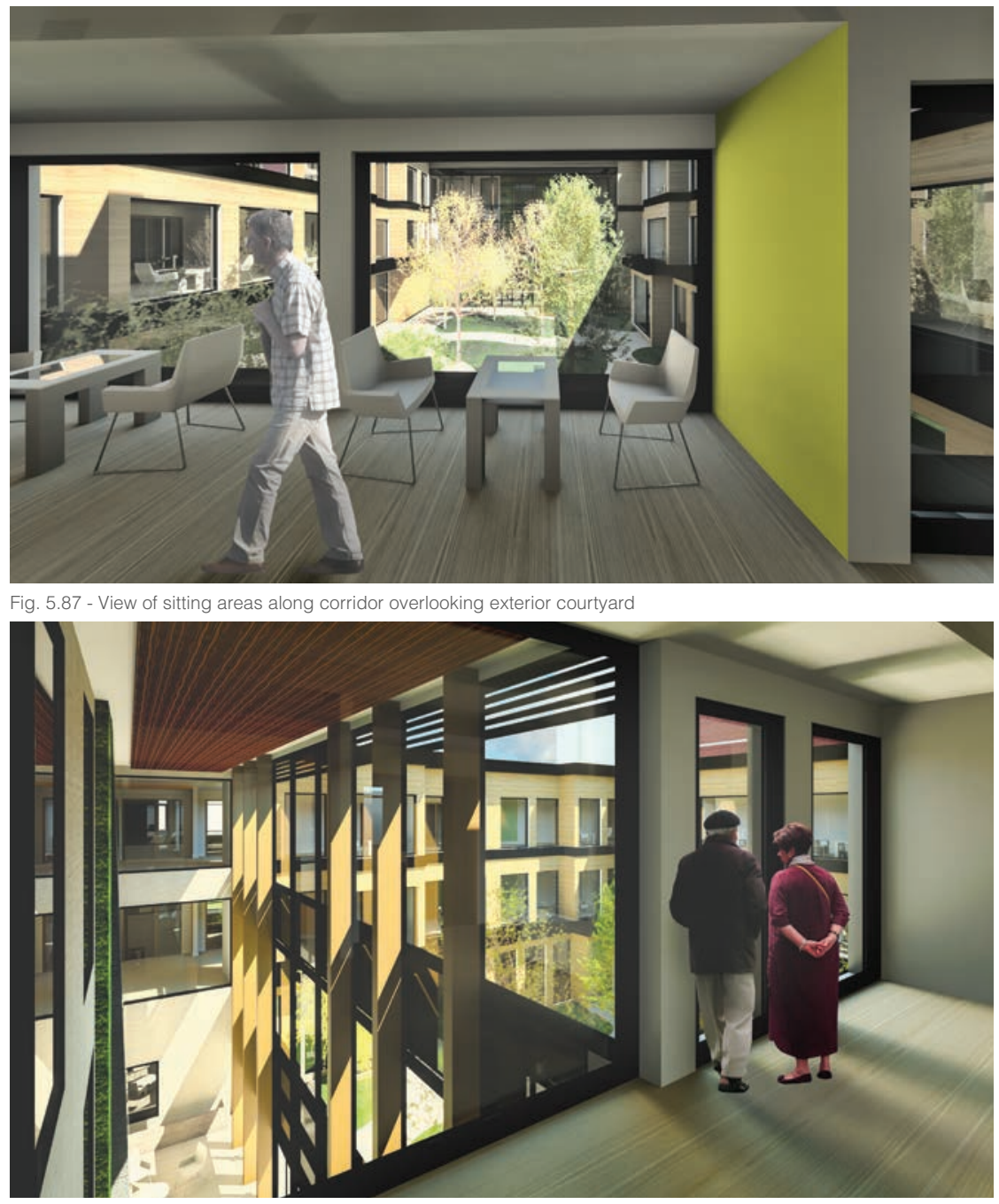

Fig. 5.88 - View from third floor overlooking winter garden atrium and outdoor courtyard 


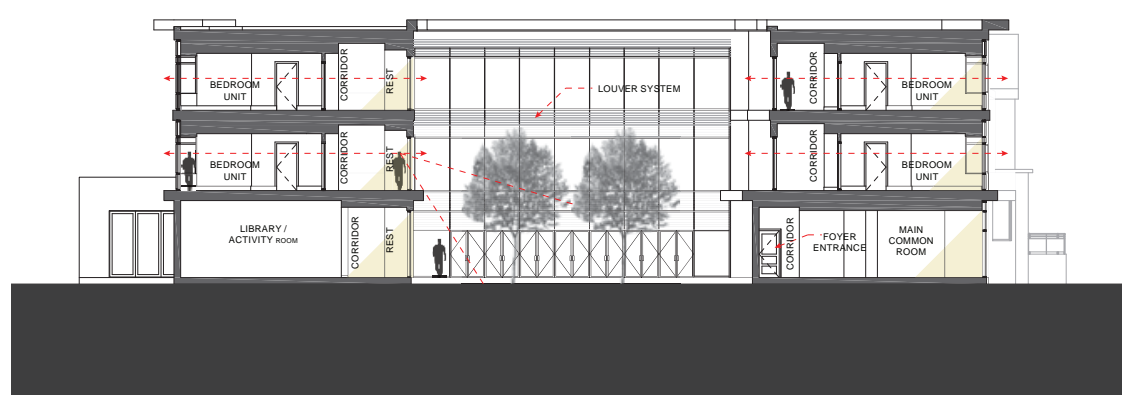

Fig. 5.89 - Building section at bedroom units and outdoor courtyard

The elevations of the building are designed to respond to the historic urban morphology of the site and area. As a result, the elevations provide a balance between the vertical and horizontal rhythm of the existing residential area, by organizing openings that characterize the day centre and respite functions. In figure 5.90, the east elevation illustrates the final iteration of utilizing previous property line boundaries of the site, thus breaking down the massing of the building. Interior functional spaces are expressed through the manipulation of solid and void areas of the facade. The resident rooms are equipped with ample amounts of glazing to maximize natural daylight, whereas within the day centre spaces at grade, the glazing responds in a gradient of low to high transparency.

The east elevation materiality (fig. 5.91 and 5.92) is a composition of light brick, glazing, and horizontal dark grey fiber-c concrete slats. The fiber-c concrete slats are used in the recessed portions of the facade to accentuate the volumetric forms and the different functions that occur at those locations. In maintaining continuity to people's lives, the project's overall material palette respects the contextual character of the neighbourhood.

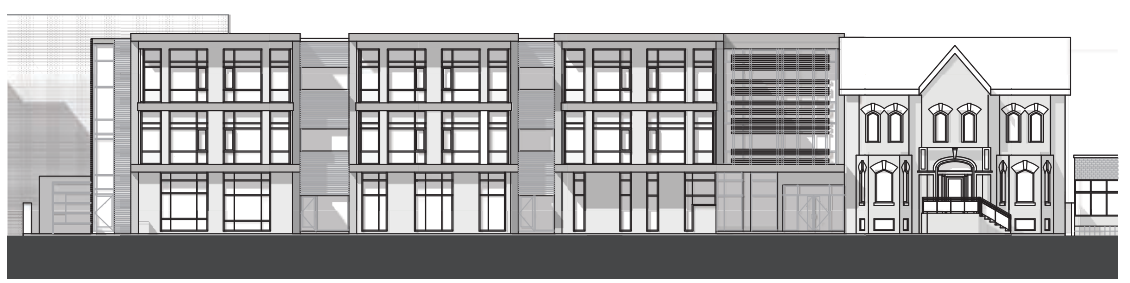

Fig. 5.90 - West building elevation 


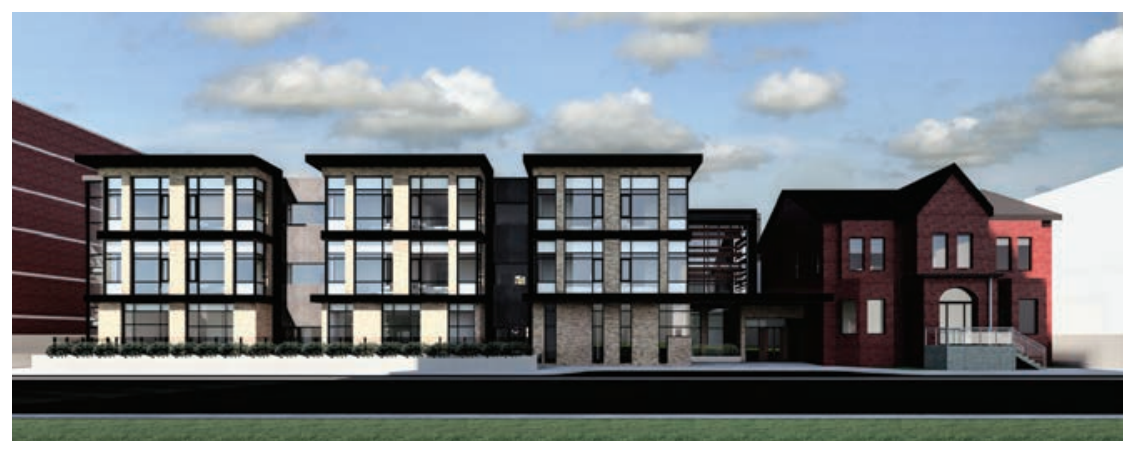

Fig. 5.91 - West building elevation rendering indicating materiality

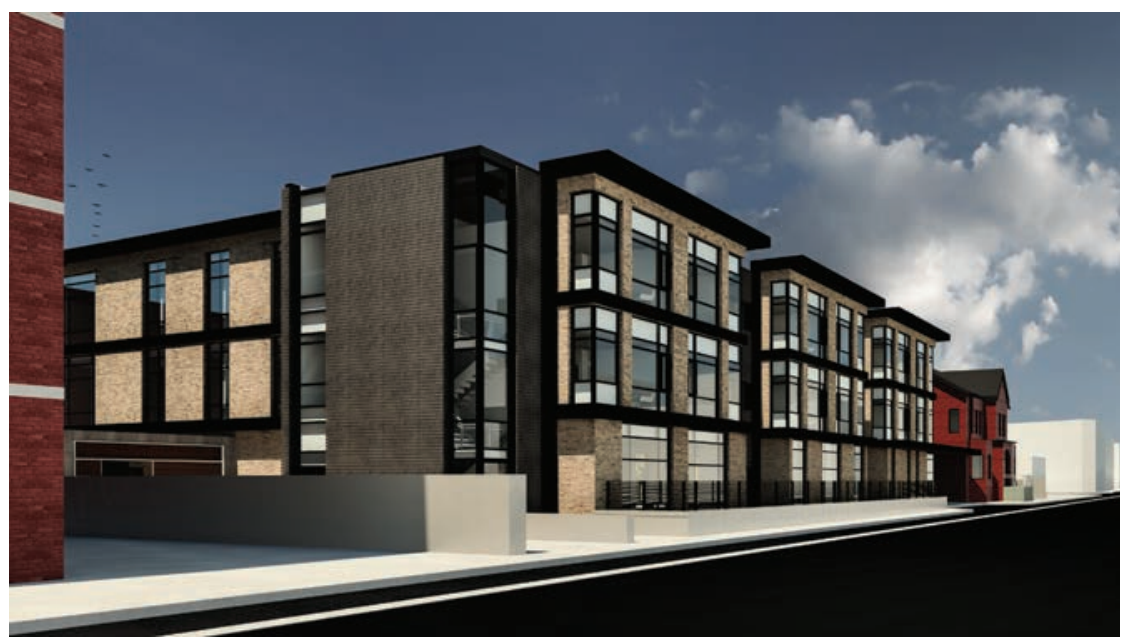

Fig. 5.92 - Perspective looking north west approach to building 




\section{Bibliography / References}

Alzheimer Society. (2010). Rising Tide: The Impact of Dementia on Canadian Society. Canada: Alzheimer Society of Canada.

Alzheimer Society. (2012). Dementia Evidence Brief: Ontario. Toronto: Alzherimer Society Ontario.

Alzheimer Society Canada. (2013, March 3). What is Dementia? Retrieved from Alzheimer Society Canada: http://www.alzheimer. ca/en/About-dementia/Dementias/What-is-dementia

Brawley, E. (1997) Designing for Alzheimer's Disease: Strategies for Creating Better Care Environments. New York: Wiley

Brawley, E. (2006). Design Innovations for Aging and Alzheimer's: Creating Caring Environments. New Jersey: John Wiley \& Sons.

Calkins, M. P. (2009). Evidence-based long term care design. NeuroRehabilitation - An Interdisciplinary Journal, 25(3), $145-153$.

Calkins, M. P. (2011). History of Creating Settings for People with Dementia. Retrieved from Dementia Design Info: https://www4. uwm.edu/dementiadesigninfo/

Dening, T., \& Miline, A. (2011). Mental Health \& Care Homes. New York: Oxford University Press.

Designing Inclusive Systems. (2012). Spatial Clues for Orientation: Architectural Design Meets People with Dementia. In I. Van Steenwinkel, C. Van Audenhove, \& A. Heylighen, Designing Inclusive Systems (pp. 227-236). London, UK: Springer-Verlag London.

Drake, S. (2014). The Elements of Architecture: Principles of Environmental Performance in Buildings. New York: Earthscan.

Eberhard, J. (2009). Memory of Places and Spaces and the Design of Facilities for the Aging. In J. Eberhard, Brain Landscape: The Coexistence of Neuroscience and Architecture (pp. 117-134). USA: Oxford University Press.

Eberhard, J. P., \& Patoine, B. (2004, April 01). Architecture with the Brain in Mind. Retrieved October 2013, from Dana Foundation: www.dana.org/news/cerebrum/detail.aspx?id=1254

Evans, G. W. (2003). The Built Environment and Mental Health. Journal of Urban Health: Bulletin of the New York Academy of Medicine, 536-549.

Golembiewski, J. (2012). The neurological basis of health-promoting environments. World Health Design, 62-69.

Jencks, C. (2012). Can Architecture Affect Your Health? Netherlands: Artez Press. 
Kitwood, T. (1997). Dementia Reconsidered: The Person Comes First (Rethinking Ageing). Maidenhead, UK: Open University Press.

Kronaus, C., \& Kinzelbach, E. A.-H. (2010, May 24). Hainburg Nursing Home / Christian Kronaus + Erhard An-He Kinzelbach. Retrieved from Archdaily: http://www.archdaily.com/61115/hainburg-nursing-home-christian-kronaus-erhard-an-he-kinzelbach/ Marmot, A. (2002). Architectural determinism: Does design change behaviour? The British Journal of General Practice, 252253.

Martinussen, K. (2010). How Architecture Shapes Behaviour: Mind your Behaviour. Copenhagen: Actar.

National Collaborating Centre for Mental Health. (2007). Dementia: A NICE-SCIE Guideline on supporting people with dementia and their carers in health and social care. Great Britain: The British Psychological Society and Gaskell.

National Institute on Aging. (2009, April 1). New research illuminates memory loss and early dementia. Retrieved from U.S Department of Health and Human Sciences: http://www.nia.nih.gov/alzheimers/features/new-research-illuminates-memoryloss-and-early-dementia

Piaget, J., \& Inhelder, B. (1971). The childs conception of space. London, UK: Routledge and Kegan Paul.

Regnier, V., Denton, A.(2009). Ten new and emerging trends in residential group living environments. Architecture and Gerontology, NeuroRehabilitation, 169-188.

Roe, B., \& Beech, R. (2005). Intermediate and Continuing Care: Policy and Practice. Victoria, Australia: Blackwell Publishing.

Toronto Community Foundation. (2013). Toronto Vital Signs 2013 Report. Toronto: Toronto Community Foundation.

Torrington, J. (2006, March). What has architecture got to do with dementia care? Quality in Ageing, 7(1), 34-48.

Verderber, S. (2003). Architecture for Health - 2050: An International Perspective. The Journal of Architecture, $281-302$.

Verderber, S. (2010). Innovations in Hospital Architecture. New York: Routledge.

Warmann, C. (2011, 02 7). House for elderly people by Aires Mateus Arquitectos. Retrieved from Dezeen Magazine: http://www. dezeen.com/2011/02/07/house-for-elderly-people-by-aires-mateus-arquitectos/

Watson, S. D. (2009). From Almshouses to Nursing Homes and Community Care: Lessons from Medicaid's History. Georgia State University Law Review, Vol. 26(Iss. 3), 937-969.

World Health Organization. (2007). Global Age-friendly Cities: A Guide. France: World Health Organization. 
World Health Organization. (2012). Dementia: A Public Health Priority. United Kingdom: World Health Organization.

World Health Organization. (2012). Dementia: A Public Health Priority. World Health Organization.

Zeisel, J. (2003a). Environmental Correlates to Behavioral Health Outcomes in Alzheimer's Special Care Units. The Gerontologist, Vol. 43, No 5, 697-711

Zeisel, J. (2003). Marketing Therapeutic Environments for Alzheimer's Care. Journal of Architectural and Planning Research, $75-86$.

Zeisel, J. (2010). I'm Still Here: A New Philosophy of Alzheimer's Care. New York: Penguin Group. 
